Universidad de Lima

Facultad de Comunicación

Carrera de Comunicación

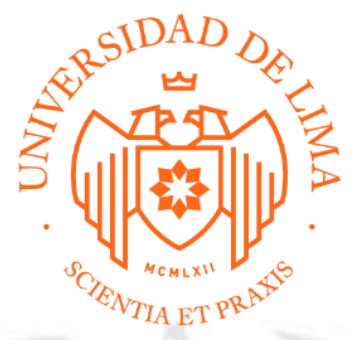

\title{
CAMPAÑA DE COMUNICACIÓN: \\ VILLA DE ATLETAS CONDOMINIO
}

Trabajo de Suficiencia Profesional para optar el Título Profesional de Licenciado en Comunicación

Salas Limache, Camila

Código 20133162

San Martín Hancco, Betsy Pamela

Código 20133175

Lima - Perú

Octubre, 2019 


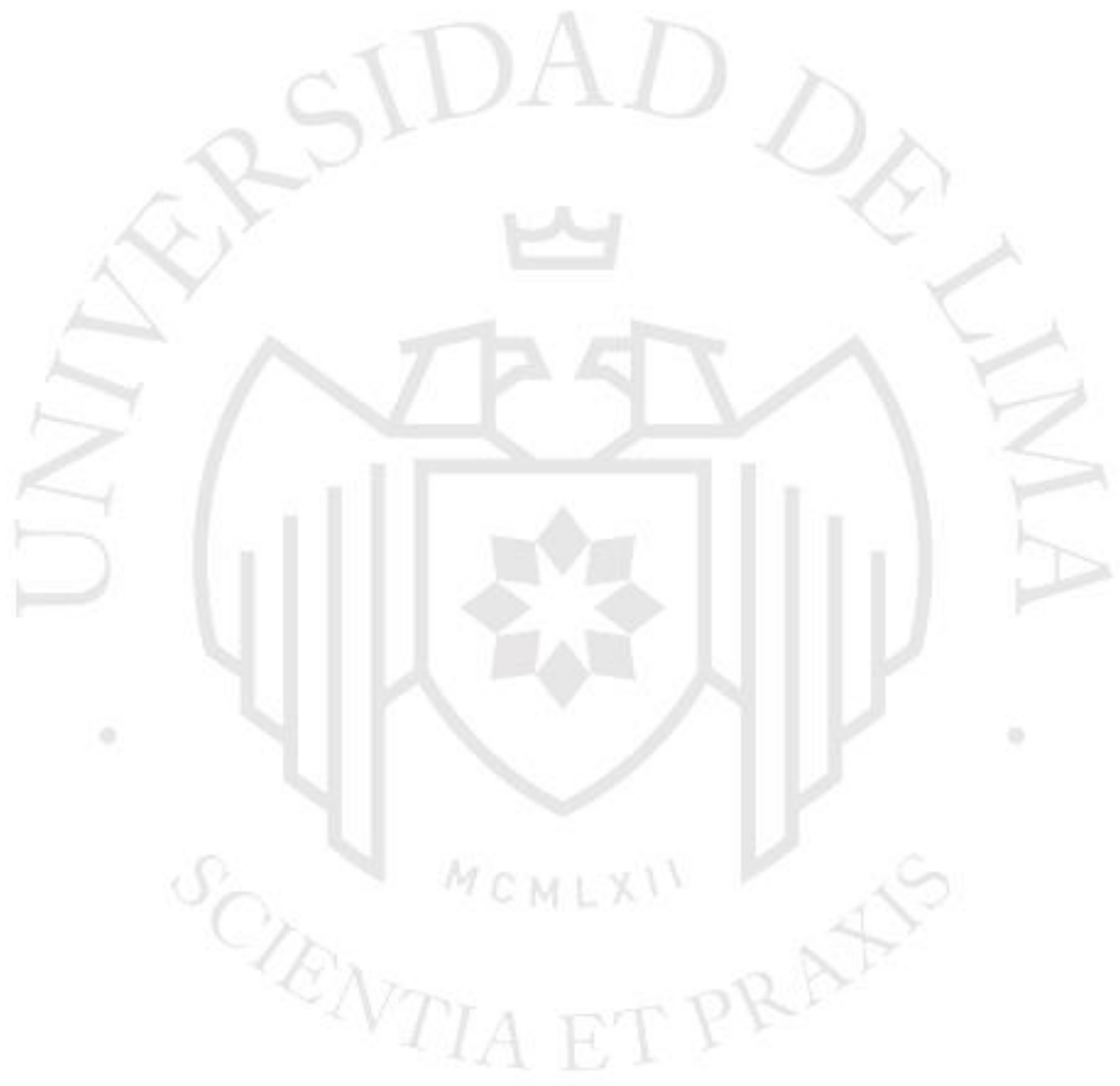




\section{CAMPAÑA DE COMUNICACIÓN: \\ VILLA DE ATLETAS CONDOMINIO}




\section{ÍNDICE}

RESUMEN

Pág. 12

INTRODUCCIÓN

.Pág. 13

\section{CONTEXTO}

1.1 Político Pág. 14

1.2 Económico Pág. 15

1.3 Sociales Pág. 17

1.4 Tecnológico. Pág. 18

1.5 Ambiental Pág. 20

\section{PÚBLICO OBJETIVO}

2.1 Perfil demográfico y familiar

Pág. 22

2.2 Perfil laboral Pág. 24

2.3 Perfil económico y financiero Pág. 24

2.4 Entretenimiento y consumo de medios Pág. 25

2.5 Comportamiento tecnológico. Pág. 26

2.6 Empathy Map

Pág. 28

\section{HALLAZGOS CLAVES}

3.1 Del mercado .Pág. 29

3.2 De la competencia Pág. 30

3.2.1 Bench de la competencia Pág.30

3.3 Del público Pág.34

3.3.1 Encuestas Pág.34

3.4 Del producto Pág.38

3.5 FODA

Pág.39

\section{PROYECTO}

4.1 Posicionamiento de Villa de Atletas. .Pág.41

4.2 Promesa Pág.41

4.3 Soporte (Reason Why) .Pág.41 


\section{IMAGEN DE MARCA}

$5.1 \log 0$

5.1.1 Concepto ...........................................Pág.44

5.1.2 Proceso .............................................Pág.44

5.1.3 Tipografía .............................................ág.47

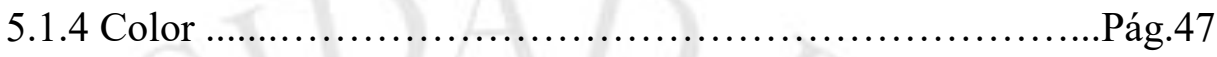

5.2 Manual de identidad

5.2.1 Logotipo..................................................

5.2.2 Versiones Positivo / Negativo ...........................Pág.49

5.2.3 Escalabilidad ...........................................ág.49

5.2.4 Área de seguridad del logotipo...........................Pág.50

5.2.5 Uso incorrecto del logotipo ..................................51

5.2.6 Colores ................................................... 51

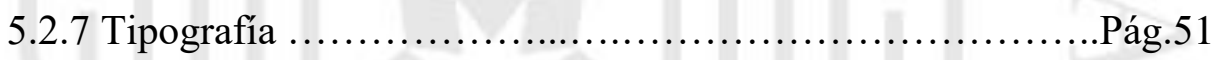

5.2.8 Aplicaciones ........................................Pág.53

\section{ESTRATEGIA DE COMUNICACIÓN}

\subsection{Objetivos}

6.1.1 Objetivos de marketing .................................Pág.57

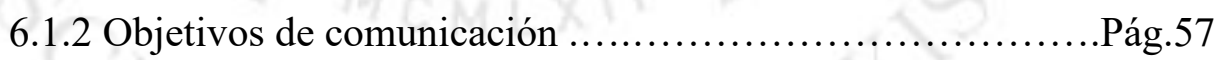

\subsection{Estrategia}

6.2.1 Concepto .Pág.57

6.2.2 Idea ejecucional ........................................Pág.58

6.2.3 Eslogan ..............................................ág.58

\subsection{Plan de comunicación o estrategia de medios}

6.3.1 Etapas de la campaña ..................................

6.3.2 Ecosistema de medios ...................................Pág.61

6.3.3 Piezas Publicitarias 
6.3.3.1 Etapa de Pre - lanzamiento

6.3.3.1.1 ATL Pág.69

6.3.3.1.2 Medios digitales Pág.71

\subsubsection{Etapa de Lanzamiento}

6.3.3.2.1 ATL Pág.74

6.3.3.2.2 Medios Digitales .Pág.77

\subsubsection{Etapa de Mantenimiento}

6.3.3.3.1 Medios Digitales Pág. 81

\section{DISTRIBUCIÓN DE LA INVERSIÓN}

7.1 Sustentación de presupuesto. .Pág. 83

8. CONCLUSIONES Pág. 84

9. RECOMENDACIONES Pág.86

10. REFERENCIAS .Pág.87

11. ANEXOS .Pág.93 
https://drive.google.com/drive/u/1/folders/1N14cf_icJfXiLF3q iw-O6zdJ0ExdSODn 


\section{ÍNDICE DE FIGURAS}

- Figura 1. Boletín Estadístico. Fuente: FMV

- Figura 2. Mercado de viviendas nuevas y oficinas prime en Lima Metropolitana. Fuente: BBVA Research

- Figura 3.Mercado de viviendas nuevas y oficinas prime en Lima Metropolitana. Fuente: BBVA Research

- Figura 4. Video "Pradera del Rímac". Fuente: Besco

- Figura 5. Post Fanpage. Fuente: Besco

- Figura 6. Post Fanpage. Fuente: Viva.GyM

- Figura 7. Post Fanpage. Fuente: Dh mont Inmobiliaria

- Figura 8. Recorrido virtual Ciudad Sol el Retablo. Fuente: Página web Demont Inmobiliaria

- Figura 9. Video "Los Parques de San Martín de Porres” Fuente. Viva GyM

- Figura 10. Gráfica interés de adquisición. Encuesta Villa de Atletas Condominio. Fuente: Elaboración propia

- Figura 11. Gráfica de valoración. Encuesta Villa de Atletas Condominio. Fuente: Elaboración propia

- Figura 12. Gráfica preferencia de distritos para vivir. Encuesta Villa de Atletas Condominio. Fuente: Elaboración propia

- Figura 13. Gráfica disposición de precios. Encuesta Villa de Atletas Condominio. Fuente: Elaboración propia

- Figura 14. Gráfica atributos de Condominio. Encuesta Villa de Atletas Condominio. Fuente: Elaboración propia

- Figura 15. Pictogramas Lima 2019. Fuente: Lima 2019

- Figura 16. Detalle de tipografía Scifly

- Figura 17. Detalle de tipografía Monserrat

- Figura 18. Distribución de medios

- Figura 19. Gráfica distribución de presupuesto. Fuente: Elaboración propia 


\section{ÍNDICE DE ILUSTRACIONES}

- Ilustración 1. Propuesta de logotipo 1. Fuente: Elaboración Propia

- Ilustración 2. Propuesta de logotipo 2. Fuente: Elaboración Propia

- Ilustración 3. Propuesta de logotipo 3. Fuente: Elaboración Propia

- Ilustración 4. Logotipo versión en verde y blanco. Fuente: Elaboración Propia

- Ilustración 5. Logotipo versión Negativo. Fuente: Elaboración Propia

- Ilustración 6. Logotipo escalabilidad. Versión Impresa. Fuente: Elaboración Propia

- Ilustración 8. Área de seguridad del logotipo. Fuente: Elaboración Propia

- Ilustración 9. Uso incorrecto del logotipo. Fuente: Elaboración Propia

- Ilustración 10. Aplicación de logotipo en polo. Fuente: Elaboración Propia

- Ilustración 11. Aplicación de logotipo en llavero. Fuente: Elaboración Propia

- Ilustración 12. Aplicación de logotipo en caramelo. Fuente: Elaboración Propia

- Ilustración 13. Aplicación de logotipo papelería. Fuente: Elaboración Propia

- Ilustración 14. Aplicación de logotipo en bolsa ecoamigable. Fuente: Elaboración Propia

- Ilustración 15. Tarjetas de presentación. Versión negra. Fuente: Elaboración Propia

- Ilustración 16. Tarjetas de presentación. Versión blanca. Fuente: Elaboración Propia

- Ilustración 17. Vallas en Metro de Lima. Etapa pre lanzamiento. Fuente: Elaboración Propia

- Ilustración 18. Leds. Etapa pre lanzamiento. Fuente: Elaboración Propia

- Ilustración 19. Prensa. Etapa pre lanzamiento. Fuente: Elaboración Propia

- Ilustración 20. Post en Facebook. Etapa pre lanzamiento .Fuente: Elaboración Propia

- Ilustración 21. Instastorie. Etapa pre lanzamiento. Fuente: Elaboración Propia

- Ilustración 22. Portal web Villa de Atletas. Etapa pre lanzamiento. Fuente: Elaboración Propia

- Ilustración 23. Anuncio en el Trome. Etapa lanzamiento. Fuente: Elaboración Propia

- Ilustración 24. Vallas en Metro de Lima. Etapa lanzamiento. Fuente: Elaboración Propia 
- Ilustración 25. Leds. Etapa lanzamiento. Fuente: Elaboración Propia

- Ilustración 26. Pantallas de cine. Etapa lanzamiento. Fuente: Elaboración Propia

- Ilustración 27. Storyboard. Etapa lanzamiento. Fuente: Elaboración Propia

- Ilustración 28. Monitor 3D. Etapa lanzamiento. Fuente: Elaboración Propia

- Ilustración 29. Post en Facebook. Formato PPV. Etapa lanzamiento Fuente: Elaboración Propia

- Ilustración 30. Post en Facebook. Formato Carrusel. Etapa lanzamiento Fuente: Elaboración Propia

- Ilustración 31. Post en Instagram. Formato secuencia con Form. Etapa lanzamiento Fuente: Elaboración Propia

- Ilustración 32. Instastories. Etapa lanzamiento. Fuente: Elaboración Propia

- Ilustración 33. Email marketing. Etapa lanzamiento.Fuente: Elaboración Propia

- Ilustración 34. Anuncio en Youtube. Etapa lanzamiento.Fuente: Elaboración Propia

- Ilustración 35. Post Facebook. Etapa mantenimiento.Fuente: Elaboración Propia

- Ilustración 36. Instastorie. Etapa mantenimiento.Fuente: Elaboración Propia

- Ilustración 37. Email marketing. Etapa mantenimiento.Fuente: Elaboración Propia 


\section{ÍNDICE DE TABLAS}

- Tabla 1: Distribución de la población según distrito en la zona 9. Fuente:

Elaboración propia

- Tabla 2: Distribución de la población según distrito en la zona 4. Fuente: Elaboración propia

- Tabla 3: Información de departamentos en Villa de Atletas. Fuente: Revista Perú Construye

- Tabla 4: Plan de comunicación. Fuente: Elaboración propia

- Tabla 5: Comparativo costos de publicidad en Tv y Pantallas de cine. Fuente: Elaboración propia. 


\section{RESUMEN EN ESPAÑOL}

En el presente trabajo se planteará una estrategia de comunicación y marketing para impulsar la venta total de los departamentos ubicados en el Condominio Villa de Atletas, los cuales fueron construidos para alojar a las delegaciones internacionales participantes de los Juegos Panamericanos y Parapanamericanos Lima 2019.

Esta estrategia consta de la definición de la imagen de marca del Condominio y la estrategia de medios a utilizar, con la finalidad de alcanzar los objetivos planteados.

Palabras clave: Comunicación, marketing, estrategia de medios, Juegos Panamericanos, Condominio Villa de Atletas.

\section{RESUMEN EN INGLÉS}

In this work, a communication and marketing strategy will be proposed to make the total sale of the departments located in the Villa de Atletas

Condominium, which were built to accommodate the international delegations participating in the Pan American and Parapan American Games Lima 2019.

This strategy consists in the definition of the brand image of the Condominium and the media strategy to be used in order to achieve the objectives set.

Keywords: Communication, marketing, Media Strategy, Pan American Games, Villa de Atletas Condominium 


\section{INTRODUCCIÓN}

En el Perú, el mercado inmobiliario se ha venido acrecentando a lo largo de los años gracias a las facilidades de acceso a créditos hipotecarios con tasas de interés bajas y colocaciones de créditos otorgados por programas sociales tales como los del Fondo Mivivienda. En este sentido, se estima que las ventas aumentarán al cierre del año gracias a la demanda que existe y que va encontrando un soporte importante en nuevos segmentos: la clase media emergente (C) y clase popular (D), compuesta por personas jóvenes de entre 30 a 40 años de edad.

Ante esta oportunidad, presentamos una estrategia de comunicación y marketing para el Condominio Villa de Atletas, tras el marco de los Juegos Panamericanos y Parapanamericanos Lima 2019, con el objetivo de generar conocimiento y reforzar el branding de la marca, en una primera etapa, y posteriormente, impulsar la venta de los departamentos a través de una campaña de comunicación 360.

De esta manera, realizaremos un análisis del contexto y perfil del público objetivo elegido, con la finalidad de plantear un plan de comunicación dividida en tres etapas: prelanzamiento, lanzamiento y mantenimiento, con soportes en medios ATL y Medios Digitales, a lo largo del proceso. 


\section{CAPÍTULO 1: CONTEXTO}

\subsection{Político}

El Gobierno del Perú por medio del Ministerio de Vivienda, Construcción y Saneamiento, viene tomando

El programa Techo Propio, otorga un bono gratuito, que no se devuelve, denominado "Bono Familiar Habitacional", que se otorga a las familias como un premio por ser ahorradores. Este Bono asciende al monto de S/ 33,200, y debe ser usado para la compra de una vivienda. Las familias que pueden acceder a este beneficio deben cumplir los siguientes requisitos:

- Ingreso mensual en conjunto menor a los S/ 3,626 para acceder a la compra de una vivienda.

- No tener vivienda, terreno propio o aires independizados para vivienda a nivel nacional.

El programa Nuevo crédito Mivivienda, consiste en un crédito hipotecario que puede financiar la compra de una vivienda, mientras su precio oscile entre S/ 58,800 y S/ 419,600, el cuál debe ser equivalente como máximo el $90 \%$ del valor de la vivienda. Además, en esta modalidad se puede acceder al Bono del Buen Pagador (BBP), en la que el Ministerio de Vivienda, Construcción y Saneamiento asume parte del pago de la cuota inicial, dependiendo del rango del precio del valor de la vivienda. En paralelo, como medida para incentivar la sostenibilidad, para disminuir el impacto en el medio ambiente, se puede acceder al Bono Mivivienda Verde, que otorga un bono adicional a las viviendas certificadas con criterios de sostenibilidad en su diseño y construcción. Este otorga entre $3 \%$ y $4 \%$ del valor del financiamiento de la vivienda. (Fondo Mivivienda, s.f)

Para acceder a este programa las familias deben cumplir los siguientes requisitos:

- Ser mayor de edad

- Ser calificado por una entidad financiera por la cual se accederá a la compra de una vivienda

- No ser propietario o copropietario de una vivienda a nivel nacional. 
- Tener el $10 \%$ del valor de la vivienda a adquirir, como monto de la cuota mínima inicial.

\subsection{Económico}

A lo largo de los años, el mercado inmobiliario se ha venido acrecentando a nivel mundial. Sin embargo, existe una amenaza debido a la desaceleración de la economía global y del crecimiento interno de algunos países emergentes, como es el caso de América Latina. De acuerdo a un informe publicado por El País, se pronosticó que el crecimiento pasaría del 0,4\% de 2018 al 0,2\% del año en curso, en buena medida por la profunda recesión venezolana (-23\%) (El País, 2019). A pesar de ello, existen excepciones como Bolivia con un crecimiento de $+4 \%$ y Perú, con un $+3,3 \%$. Citando a la directora de inversiones de AC Capitales SAFI, Jenny Esaine, dijo que en el 2018 la venta de viviendas fue de 14,500. Para este año, dijo que se espera un crecimiento de $10 \%$ en las ventas de las empresas inmobiliarias. (Perú 21, 2019)

En este sentido, el sector inmobiliario se desenvuelve en un marco positivo con respecto al mercado peruano, ya que en el 2018 se recuperó el dinamismo gracias a facilidades de acceso y disminución de tasas de interés de los créditos hipotecarios y el impulso de las colocaciones de créditos otorgados por programas sociales de vivienda promovidos por el Gobierno, (El Economista, 2019) lo que depararía para el año 2019 un crecimiento continuo en el sector de viviendas sociales e incentivando a su vez, colocaciones de bonos con Techo Propio y Mivivienda.

Con respecto a la colocación de créditos del Fondo Mivivienda, como se menciona líneas anteriores, ha venido en incremento, creciendo $37.6 \%$ en el mes de Julio, con respecto al mismo mes del año anterior, lo que se traduciría en S/ 131.8 millones.

De acuerdo al boletín estadístico de Fondo Mivivienda, dentro de las Instituciones Financieras (IFI's) que más resaltan, los bancos abarcaron el 58.6\% de las colocaciones de créditos en el mes de julio (607 en total), destacando el BCP, con 273 créditos; seguido de Financiera TFC, con 179 créditos e Interbank, con 114 créditos en tercera posición. (Fondo Mivivienda, 2019) 


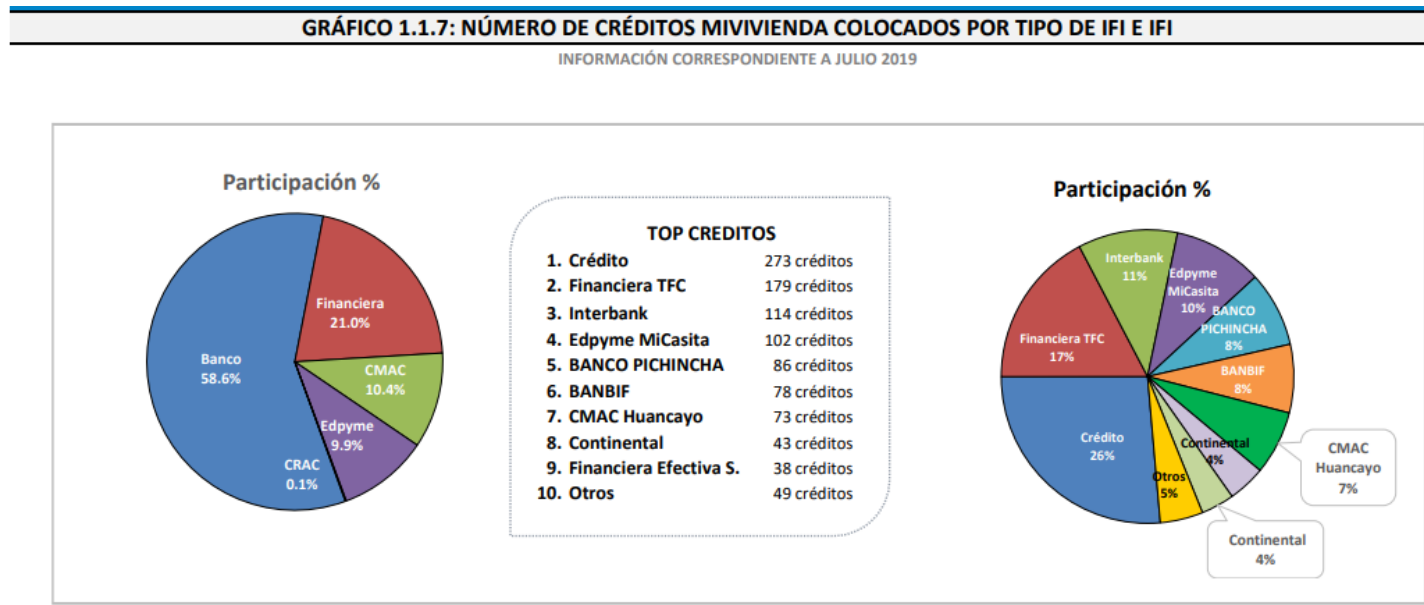

Fuente: FMV
"CMAC: Cajas Municipales de Ahorro y Crédito
"*CRAC: Cajas Rurales de Ahorro y Crédito

Figura 1. Boletín Estadístico. Fuente: FMV

En cuanto a los Bonos Mivivienda Verde alcanzaron un total de 464 bonos cuyo monto totalizó S/ 2.5 millones en el mes de julio del presente año. Cabe mencionar que, entre enero y julio, del presente año se han desembolsado un total de 2,778 bonos. (Fondo Mivivienda, 2019)

De acuerdo a un informe de Paz Centenario, las ventas del sector inmobiliario aumentaron entre $10 \%$ y $15 \%$ en el primer semestre del año producto de las facilidades que se están incentivando para la obtención de una vivienda, y se espera que el año cierre con un aumento de precios entre $5 \%$ y $8 \%$ por metro cuadrado $\left(\mathrm{m}^{2}\right)$. En línea con la expectativa del crecimiento, Diego Abarca, gerente comercial de Paz Centenario, agregó que se observa un incremento de entre $12 \%$ y $13 \%$ en el precio de una vivienda en un período de dos años. (Gestión, 2019)

Citando un fragmento de la entrevista a Abarca por el diario Gestión:

"El Perú es un mercado muy interesante para este tipo de inversiones porque tenemos el valor de $\mathrm{m}^{2}$ más barato de la región si lo comparamos con los países cuya economía crece sostenidamente como Colombia, Chile, Brasil y Ecuador” (Abarca, 2019) 
Dado el contexto en el que nos encontramos, el estudio de BBVA Research, Perú Mercado de viviendas nuevas y oficinas prime en Lima Metropolitana, se estima que las ventas alcanzarán entre 16,5 mil y 17 mil unidades en el año y que, en el medio plazo, la demanda de viviendas nuevas encontrará soporte en la expansión de la clase media, (Marzo, 2019) conformada por la clase media emergente (C) y clase popular (D). (BBVA Research , Marzo 2018)

Estructura de los hogares urbanos por nivel socioeconómico (\% del total de hogares urbanos)

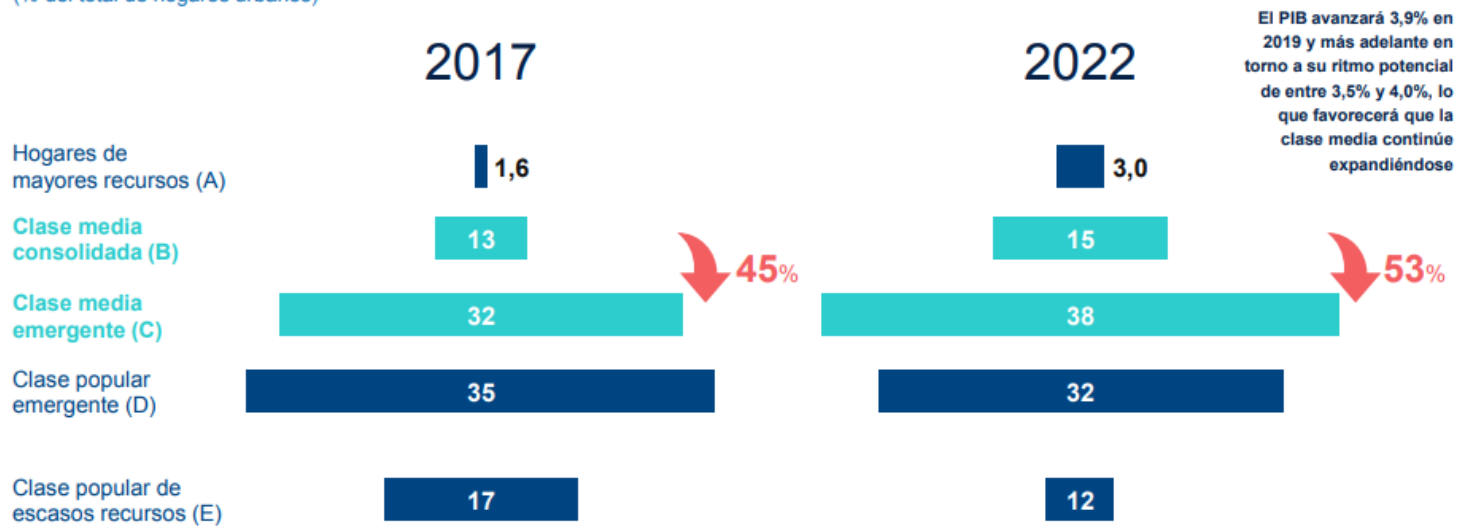

Figura 2. Mercado de viviendas nuevas y oficinas prime en Lima Metropolitana. Fuente: BBVA Research

\section{$1.3 \underline{\text { Sociales }}$}

El boom del sector inmobiliario viene acompañado de varias características sociales que impactan positiva o negativamente en el rendimiento de las ventas, empezando por el tipo de vivienda que prefieren adquirir las personas hoy en día, es decir, casas o departamentos. El estudio de BBVA Research, Perú Mercado de viviendas nuevas y oficinas prime en Lima Metropolitana, menciona que hubo un 13\% de crecimiento en la venta de departamentos nuevos en el año 2018 con respecto al año anterior y ello se debe a que los peruanos prefieren este tipo de vivienda por la seguridad, por ejemplo, el uso de un sistema de cámaras de vigilancia cerrado y portería, además de los espacios comunes que generalmente traen consigo. (BBVA Research, Marzo 2018) 
Hay una tendencia en el mercado que se preocupa por obtener una vivienda cómoda, que cumpla con sus necesidades básicas y esto también se debe a un tema generacional. En un informe del diario Gestión, el 60\% de millennials que adquiere una vivienda lo hace con fines de inversión, mientras que el $40 \%$ restante lo hace para independizarse. (Gestión, El 60\% de millennials que adquiere vivienda lo hace con fines de inversión, 2019)

En una entrevista a Alfonso Vigil, gerente comercial de Edifica, menciona:

“Aprovechan su vínculo familiar para seguir viviendo en casa y capitalizan su inversión alquilando el inmueble que compraron" (Vigil, 2019)

En esta misma línea, Rolando Arellano, menciona que en la próxima década "viene un boom de demanda inmobiliaria", de parte de los jóvenes que actualmente tienen entre 20 a 30 años, quienes requerirán de una vivienda propia y se convertirán en el más grande segmento poblacional. (Gestión, Arellano: "Viene un boom de demanda inmobiliaria, pero hace falta innovar en los créditos”, 2019)

En este sentido, hay una lista de distritos en los que el tiempo para recuperar la inversión sería más corto. Surquillo es el distrito limeño en que la inversión en vivienda se recupera más rápido, según datos de la reciente publicación del Banco Central de Reserva (BCR), seguido de Lince, Pueblo Libre, San Miguel, Magdalena y Barranco, este último con los precios más altos y mostrando una mejor rentabilidad. (DIPROMIN, 2019)

Sin embargo, es necesario mencionar que la demanda de departamentos excede la oferta disponible en el mercado limeño, es decir, en el periodo de dos años, se estima que se querrán adquirir alrededor de 58 mil viviendas, siendo 27 mil la oferta de departamentos disponibles. Esto se debe a que existen problemas estructurales que limitan equiparar una oferta contra la demanda, por ejemplo: permisos de construcción, escasez de suelo, falta de acceso a servicios básicos (luz y agua potable) y una regulación municipal adecuada.

\subsection{Tecnológico}

El desarrollo de la tecnología se ha dado de manera integral en todos los ámbitos para el bienestar de la población. El sector inmobiliario no ha escapado de este desarrollo 
tecnológico, por ello vemos el avance tanto en la construcción de inmuebles, como el uso de la tecnología para mejorar la experiencia del cliente en el proceso de compra.

Hoy en día existen diversas herramientas tecnológicas para innovar en el negocio y destacarse de su competencia. De acuerdo a un artículo publicado por El País, se trataría de las llamadas proptech, "un término acuñado en el mercado anglosajón para definir a toda aquella industria tecnológica que está creando valor al sector inmobiliario: desde portales inmobiliarios, pasando por el crowdfunding, el big data, la realidad virtual para comercialización, la visualización de inmuebles, el software de gestión, la domótica o el Internet de las cosas" (El País, 2017) Se trata pues de una revolución, que simplifica y hace más dinámica la experiencia del cliente transportándolo virtualmente a una casa piloto en cuestión de segundos, hasta permitirle descubrir cómo quedaría o podría ser remodelada su vivienda de manera muy sencilla.

En una entrevista brindada por Luciano Barredo, gerente de Marketing de Navent, y publicado en La República, "La implementación de herramientas tecnológicas es un tema aún pendiente en nuestro país. Este escenario, desde una mirada optimista, se presenta como una ventana de oportunidades para que nuevas técnica y herramientas entren al mercado para mejorar la experiencia de los clientes y el tiempo de respuesta de las inmobiliarias” (La República, 2019)

El uso del Big Data, por ejemplo, está revolucionando el sector. En un artículo publicado por el blog Idealista/news, la posibilidad de tener una base con las preferencias y datos de los usuarios o sobre qué espacios son los predilectos en las viviendas u oficinas, ayuda maximizar el valor del producto final, sea cual sea. (Idealista News, 2018). En esta misma línea, la publicidad en base a geolocalización mediante herramientas como Facebook, Google, Instagram y Waze pueden ayudar a incentivar el mercado cuando estés cerca de alguna vivienda y aparezca publicidad relacionada a la misma.

También cabe mencionar otra de las herramientas importantes que tienen un gran impacto en el rubro: el CRM, que transforma no sólo la experiencia con el cliente sino también hasta la toma de decisiones. De acuerdo a La República, los programas de gestión de clientes o CRM son herramientas que permiten gestionar las principales tareas 
relacionadas a la atención al cliente, y tienen como objetivo reducir tiempos de respuesta e incrementar las conversiones a ventas (La República, 2019)

Por otro lado, el BIM es una tecnología que está ayudando en la construcción de inmuebles, pues permite mantenerse dentro del presupuesto en el proceso de construcción; además, establece un flujo de comunicación transversal entre todos los agentes involucrados en la construcción de un inmueble, generando un modelo virtual que contiene toda la información relacionada con el edificio durante todo su ciclo de vida, desde su concepción inicial, durante su construcción y toda su vida útil, hasta su demolición. (Kaizen, 2015). En una entrevista brindada por Jonathan Hunter, director de operaciones en Elecosoft, y publicado en Gestión, "BIM está siendo adoptado por contratistas de la construcción, empresas de construcción de tamaño mediano y constructores de casas, ya que se vuelve asequible y sus beneficios son tangibles" (Gestión, 2018)

Finalmente, cabe mencionar que, en una entrevista brindada por el Ministro de Vivienda, Construcción y Saneamiento, que desde el 2020 los proyectos inmobiliarios deberán contar con mayor tecnología ecosostenible para poder calificar a los beneficios del BMV. (Mi vivienda, 2019). Esto es, sistemas de ahorro de agua, electricidad, manejo de residuos sólidos, etc.

\subsection{Ambiental}

La preocupación de la población por cuidar el medio ambiente se ha ido acrecentando con el pasar de los años, pues se han comenzado a ver evidencias de los estragos y consecuencias causados por la contaminación, con manifestaciones como huaycos, cambios climáticos inesperados, radiación solar intensa, entre otras. Es en este contexto que la sociedad está en la constante búsqueda de acciones para preservar y conservar el medio ambiente, por medio del reciclaje, formación de grupos de limpieza de playas, entre otros. La preocupación por desarrollar acciones sostenibles ha llegado a todos los sectores, incluyendo el inmobiliario.

Por parte del Gobierno del Perú, se ha comenzado a incentivar en el mundo inmobiliario la construcción de viviendas sostenibles, que permitan ahorrar a las familias entre un $30 \%$ o $40 \%$ en el uso de energía y agua. Por ello, han desarrollado el programa Mivivienda 
Verde, que permite impulsar el desarrollo de un ecosistema inmobiliario, fortaleciendo el crecimiento de la urbe sostenible, y por el lado de las familias peruanas, que puedan tener acceso a su vivienda propia y aporten en el cuidado del medio ambiente.

Según la PNUD, en el año 2050 dos tercios de la población mundial vivirán en zonas urbanas, por la cual es necesario que los Gobiernos impulsen el desarrollo de ecosistemas sostenibles, con la construcción de viviendas, transporte público, crear áreas públicas verdes y mejorar la planificación y gestión urbana de manera que sea participativa e inclusiva. (PNUD, 2019) 


\section{CAPÍTULO 2: PÚBLICO OBJETIVO}

Para plantear nuestra estrategia de comunicación y marketing, decidimos enfocarnos en el siguiente público objetivo: mujeres y varones del NSE C que se encuentren dentro del rango de edad de 30 a 40 años. Este P.O. son casados, convivientes o solteros con pareja, con familia o potenciales a formar una familia y con interés en adquirir una vivienda propia.

A continuación, la descripción completa de nuestro público objetivo.

\subsection{Perfil demográfico y familiar}

- Según el dashboard de APEIM, el 40,9\% de la población limeña (3'811,880 personas) pertenece el NSE C. (APEIM, 2018)

- Según el dashboard de APEIM, en el departamento de Lima, el 48,5\% de la población son varones y el 51,5\% son mujeres, ambos del NSE C. (APEIM, 2018)

- Según el dashboard de APEIM, en el departamento de Lima, el 6,7\% de la población se encuentra en el rango de edad de 31 a 35 años y el 12,9\% se encuentra en el rango de edad de 36 a 45 años, ambos del NSE C. (APEIM, 2018)

- De acuerdo al estudio realizado por CPI, Perú: Población 2019, el $42 \%$ de hogares pertenecen al NSE C, y el 25.5\% tienen de 25-39 años; siendo el segmento con mayor población. (CPI, 2019)

- De acuerdo al informe "Perfil del adulto joven" publicado por IPSOS, el $62 \%$ de la población adulto joven tiene pareja, ya sea conviviente, soltero con pareja o casado. (Ipsos, Perfil del adulto joven peruano, 2018)

- De acuerdo al informe "Perfil del adulto joven" publicado por IPSOS, el $40 \%$ de la población adulto joven del rango de edad de 31 a 35 años tiene la intención de mudarse en los próximos 2 años. (Ipsos, Perfil del adulto joven peruano, 2018)

- De acuerdo al informe "Perfil del adulto joven" publicado por IPSOS, la edad promedio para independizarse es de 31 años. (Ipsos, Perfil del adulto joven peruano, 2018)

- De acuerdo al informe "Perfil del adulto joven" publicado por IPSOS, el 79\% de los adultos jóvenes ahorra, principalmente para la compra de un inmueble o para invertir en un negocio. (Ipsos, Perfil del adulto joven peruano, 2018) 
- En esta misma línea, las metas más importantes para los peruanos jóvenes son tener trabajo seguido de tener una casa propia. (Ipsos, Perfil del adulto joven peruano, 2018)

- Según el informe de "Perfiles Socioeconómicos Lima Metropolitana 2017" realizado por IPSOS, el 18\% de jefes de hogares del NSE C se encuentran en el rango de edad de 25 a 39 años. (Ipsos, Perfiles Socioeconómicos Lima Metropolitana, 2017)

- Según el dashboard de APEIM, la población del NSE C del departamento de Lima, el 14,9\% (567,970 personas) vive en la zona 9 (Villa El Salvador, Villa María del Triunfo, Lurín, Pachacamác) y el otro grupo mayoritario con 14,9\% (483,343 personas) vive en la zona 4 (Cercado, Rímac, Breña, La Victoria). Ambas zonas hacen un total de 27,6\% (1,051,313 personas). (APEIM, 2018)

- En un estudio realizado por CPI, Perú: Población 2019, se desglosa la Población y hogares según distritos mencionados previamente: (CPI, 2019)

- Zona 9:

\begin{tabular}{|l|l|l|}
\hline Distrito & Población & Nro Hogares \\
\hline $\begin{array}{l}\text { Villa María del } \\
\text { Triunfo }\end{array}$ & 442.2 & 107.7 \\
\hline Villa El Salvador & 437.1 & 99 \\
\hline Pachacamac & 121.5 & 31.5 \\
\hline Lurin & 97.9 & 24.6 \\
\hline
\end{tabular}

Tabla 1: Distribución de la población según distrito en la zona 9.

Fuente: Elaboración propia

- Zona 4:

\begin{tabular}{|l|l|l|}
\hline Distrito & Población & Nro Hogares \\
\hline Lima Cercado & 294.4 & 81.1 \\
\hline Rimac & 192.3 & 50.2 \\
\hline La Victoria & 191.1 & 52.9 \\
\hline Breña & 93.4 & 26.2 \\
\hline
\end{tabular}

Tabla 2: Distribución de la población según distrito en la zona 4.

Fuente: Elaboración propia 
- De acuerdo al Estudio de demanda de vivienda a nivel de las principales ciudades, realizado en la zona Lima Sur, el 34.7\% de jefes de hogar del NSE C se encuentran conviviendo, el $23.3 \%$ son solteros y el $19.3 \%$ son casados. (Fondo Mivivienda, 2018)

\subsection{Perfil laboral}

- Según el estudio "Provincia de Lima compendio estadístico 2017" de la INEI, 59,9\% de la población económicamente activa (PEA), se encuentra en el rango de edad de 25 a 59 años. (INEI, 2017)

- De acuerdo al dashboard de APEIM, el 39,3\% de la población limeña, que pertenece al NSE C, son trabajadores dependientes; el 19,5\% son independientes y el 3,2\% son dueños de una PYME. (APEIM, 2018)

- De acuerdo al informe "Perfil del adulto joven" publicado por IPSOS, el 65\% de la población adulto joven solo de dedica a trabajar.

\subsection{Perfil económico y financiero}

- De acuerdo al dashboard de APEIM, el promedio de ingreso de la familia limeña, que pertenece al NSE C, es de S/ 4,164, mientras que el del NSE D, es de S/ 2,818. (APEIM, 2018)

- En esta misma línea, el 11.8\% del NSE C posee una vivienda Alquilada. (APEIM, 2018)

- De acuerdo al informe "Bancarización del peruano. Bancos, Cajas y Financieras" publicado por IPSOS, el índice de bancarización de acuerdo a la edad, el 46\% posee entre 25 a 39 años. (2018)

- En esta misma línea, el $48 \%$ pertenece al NSE C y son trabajadores dependientes con un 54\%. "El bancarizado peruano tiene 39 años, es soltero o con pareja, tiene hijos, pertenece al NSE C y es trabajador dependiente." (IPSOS, 2018)

- El segmento del NSE C pertenece principalmente a algún banco con un 89\%, mientras que sólo el 7\% pertenece a una Financiera. (IPSOS, 2018)

- En cuanto al banco con el que la mayoría ingresa al sistema financiero como cliente es el BCP, con un 36\%, seguido del BBVA con 12\%. (IPSOS, 2018)

- Los hábitos de ahorro varían de acuerdo a la edad, en donde el rango de edades entre 25-39 años representa el 42\% de los que sí ahorran. (IPSOS, 2018)

- El control de los ingresos y gastos se realiza a través de un presupuesto mensual en mayor porcentaje (56\%), en donde el NSE C abarca un 49\% de la población, entre la edad de 25 a 39 años (60\%) (IPSOS, 2018) 
- Siguiendo con el informe publicado por IPSOS, el bancarizado cree que es razonable dedicar hasta un 25\% de los ingresos mensuales para pagar deudas. (IPSOS, 2018)

- Al momento de elegir un préstamo, se valoran las siguientes variables:

- Tasa de interés baja (85\%)

- Fácil de obtener (47\%)

○ Menos documentos $(44 \%$

- Plazos de pago accesibles (36\%)

- En cuanto al interés en productos en los próximos 12 meses, el 25\% piensa solicitar alguno, como crédito personal (10\%), Tarjeta de crédito (4\%) y Crédito Mivivienda (3\%). (IPSOS, 2018)

- De acuerdo al informe publicado en la Revista Mivivienda, las personas que solicitan el Nuevo Crédito Mivivienda, tienen entre 30 y 40 años con un $38 \%$ (1862 personas) en el último semestre del año, siendo el grupo con mayores solicitudes dentro del grupo. (Revista Mivivienda, Julio 2019)

- En cuanto al estado civil de las personas que adquieren al Nuevo Crédito Mivivienda, se encuentran solteras con 69\% (3345 personas), siendo el mayor porcentaje del grupo, seguido de casados con 20\% (956 personas) (Revista Mivivienda, Julio 2019)

\subsection{Entretenimiento y consumo de medios}

- Según el informe" Transporte utilizado diariamente" de CPI, el 12,5\% del NSE C usa el tren (Metro de Lima) para transportarse, siendo el segundo medio más usado, el primero son los buses/ combis con un 90,6\%. (CPI,2016)

- Según la encuesta realizada por la empresa de e-commerce Groupon Peixe publicada en el diario El Comercio, $49 \%$ de los peruanos va al menos una vez a la semana al cine. (El Comercio, 2019)

- Según el diario Gestión, Cineplanet Mall del Sur, es el que genera mayor cantidad de ingresos a la cadena Cineplanet con más de 177 mil espectadores solo en el mes de diciembre 2017. (Gestión, 2018)

- Según el informe de IPSOS "Publicidad digital versus tradicional" publicada en Gestión, la publicidad en el Cine capta un 34\% de la atención de los espectadores versus un 30\% en TV de señal abierta. Asimismo, en Facebook es de 33\%, YouTube de 30\% y Radio del 29\%. (Gestión, 2019)

- Según el informe de Apoyo \& Asociados, el 53.1\% de la participación del mercado del cine le pertenece a Cineplanet. (Apoyo \& Asociados, 2019) 
- Según el informe de "CONSUMO DE MEDIOS 2018-Consumo de medios de comunicación digitales y tradicionales" realizado por IPSOS, del NSE C su consumo de medios tradicionales es de $54 \%$ y $46 \%$ digital. (IPSOS, 2018)

- Según el informe de "CONSUMO DE MEDIOS 2018-Consumo de medios de comunicación digitales y tradicionales" realizado por IPSOS, del NSE C 62\% está expuesto 1 o varias veces por semana a medios digitales. (IPSOS, 2018)

- De acuerdo al informe de "CONSUMO DE MEDIOS 2018-Consumo de medios de comunicación digitales y tradicionales" realizado por IPSOS, del NSE C los medios digitales más consumidos semanalmente son: Facebook (04:56 horas) y YouTube (04:55 horas). (IPSOS, 2018)

- De acuerdo al informe de "CONSUMO DE MEDIOS 2018-Consumo de medios de comunicación digitales y tradicionales" realizado por IPSOS, el mayor porcentaje de consumo de publicidad OOH es de 34\%, perteneciente al NSE C. (IPSOS, 2018)

- De acuerdo al informe de "CONSUMO DE MEDIOS 2018-Consumo de medios de comunicación digitales y tradicionales" realizado por IPSOS, el mayor porcentaje de consumo de publicidad en Puntos de Venta es de 34\%, perteneciente al NSE C. (IPSOS, 2018)

- De acuerdo al informe de "CONSUMO DE MEDIOS 2018-Consumo de medios de comunicación digitales y tradicionales" realizado por IPSOS, el canal líder de TV de señal abierta es América TV. (IPSOS, 2018)

- De acuerdo al informe de "CONSUMO DE MEDIOS 2018-Consumo de medios de comunicación digitales y tradicionales" realizado por IPSOS, el periódico informativo líder es Trome, le sigue El Popular. (IPSOS, 2018)

\subsection{Comportamiento tecnológico}

- De acuerdo con el dashboard elaborado por APEIM, el 66,7\% de la población limeña, que pertenece al NSE C, tienen acceso a internet. De este total el 71,9\% tiene acceso móvil a internet. (APEIM, 2018)

- De acuerdo con el informe "Bancarización del peruano. Bancos, Cajas y Financieras" publicado por IPSOS, más de la mitad de entrevistados posee un celular, con un $88 \%$, y, por otro lado, el 52\% posee un smartphone, ambos del NSE C (2018)

- En un artículo publicado por El Comercio, la mayoría de las compras todavía se realiza en las tiendas físicas, pero son altamente influenciados por el internet. Citando un fragmento: 
"Un reciente análisis de Kantar TNS, encomendado por Google, sobre la conducta de compra de los peruanos que señala que el $71 \%$ de los clientes que compraron en 'retail' realizaron una investigación online previa." (El Comercio, 2018).

- En esta misma línea, la decisión final de compra es influenciada por la información hallada en internet en un $94 \%$.

- Según el informe de "CONSUMO DE MEDIOS 2018 - Consumo de medios de comunicación digitales y tradicionales" realizado por IPSOS, del NSE C 49\% son heavy users, es decir se conecta 7 o más veces por semana. (IPSOS, 2018).

- De acuerdo al informe de "CONSUMO DE MEDIOS 2018-Consumo de medios de comunicación digitales y tradicionales" realizado por IPSOS, el APP de mapas más usado es Google Maps. (IPSOS, 2018). 


\subsection{Empathy Map}

¿Con quién estamos

\section{empatizando?}

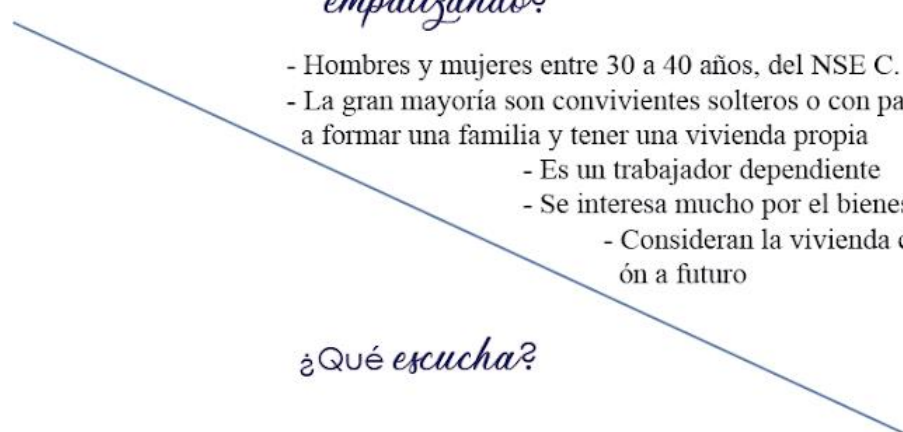

- Los precios de los departamentos en la Villa son muy caros para la zona

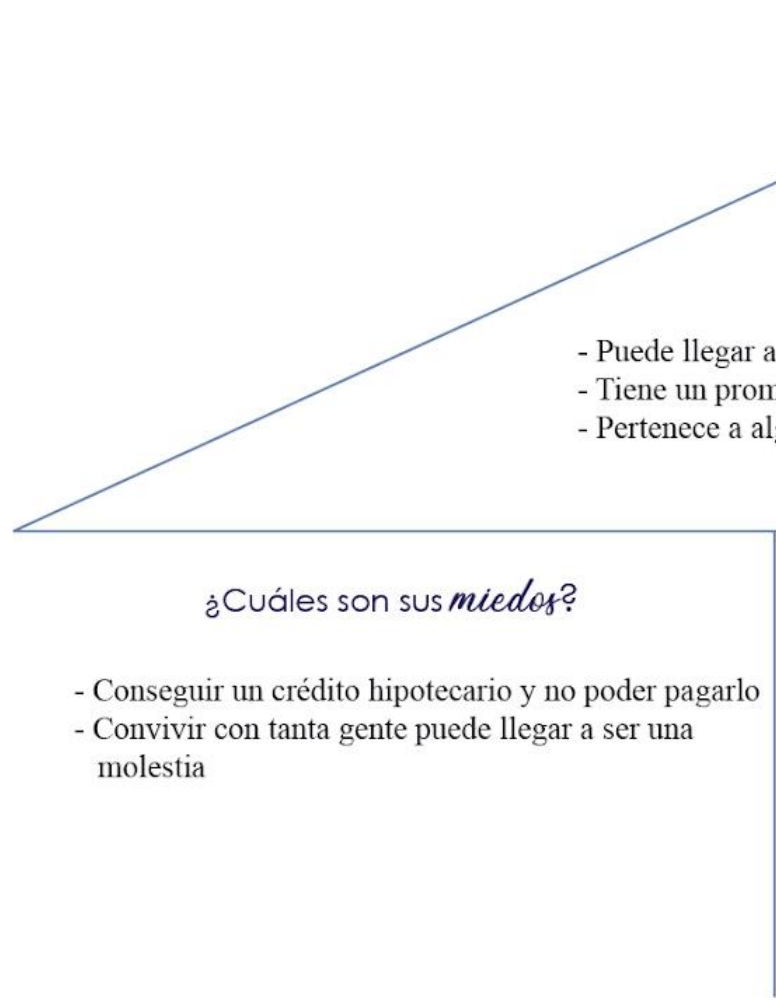

¿Qué necesitamos

\section{hacer?}

Comunicar efectivamente el lanzamiento de los departamentos de la Villa del Atleta, en base a los intereses de nuestros compradores potenciales

- Vender la mayor cantidad de departamentos posibles gracias a

la comunicación.

\section{¿Qué observa?}

- La decisión fínal de compra es influenciada en gran medida por el internet.

- Valora mucho el precio y ubicación de la vivienda.

- Las facilidades que le pueda brindar el Estado a través de los créditos.
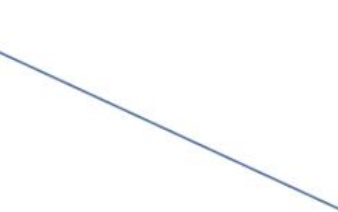

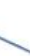

as.

Tiene un promedio de ahorro mensual.

Pertenece a alguna entidad financiera, sobre todo bancos.

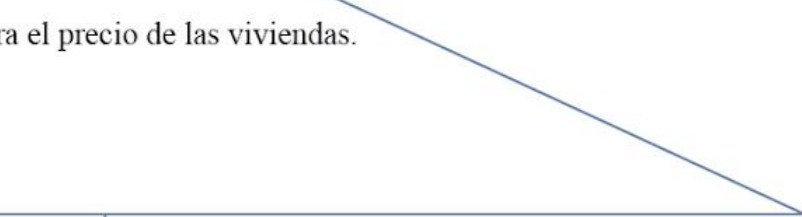

\section{¿Qué piensa y siente?}

-Tiene una preferencia de vivir en SJL debido a factore económicos, comercio y facilidad de transporte; sin embargo, aspira a llegar a distritos como Surco, San Borja y Miraflores.

Identifica vivir en un condominio con seguridad, familiar y ahorro

\section{¿Cuáles son sus objetivos y metas?}

- Tener su casa propia para vivir con su familia y dejársela en un futuro a sus hijos.

- Dejar de pagar un alquiler y tener su casa propia. - Busca mayor comodidad e independencia 


\section{CAPÍTULO 3: HALLAZGOS CLAVES}

\subsection{Del mercado}

- En base a la investigación previa, se puede deducir que el mercado del mundo inmobiliario va en crecimiento y esto se ve reflejado en el crecimiento que tuvo en los últimos 6 meses (3.38\%).

- En una entrevista a Renato Riva, Gerente General de Constructora Galilea publicada por la Revista Mivivienda, menciona que el primer semestre fue bastante productivo, sin embargo, en el mes de marzo se sintió una desaceleración debido a la inseguridad de los clientes al momento de la toma de decisión de compra. (Revista Mivivienda, Julio 2019)

- Gracias al impulso del Bono Mivivienda Verde, las ventas inmobiliarias crecerían 8\% este año (Revista Mivivienda, Julio 2019)

- Se espera que el año cierre con un aumento de precios entre $5 \%$ y $8 \%$ por metro cuadrado $\left(\mathrm{m}^{2}\right)$.

- Se estima que las ventas alcanzarán entre 16,5 mil y 17 mil unidades en el año y que, en el medio plazo, la demanda de viviendas nuevas encontrará soporte en la expansión de la clase media, conformada por la clase media emergente $(C)$ y clase popular (D). (BBVA Research, marzo 2019)

- La demanda de departamentos excede la oferta disponible en el mercado limeño. (BBVA Research, marzo 2019)

- Existe una demanda y oferta de departamentos según el precio. Se observan mayores ventas en departamentos de precios bajos, pero con poca oferta disponible; mientras que, por otro lado, se tiene una gran intención de compra con precios altos. 


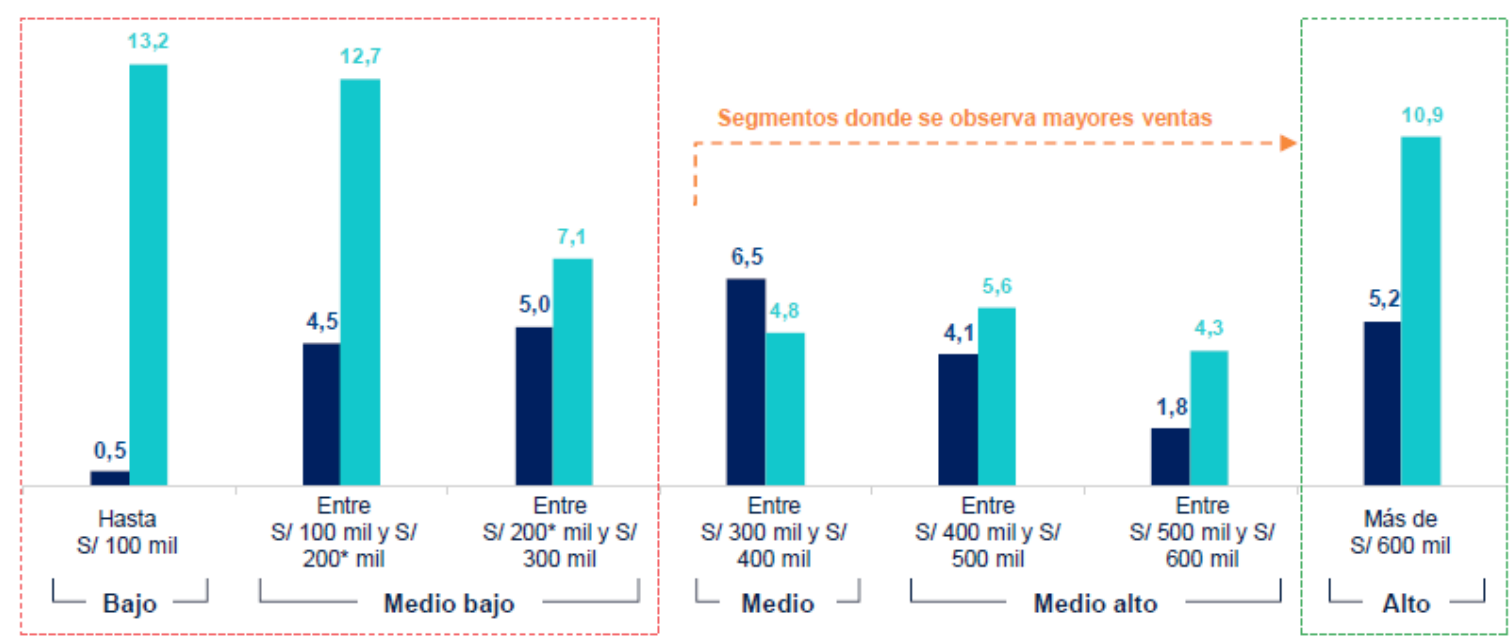

Oferta disponible Intención de compra (demanda)

Figura 3. Mercado de viviendas nuevas y oficinas prime en Lima Metropolitana. Fuente: BBVA Research

\subsection{De la competencia}

Se hizo una investigación de la competencia directa en el mercado limeño, analizando la variación de precios, área, beneficios y comportamiento a nivel digital para la difusión de las mismas.

3.2.1 Bench de la Competencia:

\section{- Condominio "Pradera del Rímac" de Inmobiliaria BESCO}

Posicionado como: "Vive en la primera urbanización de ecoamigable de la ciudad"

\section{Características:}

Ubicación: Rímac

$\mathrm{N}^{\circ}$ de pisos: 20

Tamaño del departamento: $65 \mathrm{~m} 2$ (3 dormitorios y 2 baños)

Casa Club, losas multideportivas, sala de juegos infantiles y redes internas para gas.

Precio: Desde S/ 172,100

\section{Medios digitales de publicidad:}


Uso de video en YouTube y en su página web, presentando en 3D los espacios compartidos del Condominio.

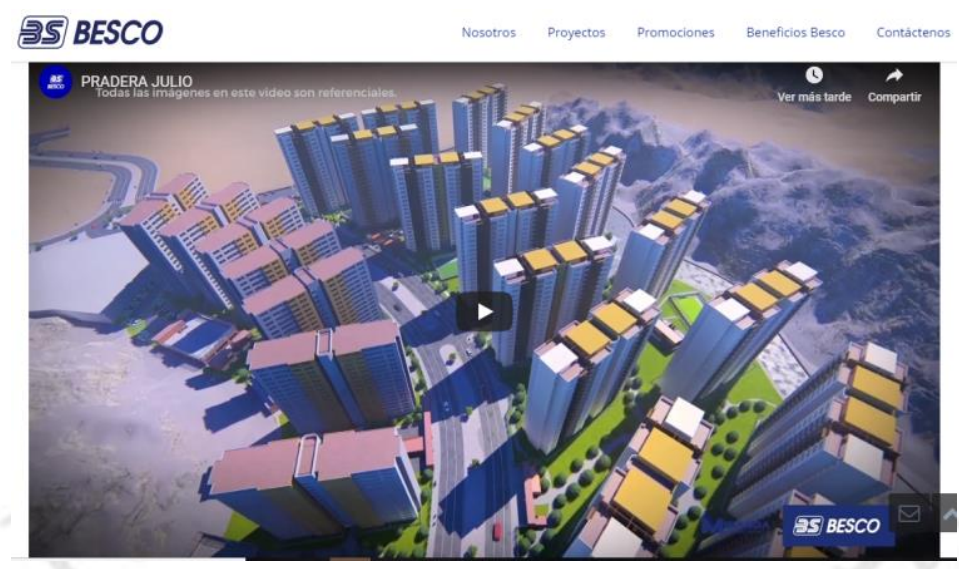

Figura 4. Video "Pradera del Rímac". Fuente: Besco

Uso de la página de Facebook de Besco para promocionar los departamentos del Condominio.

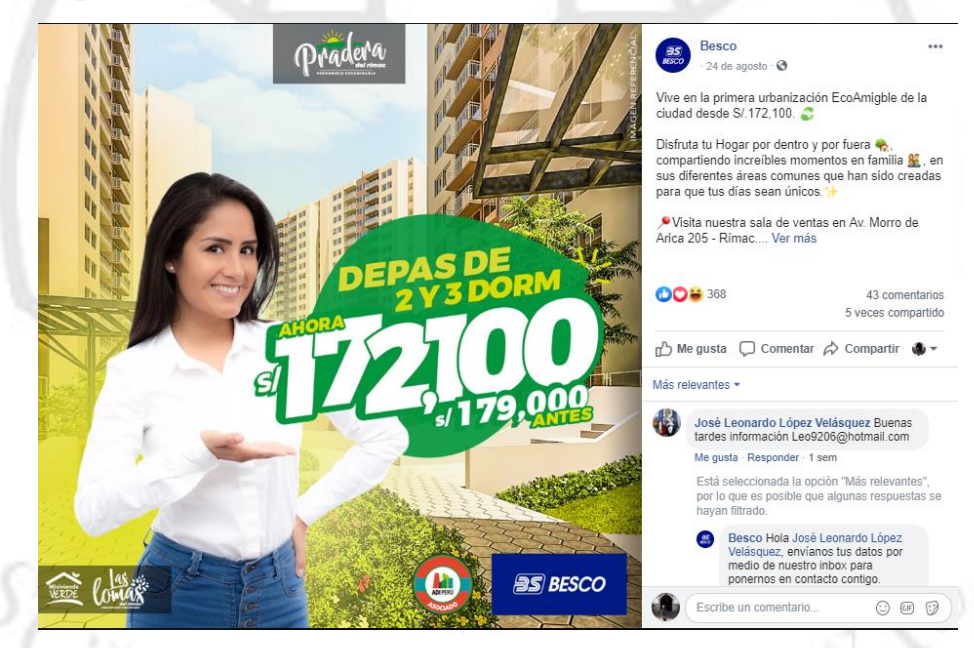

Figura 5. Post Fanpage. Fuente: Besco

\section{- Condominio Los Parques de Villa El Salvador II de Inmobiliaria Viva GYM}

Posicionado como: "Creciendo en tu propio hogar

\section{Características:}

Ubicación: Villa El Salvador

$\mathrm{N}^{\circ}$ de pisos: 5

$\mathrm{N}^{\circ}$ de edificios: 14

Tamaño del departamento: $62,37 \mathrm{~m} 2$ (3 dormitorios y 2 baños) 
Áreas verdes interiores, parque con zonas recreativas y Club House

\section{Medios digitales de publicidad:}

En Facebook, se promociona como un departamento de entrega inmediata, además que todo lo que necesitas está en tu depa.
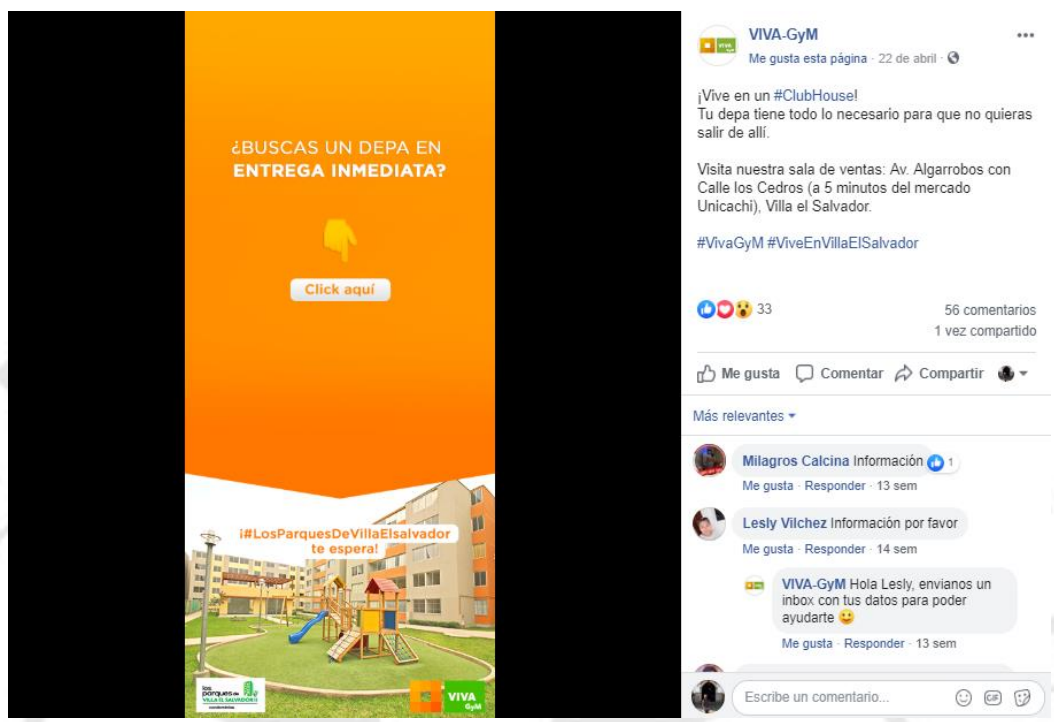

Figura 6. Post Fanpage. Fuente: Viva.GyM

\section{- Condominio Ciudad Sol el Retablo de Inmobiliaria DHMONT}

Posicionado como: "Mega proyecto habitacional que cuida el detalle y la calidad en los acabados"

\section{Características:}

Ubicación: Comas

$\mathrm{N}^{\circ}$ de pisos: 15

Tamaño del departamento: 55,61m2 (3 dormitorios y 1 baños), 70m2 (3 dormitorios y 2 baños) y $70 \mathrm{~m} 2$ ( 3 dormitorios y 2 baños

Estacionamientos, Áreas verdes interiores y parque con zonas recreativas para niños,

Precio: Desde S/ 102,700

\section{Medios digitales de publicidad:}

En Facebook, se promociona de manera bastante gráfica y directa a través de una fotografía del lugar. Así, mismo, publican tips y de decoración, de ahorro, entre otros. 


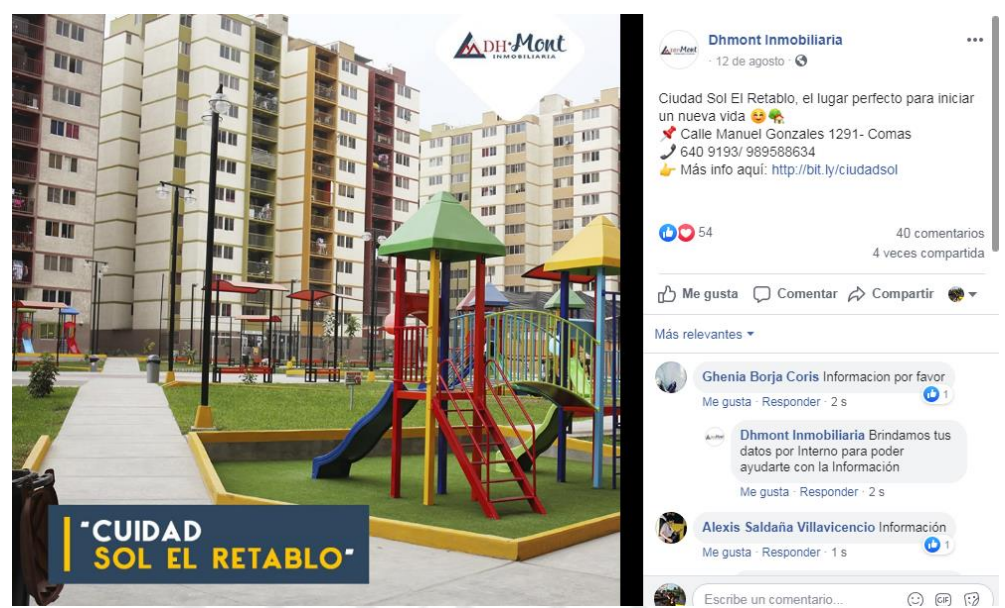

Figura 7. Post Fanpage. Fuente: Dhmont Inmobiliaria

En web, promocionan los departamentos a través de un recorrido virtual 360, de acuerdo al tamaño del departamento y la distribución de la misma.
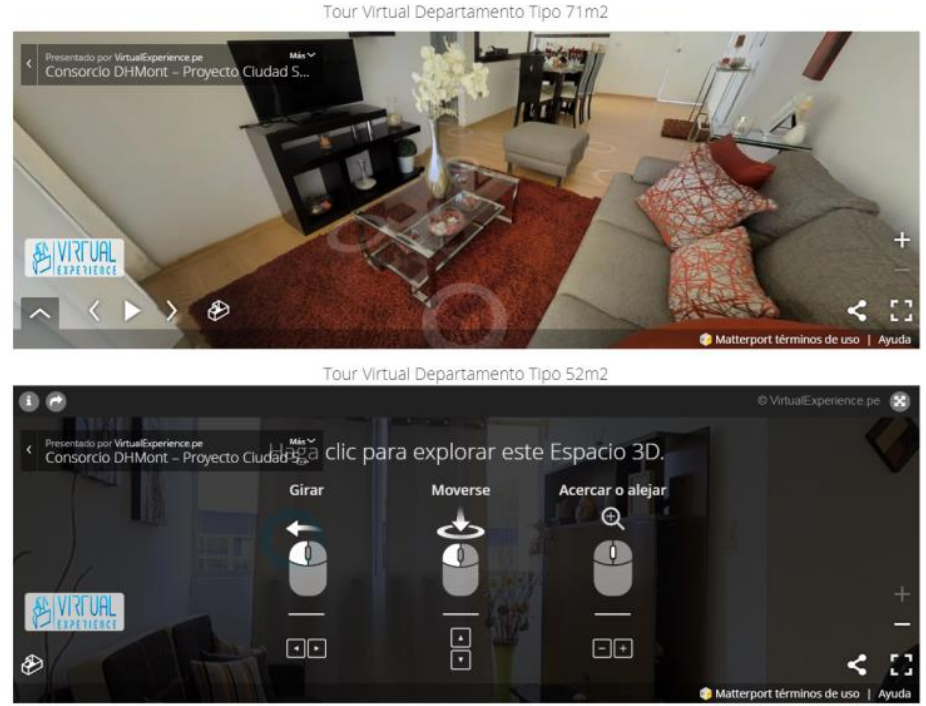

Figura 8. Recorrido virtual Ciudad Sol el Retablo. Fuente: Página web Demont Inmobiliaria

\section{- Los Parques de San Martín de Porres - Condominio Los Robles de Inmobiliaria Viva GYM}

Posicionado como: "Seguridad y Comodidad, ¡Departamentos con entrega inmediata!"

\section{Características:}

Ubicación: San Martín de Porres 
$\mathrm{N}^{\circ}$ de pisos: 5,10 y 12

$\mathrm{N}^{\circ}$ de edificios: 9

Tamaño del departamento: 58,5 m2 (3 dormitorios y 2 baños)

Áreas verdes interiores, parque con pérgola y zonas recreativas, zona de parrillas, gimnasio equipado, salón de recreación para niños y sala de juegos para adultos.

\section{Medios digitales de publicidad:}

En Facebook, se promociona como un departamento de entrega inmediata, además que todo lo que necesitas está en tu depa.

\begin{tabular}{l|l} 
- Vustube & Be \\
\hline
\end{tabular}

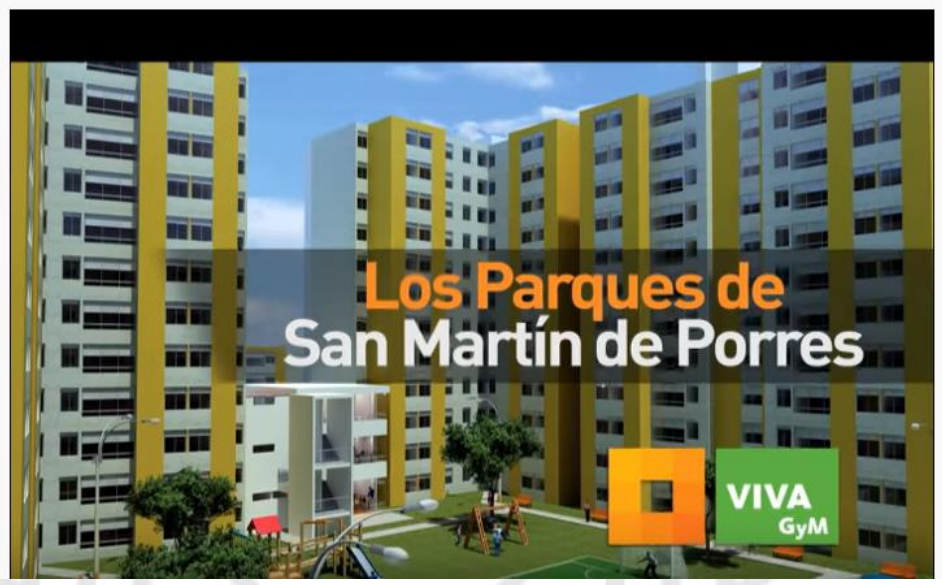

Figura 9. Video "Los Parques de San Martín de Porres” Fuente. Viva GyM

\subsection{Del público}

\subsubsection{Encuestas}

De las encuestas realizadas los hallazgos más relevantes son:

- Del total de nuestros encuestados, el 90\% está considerando adquirir una vivienda propia, por lo que estarían más propensos a buscar información o prestar atención a publicidad relacionada a la compra de inmuebles. 


\section{¿Estás considerando adquirir una vivienda propia?}

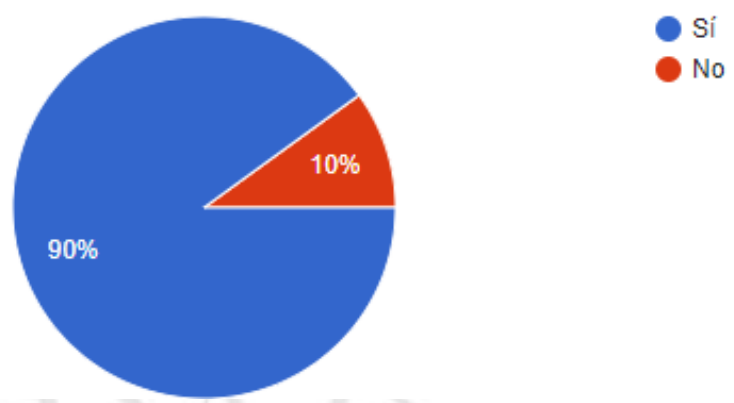

Figura 10. Gráfica interés de adquisición. Encuesta Villa de Atletas

Condominio. Fuente: Elaboración propia

- Otro de los hallazgos importantes fue, determinar por qué nuestro PO estaba dispuesto de adquirir una vivienda propia por los siguientes motivos destacados: comodidad para su familia y porque les interesaba tener algo propio brindarle a su futura familia. Por otro lado, unas de las respuestas interesantes es que pensaban adquirir una vivienda propia como una inversión a futuro.

- Al margen de los estudios de gabinete, como la publicación de Gestión, "los aspectos más determinantes al buscar un inmueble son el precio y la ubicación, seguidos por aspectos relacionados al costo de compra como los acabados y el metraje." (Gestión, 2014); en nuestra investigación de campo, podemos reafirmar que los factores precio y ubicación, son muy importantes al considerar adquirir una vivienda. Asimismo, los otros factores muy importantes hallados en nuestra investigación son: seguridad y ahorro.

¿Qué es lo que más valorarías al momento de adquirir una vivienda propia?

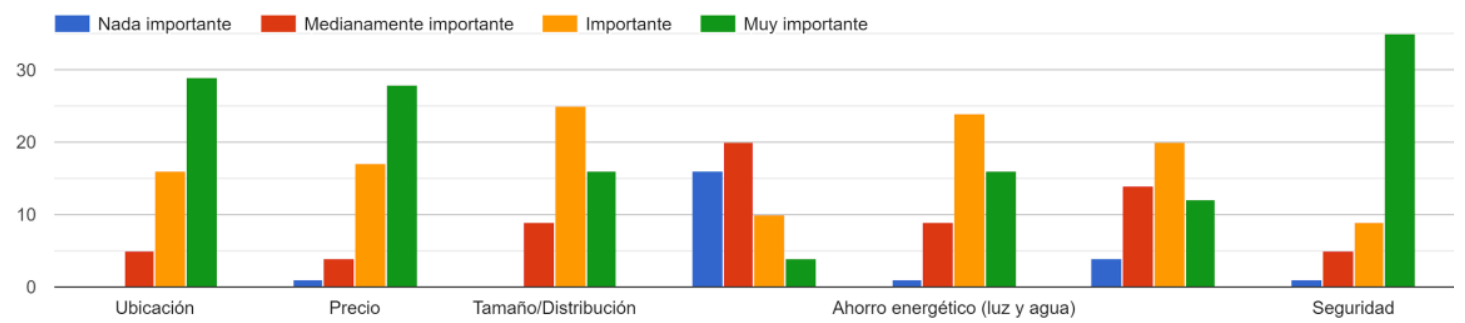

Figura 11. Gráfica de valoración. Encuesta Villa de Atletas

Condominio. Fuente: Elaboración propia 
- De acuerdo a la encuesta realizada, verificamos que un $20 \%$ del total de los encuestados prefiere vivir en San Juan de Lurigancho, por los siguientes factores: económico, distrito comercial y facilidad de moverse a otros distritos. Por otro lado, podemos destacar que nuestro PO prefiere distritos aspiracionales de Lima Moderna, como Surco, San Borja y Miraflores, porque los consideran céntricos, seguros, con áreas verdes y por la cercanía a Centros Comerciales. Es decir que nuestro PO asocia la seguridad, factor importante en el proceso de compra, a los distritos de Lima Moderna.

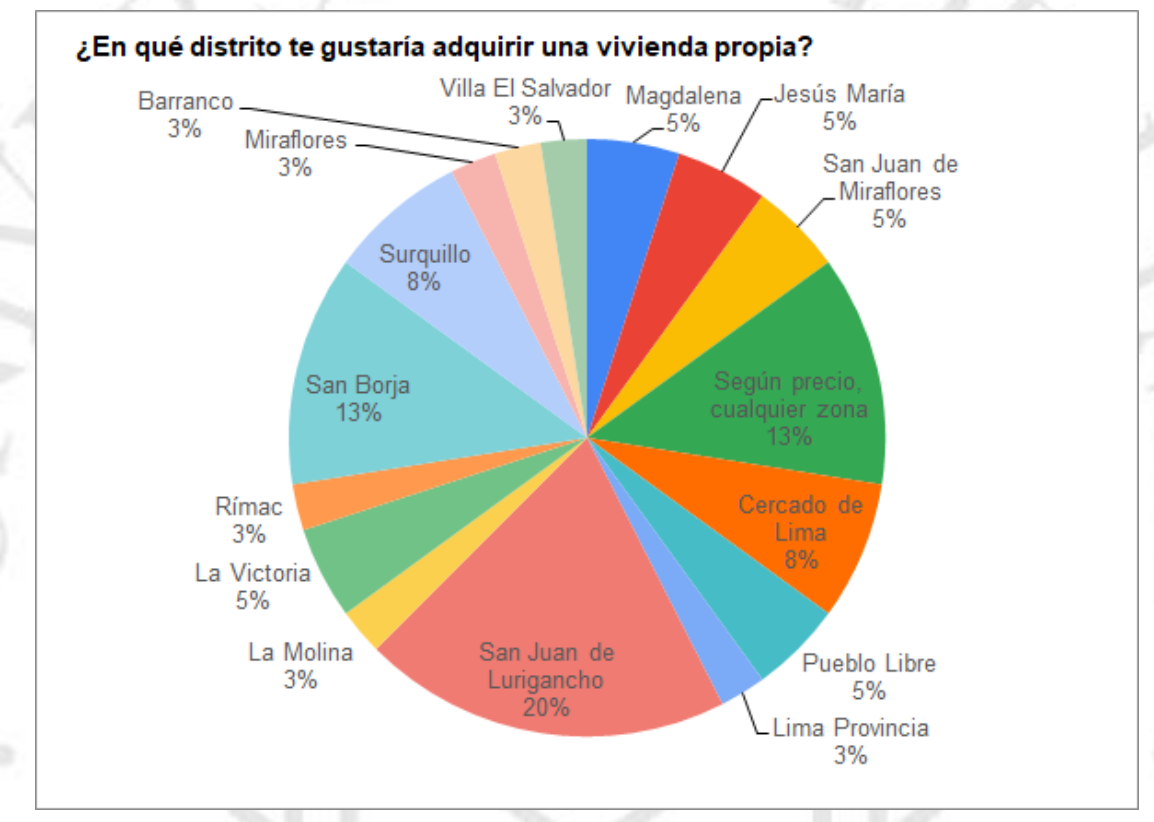

Figura 12. Gráfica preferencia de distritos para vivir. Encuesta Villa de Atletas Condominio. Fuente: Elaboración propia

- Con respecto al monto que estaría dispuesto a pagar nuestro PO, hallamos que el $32 \%$ podría pagar montos dentro del rango de S/ 120,000 y S/ 199,999. Esta información es importante, porque el precio mínimo de los departamentos en el Condominio Villa de Atletas es de S/ 186,000, que está dentro del rango aceptado por nuestro PO. 


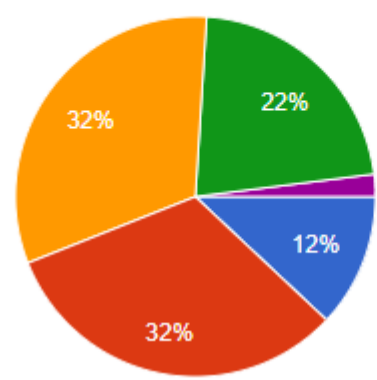

Entre S/ 40,000 y S/ 79,999

Entre $\mathrm{S} / 80,000$ y S/ 119,999

Entre S/ 120,000 y S/ 199,999

Entre $S / 200,000$ y S/ 399,999

De $\mathrm{S} / 400,000$ a más

Figura 13. Gráfica disposición de precios. Encuesta Villa de Atletas Condominio. Fuente: Elaboración propia

- Con respecto a los atributos que más asocia nuestro PO a un Condominio son: seguridad, familiar, ahorro y espacios de libre uso (espacios compartidos). Cruzando con los atributos principales a considerar para la compra de una vivienda, ahorro y seguridad, son los principales e importantes para considerar dentro de la estrategia de comunicación y marca. Asimismo, el atributo de seguridad está asociado a los distritos de Lima Moderna en los que aspiran vivir nuestro PO.

¿Qué atributos asocias a un Condominio?

50 respuestas

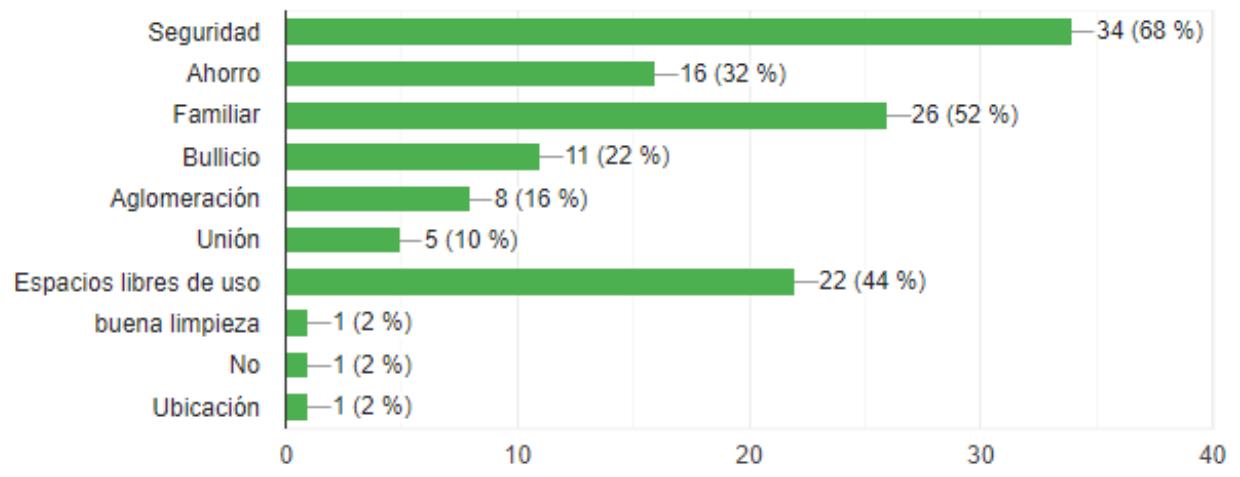

Figura 14. Gráfica atributos de Condominio. Encuesta Villa de Atletas Condominio. Fuente: Elaboración propia 


\subsection{Del Producto}

El Condominio Villa de Atletas fue desarrollado por el Consorcio Besco Besalco, se ubica en Av. El Sol y Avenida Mariano Pastor Sevilla.

De acuerdo a la revista Perú Construye, cuenta con 7 bloques correspondientes a 2 tipos de módulos: El Módulo A consta de 20 pisos y se aplica en los Bloques 1, 3, 5, y 7; mientras que el Módulo B tiene 19 pisos y se aplica en los Bloques 2, 4 y 6. (Revista Perú Construye, 2019).

Se cuenta con 4 departamentos de este tipo por nivel, situados en el centro del edificio y separados simétricamente tanto transversal como longitudinalmente. Las características de los departamentos ubicados, según el módulo al que pertenecen son:

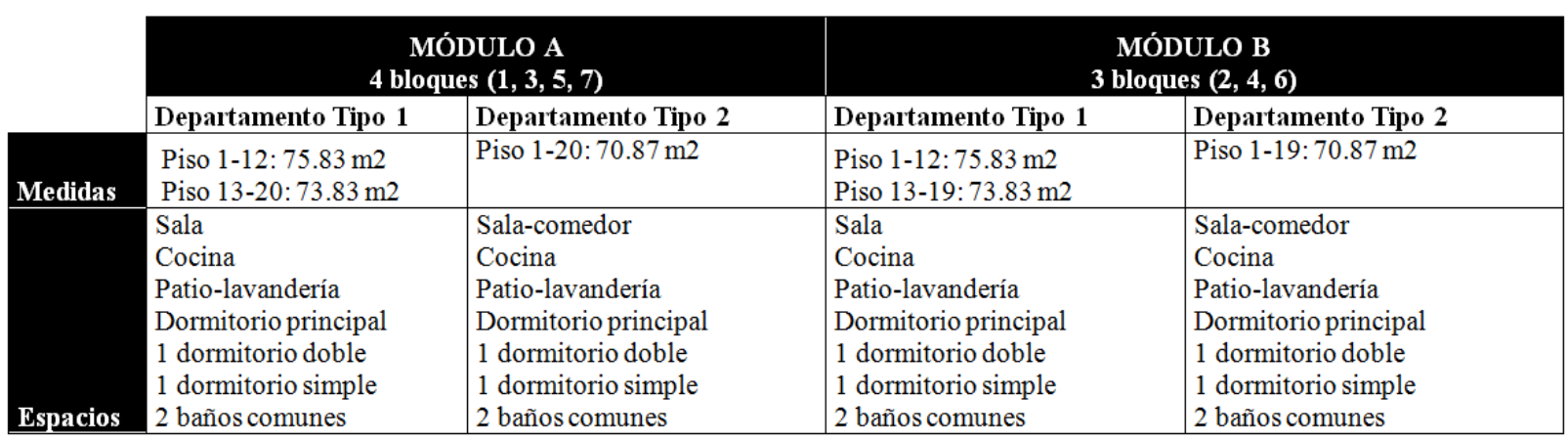

Tabla 3: Información de departamentos en Villa de Atletas.

Fuente: Revista Perú Construye

Con respecto a la infraestructura, la altura de entrepiso es de $2.41 \mathrm{~m}$, lo que permite tener mejor distribución de los espacios, buena iluminación, ventilación natural y vista hacia el exterior de los ambientes interiores.

Finalmente, son edificios ecosostenibles que permiten acceder el Grado 2 del Bono Mivivienda Verde, porque sus instalaciones poseen tecnología de bajo consumo de agua y energía, arquitectura, bioclimática y manejo de residuos sólidos. Además, posee un sistema de irrigación de las áreas verdes con aguas tratadas que provienen de los edificios. 
En los dos casos, los accesos peatonales se plantean perpendicularmente al eje longitudinal del edificio y mediante dos lobbies de ingreso que conducen al área común del primer piso. La altura de entrepisos considerada para los departamentos es de $2.30 \mathrm{~m}$, con una losa de $10 \mathrm{~cm}+1 \mathrm{~cm}$ de acabado $(11 \mathrm{~cm}$ en total), teniendo como altura de piso a piso $2.41 \mathrm{~m}$

\subsection{FODA}

\subsubsection{Fortalezas}

F1: Propuesta consolidada y con ventaja competitiva, priorizando seguridad, ahorro y adecuado para una familia.

F2: Producto que fue clave en los Juegos Panamericanos Lima 2019, pues albergó a las delegaciones de los países extranjeros participantes en el evento.

F3: Apoyo exclusivo por parte del Ministerio de Vivienda, Construcción y Saneamiento, para la venta de los departamentos por medio del Nuevo Crédito Mivivienda.

F4: Las torres son ecosostenibles, es decir, cumplen con la Certificación Bono Verde y contribuyen con el cuidado del medio ambiente y los recursos naturales. F5: El Condominio promueve la inclusividad, pues tiene instalaciones para personas con discapacidad.

\subsubsection{Oportunidades}

O1: Aceptación positiva por parte de la población hacia los Juegos Panamericanos Lima 2019

O2: Disposición de nuestro PO por obtener una vivienda propia en los próximos 2 años.

O3: El PO atribuye características positivas al tipo de vivienda Condominios, como seguridad, ahorro y familiar; características que son importantes en la consideración de compra de una vivienda propia.

\subsubsection{Debilidades}

D1: Precios de los departamentos del Condominio considerados como muy altos, incluso por encima del mercado. 
D2: Baja asociación del nombre Condominio Villa de Atletas con los Juegos Panamericanos Lima 2019.

D3: Ubicación considerada como lejana para algunas personas, lo que disminuye la intención de compra.

\subsubsection{Amenaza}

A1: Mucha competencia en el mercado y fuertemente posicionada.

A2: Ha habido una desaceleración en los últimos meses debido a la inseguridad de los clientes al momento de tomar la decisión de compra.

A3: Pensamiento de que Villa El Salvador es un lugar no seguro y alejado.

A4: Varios medios de comunicación, mencionan que los precios de los departamentos dentro del Condominio son muy altos.

A5: La oferta limitada de departamentos, lo cual no cubre la demanda disponible en el mercado limeño. 


\section{CAPÍTULO 4: PROYECTO}

\subsection{Posicionamiento de Villa de Atletas Condominio}

Condominio familiar que brinda seguridad, modernidad y ahorro por medio de la sostenibilidad de sus instalaciones. Brindamos espacios compartidos para que puedan disfrutar junto a los campeones, que, como ellos, dejaron huella al conseguir sus sueños.

\section{2 $\underline{\text { Promesa }}$}

Buscamos que las personas puedan acceder al sueño de la casa propia, brindándoles la oportunidad de disfrutar de su primer gran logro, gracias a los espacios modernos, seguros y sostenibles, que permiten la maximización del ahorro. Esto como recompensa a su esfuerzo continuo, así como nuestros deportistas, que tienen una historia de lucha detrás de cada huella lograda.

\subsection{Soporte (Reason Why)}

Nuestro condominio genera un entorno de comunidad por medio de los espacios y la distribución de los mismos, que, a su vez, desarrolla una sensación de familiaridad y calidez. Asimismo, las áreas compartidas, la seguridad y ahorro por instalaciones ecosostenibles, aportan al entorno antes mencionado. Se resumen en:

\section{Espacios compartidos:}

Los espacios compartidos que posee el condominio Villa de Atletas son: 3 salas multiusos, 1 sala de juego para jóvenes, 1 sala de juego para niños, 2 tiendas, zona de parrillas y 371 estacionamientos.

Asimismo, los espacios que promueven el desarrollo del deporte, como gimnasios al aire libre, 2 losas deportivas multiusos y una ciclovía de $1 \mathrm{~km}$. de extensión alrededor de todo el conjunto. 


\section{Seguridad:}

Por el lado de la seguridad, el edificio consta de 4 controles de vigilancia.

\section{Sostenibilidad:}

Las instalaciones poseen tecnología de bajo consumo de agua y energía, arquitectura bioclimática, manejo de residuos sólidos y sistema de irrigación de las áreas verdes con aguas tratadas que provienen de los edificios. Esto permite la maximización del ahorro de energía y agua de manera mensual; así como acceder al Bono Verde en $2^{\circ}$ grado.

\section{4 $\underline{\text { Valores }}$}

Nuestros valores son los siguientes:

- Familia: La unión familiar es promovida por medio de los espacios compartidos dentro del condominio.

- Tranquilidad: La tranquilidad se logra porque los integrantes de nuestra comunidad pueden crecer en un entorno amigable, seguro y con total libertad.

- Sostenibilidad: Nuestras instalaciones poseen sistemas innovadores que permiten ahorrar a las familias entre un $30 \%$ o $40 \%$ en el uso de energía y agua.

- Comunidad: Nuestra diversidad de espacios compartidos permiten la integración entre familias permitiendo formar lazos dentro de la comunidad.

- Esfuerzo: Valoramos la perseverancia y la superación de cada integrante que forma parte de nuestra comunidad, quienes dejan huellas al conseguir sus metas.

$\mathrm{Al}$ adaptar dichas características a nuestra personalidad nos encontramos con una marca que promueve la integración de la familia con la comunidad, priorizando su tranquilidad y seguridad en espacios sostenibles, que gracias al esfuerzo constante lograron conseguir su primer sueño, el de la casa propia. 


\subsection{Tono de comunicación}

Nos comunicaremos con nuestro público objetivo por medio de mensajes que serán motivadores, cercanos, emotivos y enérgicos, ya que ello representa el espíritu de perseverancia. Nos permitirá hacer un símil con el tono alentador que reciben los deportistas para conseguir más logros, y con ello inspirar y conseguir una identificación con nuestro target, quienes también van en búsqueda de sus sueños, como el de un departamento propio. 


\section{CAPÍTULO 5: IMAGEN DE MARCA}

\section{$5.1 \underline{\log O}$}

\subsubsection{Concepto}

Nuestro logo está basado en nuestros valores de marca: familia, esfuerzo, seguridad y sostenibilidad. La familia está representada por un semi gráfico de una casa, que es el principal representante del hogar (familia) y a su vez representa la comunidad. El esfuerzo está representado por las letras "VA" (Villa de Atletas), que, a su vez, forman el cuerpo del atleta, el cual es símbolo de la perseverancia que presenta también nuestro público objetivo. La seguridad, está representada porque los símbolos (el techo, las iniciales VA y cuerpo de Atleta) se complementan y da la sensación de que todo está encerrado visualmente y, de alguna manera, protegido por el techo de la casa.

Finalmente, la sostenibilidad se representa con el color verde, además de la energía y dinamismo que aporta. Según el trabajo de investigación "MARKETING DEL COLOR: ¿Cómo influyen el color del logotipo en la personalidad de una marca?", el color verde se asocia a naturaleza, seguridad y conexión con el aire libre. (Segura, 2016) Por ello, la naturaleza se asocia con la sostenibilidad, es decir el ahorro de recursos naturales.

En este sentido:

- Casa $=$ Familia $=$ Comunidad

- Encierro de elementos $=$ Seguridad

- Atleta = Esfuerzo

- Color verde $=$ Sostenibilidad

\subsubsection{Proceso}

Para la obtención del logo final, se trabajó por etapas:

\section{- Etapa 1:}


En esta primera etapa se planteó utilizar parte de la simbología utilizada para Lima 2019, representada por los lazos, estructuras piramidales para la cabeza de los deportistas y la Flor de Amancaes muy presente en todo el evento, haciendo algunas variaciones de estas.

En este sentido, para aprovechar la buena aceptación de nuestro público objetivo al evento Lima 2019, se buscó representar las iniciales VA de Villa de Atletas, empleando la V como un deportista levantando los brazos y la A con la silueta de la Flor de Amancaes representando una medalla, ambos elementos conformados por una suerte de lazos, similares a los que se emplearon para Lima 2019.

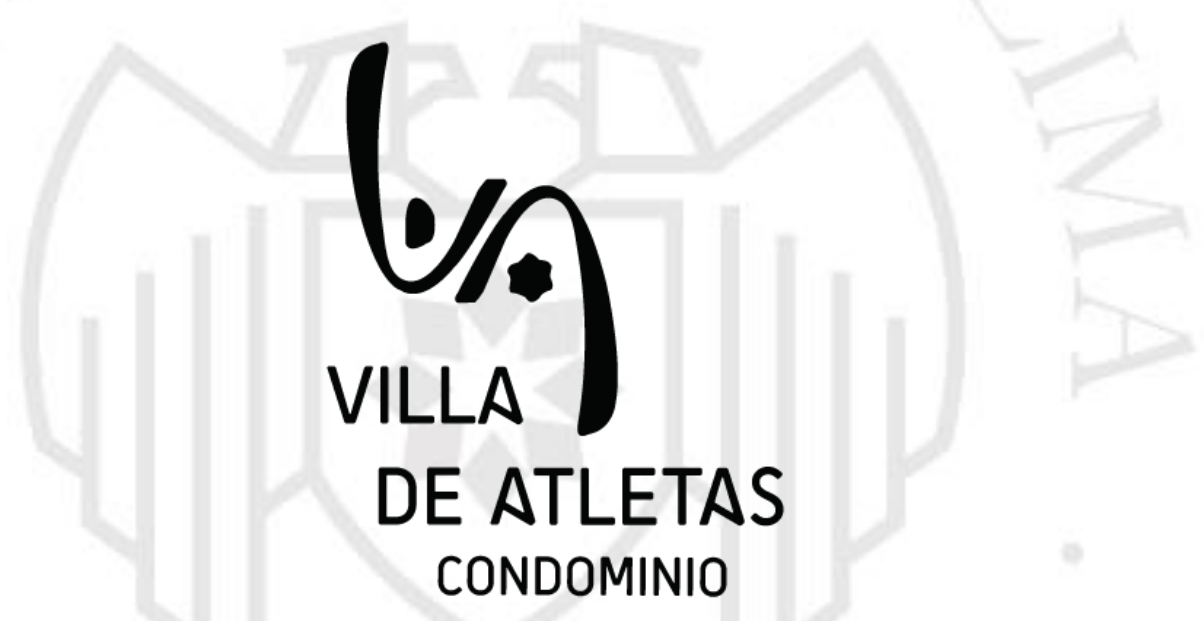

Ilustración 1. Propuesta de Logotipo 1. Fuente: Elaboración Propia

\section{- Etapa 2:}

En esta segunda etapa, se decidió unificar los elementos, sin perder la representación de las iniciales VA, pero esta vez, haciendo una variación formando el cuerpo del atleta. Se tomó como referencia el pictograma empleada por Lima 2019, en donde el Atletismo se asemejaba más a una "A" y a su vez, se complementaba con el nombre de la Villa. 


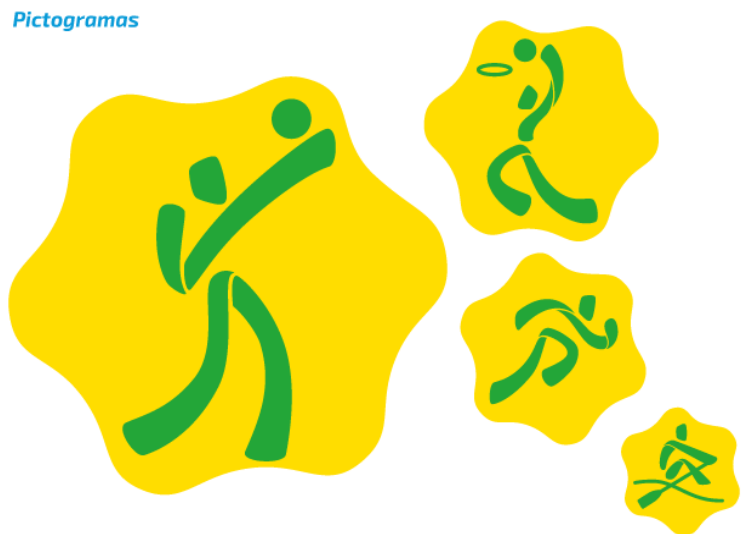

Figura 15. Pictogramas Lima 2019. Fuente: Lima 2019

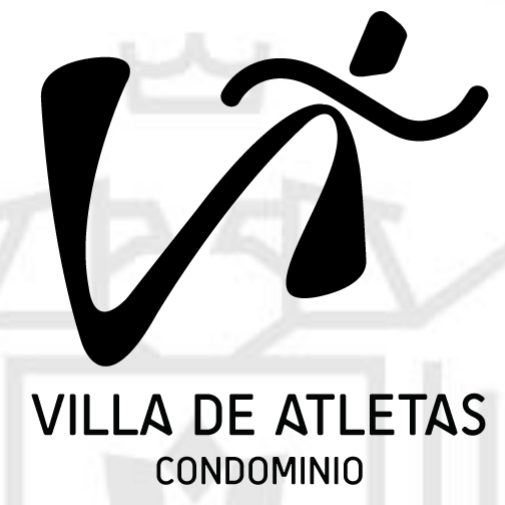

Ilustración 2. Propuesta de Logotipo 2. Fuente: Elaboración Propia

\section{- Etapa 3: Resultado final}

En la última etapa, se decidió conservar el isotipo construido en la segunda etapa, pero se agregó un cierre en la parte superior del atleta. Este elemento se asemeja al techo de una casa, el objetivo es transmitir seguridad, familia y comunidad. Además, dicho elemento se relaciona directamente con nuestro producto, los departamentos del Condominio Villa de Atletas. 


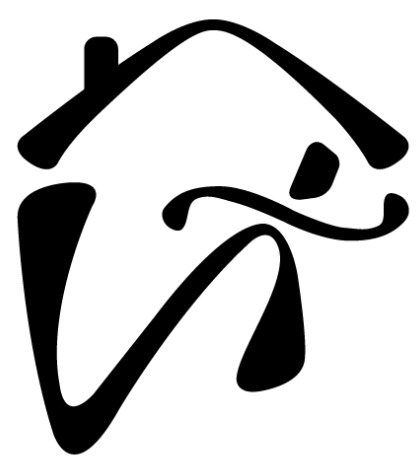

\section{VILLA DE ATLETAS \\ CONDOMINIO}

Ilustración 3. Propuesta de Logotipo 3. Fuente: Elaboración Propia

\subsubsection{Tipografía}

La tipografía no es serif, ya que busca dar un balance entre los elementos del isotipo, que tienen una leve inclinación, y el nombre. Las tipografías Palo seco mantiene el mismo grosor en toda su extensión y esto le hace transmitir fuerza y dinamismo. Son tipografías modernas por lo que están estrechamente ligadas con la actualidad. Estas tipografías son las más fáciles de leer. (LN Creatividad y Tecnología Blog, s.f.)

En este sentido, empleamos la fuente SCIFLY por las líneas curvilíneas y diagonales, y con ello, el dinamismo que se genera gracias a la limpieza y la estilización de la misma.

Esta esencia dinámica se relaciona con el concepto deportivo y la legibilidad que queremos transmitir hacia el público objetivo, llegando de manera amigable.

\subsubsection{Color}

De acuerdo con un artículo publicado por Merca 2.0, Leatrice Eiseman plantea que la elección de cierto colorido determina la capacidad de ofrecer un mensaje y el efecto que logra en las emociones de audiencias y consumidores. (Merca $2.0,2019)$

En este sentido, siguiendo la psicología del color, para la elección del color se planteó el uso de dos colores principales que van acorde a la personalidad de la 
marca y los significados que queremos proyectar en base a nuestros valores: el verde y el naranja:

- Verde: Empezando por el verde, el cual denota en la sostenibilidad que representan los departamentos al hacer un ahorro en la energía y agua, lo cual conlleva a una preocupación por el medio ambiente y la naturaleza. Además, es un color versátil que puede ser utilizado de manera enérgica y brinda una sensación agradable y acogedora, que genera esperanza y armonía.

- Naranja: Representa la energía y atrae la atención. Es un color que denota la felicidad, el éxito y determinación. Puede llegar a ser hasta divertido y ello se complementa con el dinamismo del carácter deportivo.

\subsection{Manual de identidad}

Los lineamientos de identidad a seguir para el desarrollo de las diferentes piezas de comunicación se basan en: logotipo y sus aplicaciones, colores, tipografía y aplicaciones en mockups, que apoyarán en el branding de la marca.

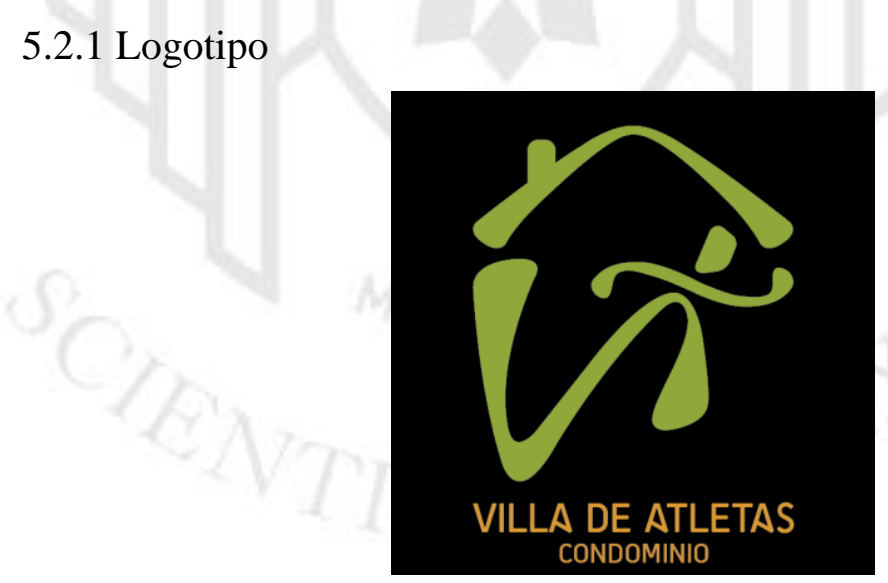

Ilustración 4. Logotipo. Fuente: Elaboración Propia

\subsubsection{Versiones Positivo / Negativo}

Estas versiones serán usadas en soportes en los cuáles el contraste de los colores corporativos se pierda con el fondo.

- Versión en verde y blanco 

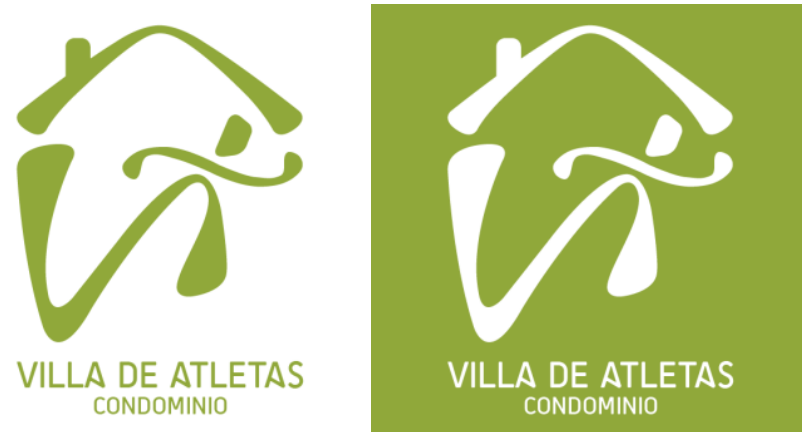

Ilustración 4. Logotipo Versión en verde y blanco.

Fuente: Elaboración Propia

- Versión en blanco y negro

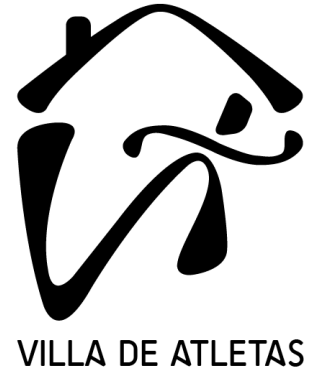

CONDOMINIO

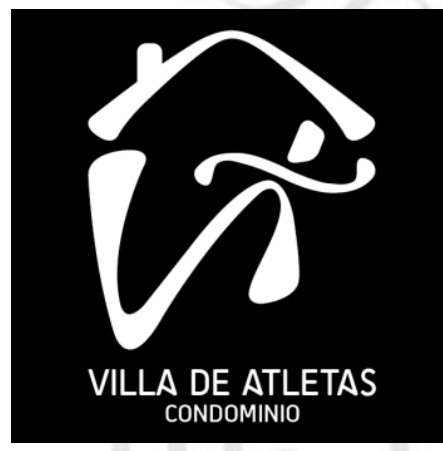

Ilustración 5. Logotipo Versión Negativo.

Fuente: Elaboración Propia

\subsubsection{Escalabilidad}

La presentación y uso correcto de nuestro logo debe realizarse de acuerdo a la versión, ya sea digital o impresa.

- En la versión impresa la medida mínima será de 24.7 mm x 33.237 $\mathrm{mm}$, sin necesidad de hacer uso del descriptor (Condominio)

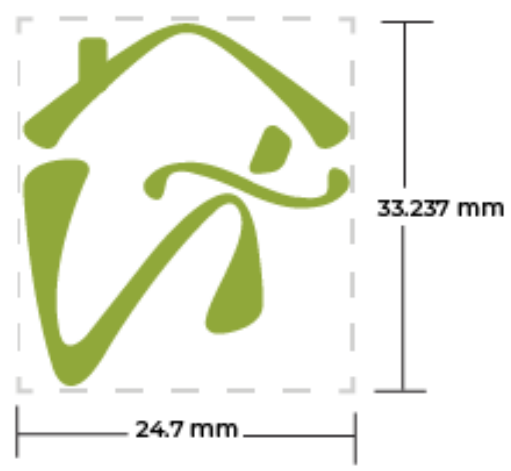

Ilustración 6. Logotipo Escalabilidad. Versión Impresa.

Fuente: Elaboración Propia 
- En la versión digital será como mínimo 90 px x 121.327 px.

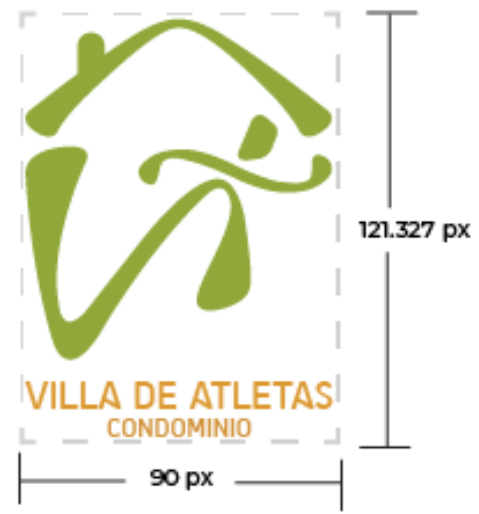

Ilustración 7. Logotipo Escalabilidad. Versión Digital.

Fuente: Elaboración Propia

5.2.4 Área de seguridad del logotipo

Para la correcta reproducción del logotipo y no perder la percepción de la identidad visual, se ha definido la siguiente área de seguridad usando la cabeza del atleta:

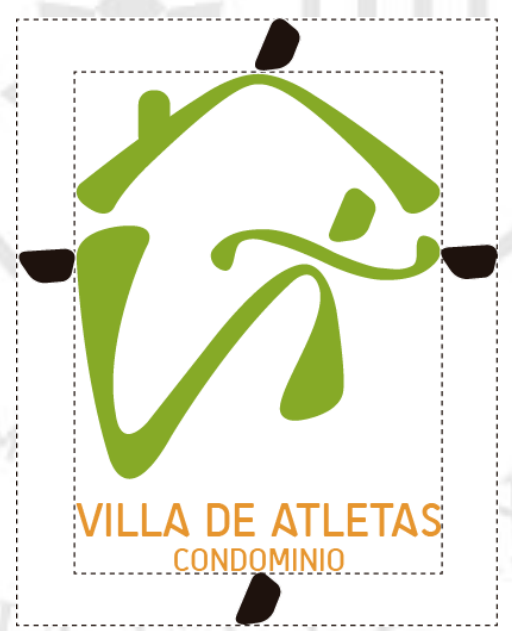

Ilustración 8. Área de seguridad del logotipo. Fuente: Elaboración Propia

\subsubsection{Uso incorrecto del logotipo}

Es importante conocer cuáles son los usos inadecuados de nuestro logotipo, como alargando, ensanchando o cambiando los colores del mismo. 

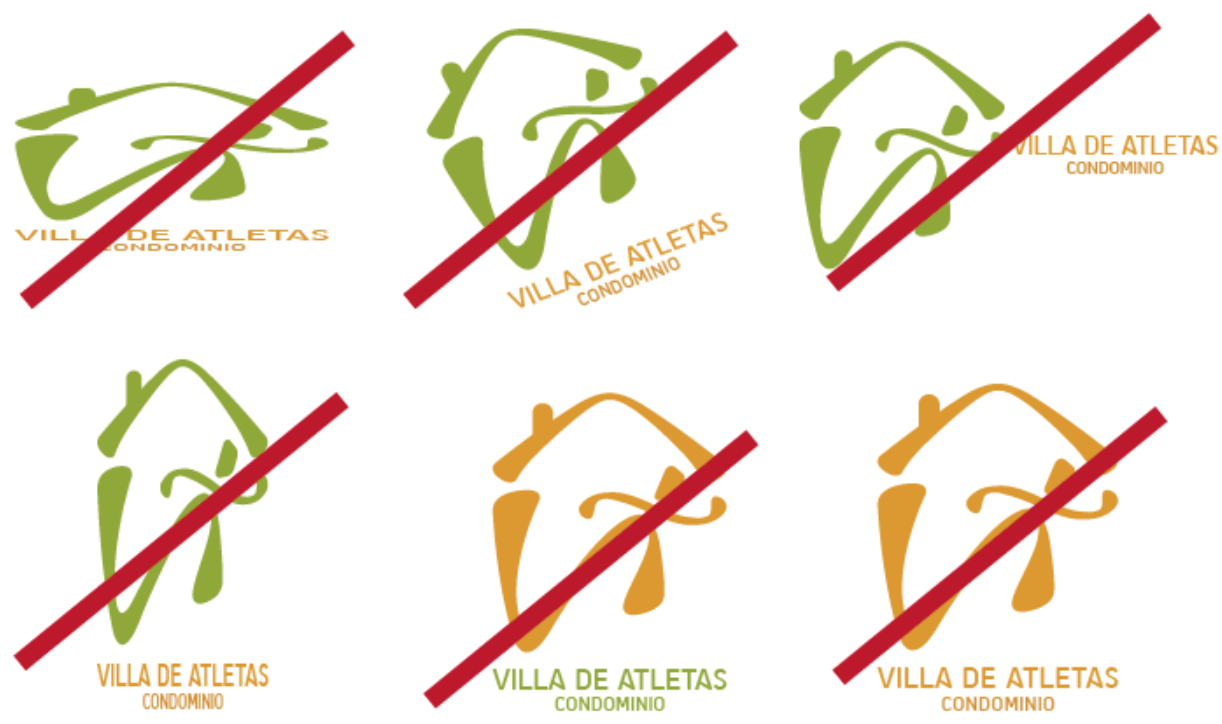

Ilustración 9. Uso incorrecto del logotipo. Fuente: Elaboración Propia

\subsubsection{Colores}

Nuestra paleta de colores para el uso dentro de las piezas de comunicación y branding son los siguientes:

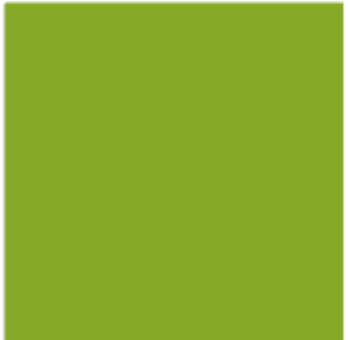

Pantone: $10325 \mathrm{C}$

RGB: 144, 168, 58

CMYK: 157, 15, 97, 0

HEX: 90A83A

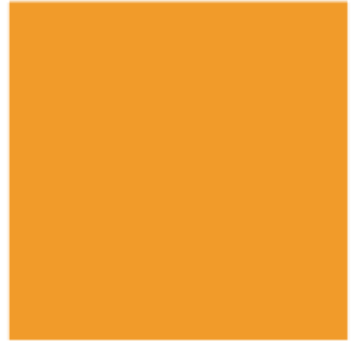

Pantone: 15-1050

TCX

RGB: 220, 153, 56

CMYK: 0, 49, 90, 0

HEX: DC9938

Ilustración 10. Colores. Fuente: Elaboración Propia

\subsubsection{Tipografía}

\section{- Tipografía Principal}

Nuestra tipografía principal será Scifly, para poder resaltar contenido de alto impacto, como títulos y subtítulos, dentro de las piezas de 
comunicación. Cabe resaltar que el uso de la misma será exclusivamente en altas.

\section{SciFly}

\section{A B C D E F G H I JKL M NO \\ $P Q R S T U V W X Y Z$}

Figura 16. Detalle de tipografía Scifly

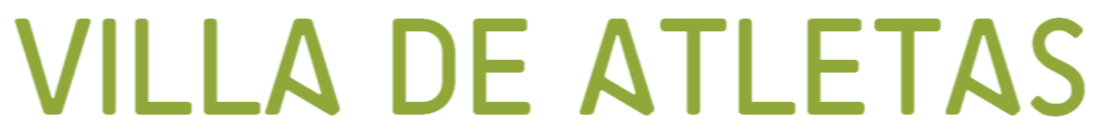

\section{- Tipografía Secundaria:}

Nuestra tipografía secundaria será Monserrat. Tendrá un uso adicional en los materiales de publicidad que requieran textos largos o adicionales a los titulares, como CTA, precios, botones, entre otros elementos que sirvan para inducir a la compra a nuestro público objetivo. Se usará la tipografía en altas y bajas, en sus versiones: regular, medium y semibold

\section{Monserrat}




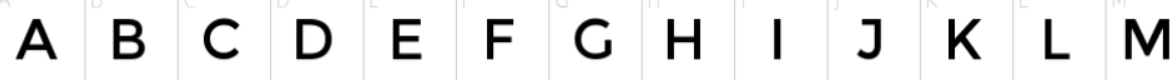
$\begin{array}{llllllllllllll}N & O & P & Q & R & S & T & U & V & W & X & Y & Z\end{array}$

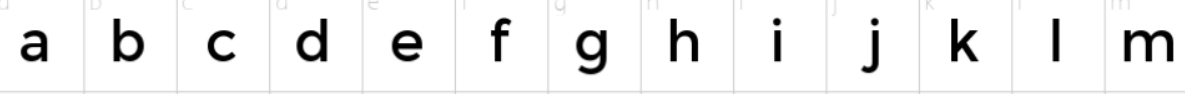

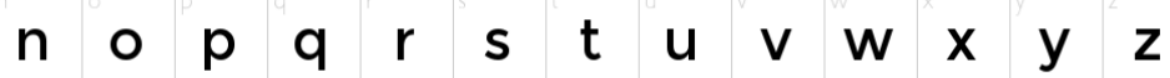
$\begin{array}{llllllllll}0 & 1 & 2 & 3 & 4 & 5 & 6 & 7 & 8 & 9\end{array}$

Figura 17. Detalle de tipografía Monserrat

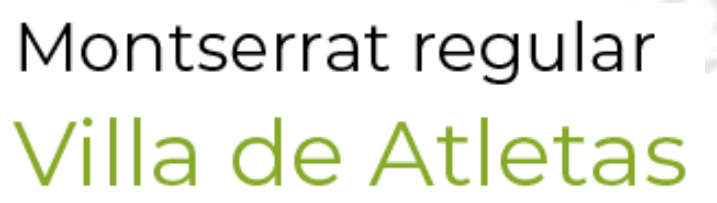

Montserrat medium

Villa de Atletas

Montserrat semibold Villa de Atletas

\subsubsection{Aplicaciones}

Para el branding de la marca se decidió realizar las siguientes piezas:

- Polos
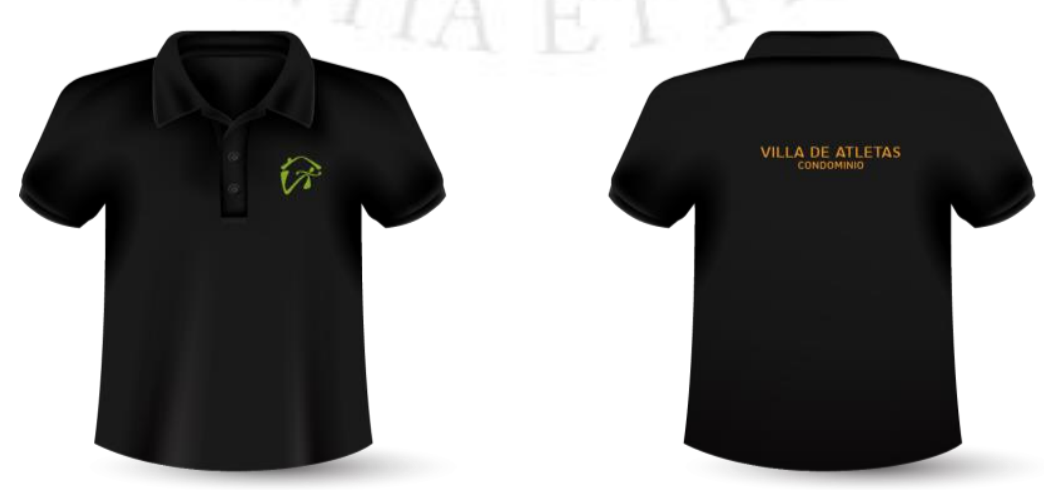

Ilustración 10. Aplicación en polos. Fuente: Elaboración Propia 
- Llaveros

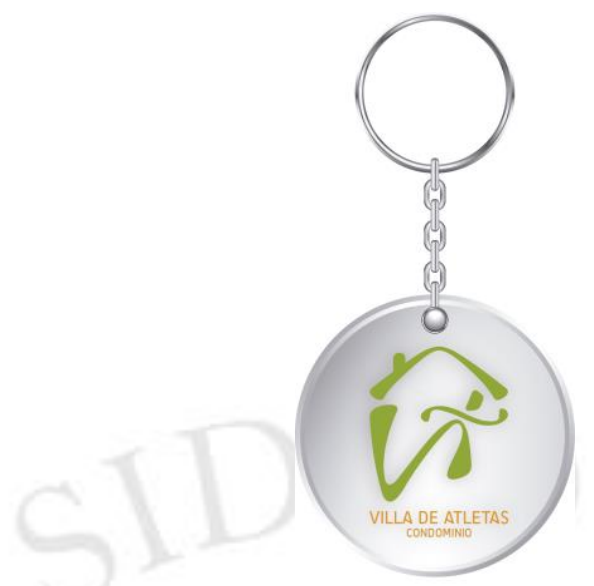

Ilustración 11. Aplicación en llaveros. Fuente: Elaboración Propia

\section{- Caramelos}

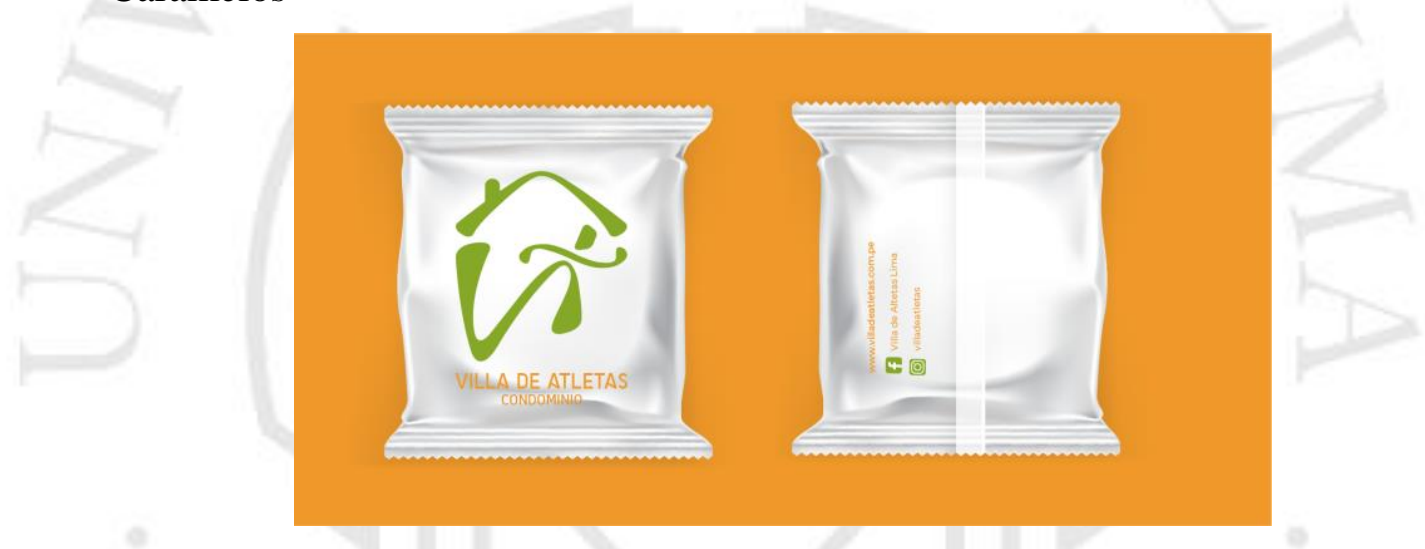

Ilustración 12. Aplicación de logotipo en caramelo. Fuente: Elaboración Propia

- Papelería 


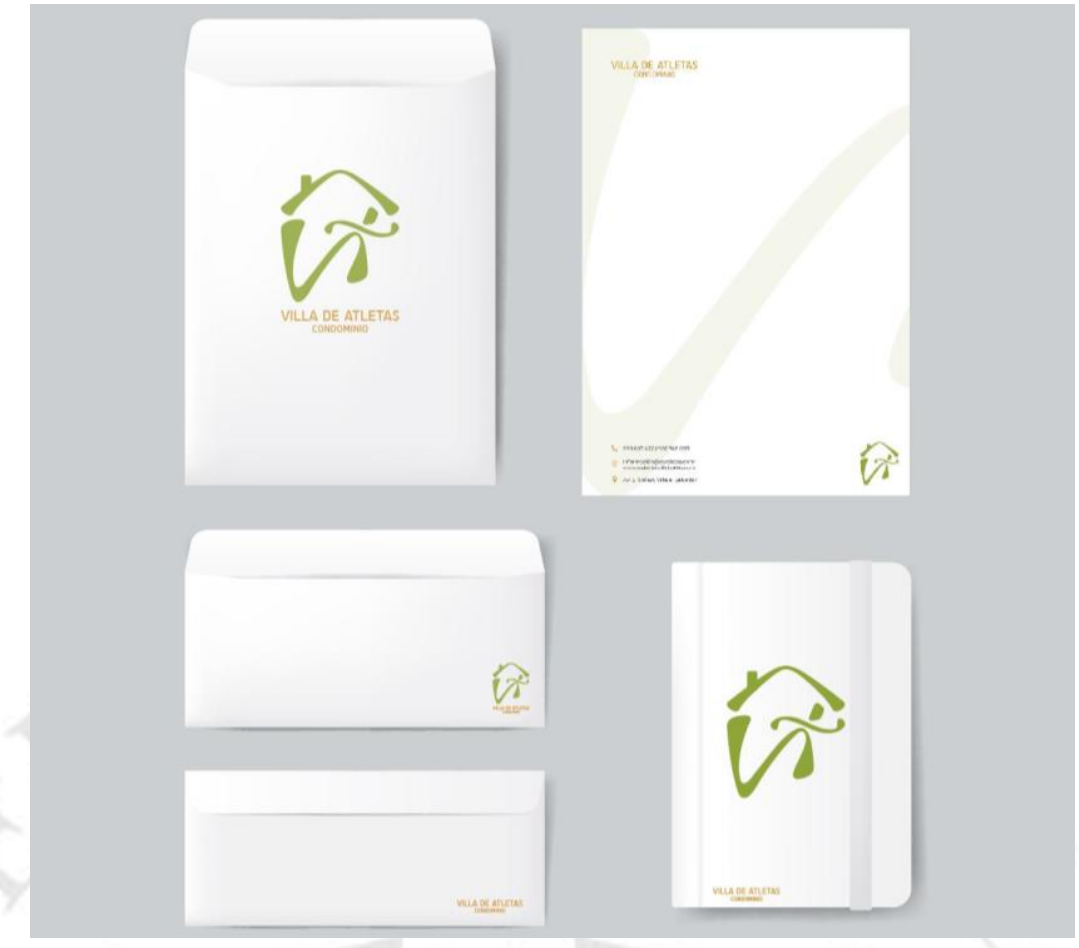

Ilustración 13. Aplicación de logotipo papelería. Fuente: Elaboración Propia

- Bolsas ecoamigables

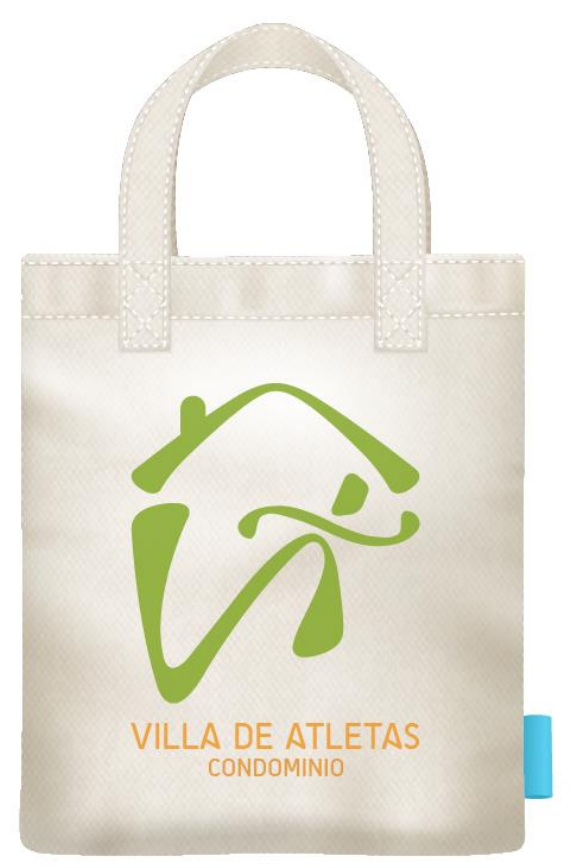

Ilustración 14. Aplicación de logotipo en bolsa ecoamigable. Fuente:

Elaboración Propia 
- Tarjetas de presentación

Tira versión negra:

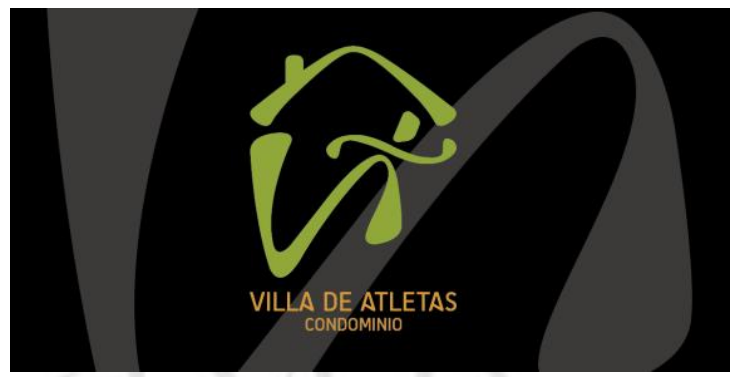

Retira versión negra:

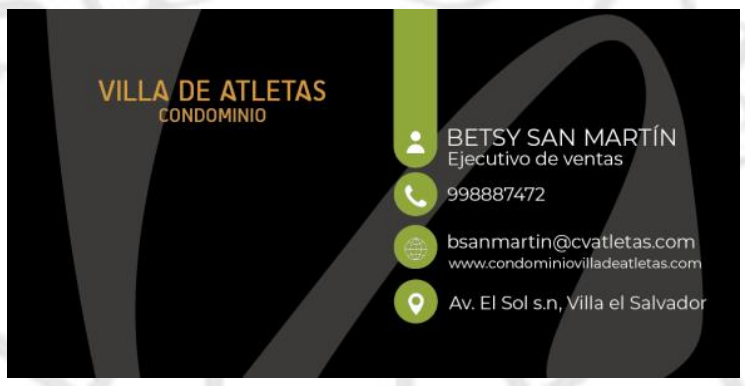

Ilustración 15. Tarjetas de presentación. Versión negra. Fuente: Elaboración

\section{Propia}

Tira versión blanca:

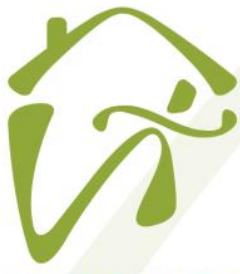

VILLA DE ATLETAS

CONDOMINIO

Retira versión blanca:

\section{VILLA DE ATLETAS} CONDOMINIO

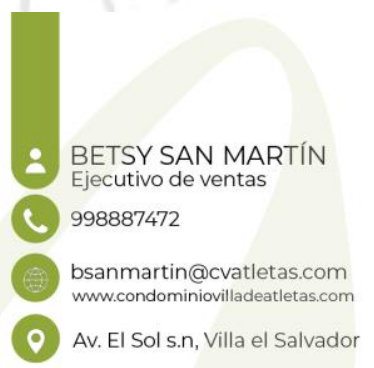

Ilustración 16. Tarjetas de presentación. Versión blanca. Fuente: Elaboración Propia 


\section{CAPÍTULO 6: ESTRATEGIA DE COMUNICACIÓN}

\subsection{Objetivos}

\subsubsection{Objetivo de Marketing}

Generar conocimiento de marca en nuestro público objetivo, con la finalidad de dar soporte al área comercial para lograr la venta del 100\% de los departamentos en el lapso de 6 meses.

\subsubsection{Objetivos de comunicación}

- Generar awareness sobre el Condominio Villa de Aletas en nuestro público objetivo, asociados a nuestros valores de marca.

- Posicionarnos en el top of mind de nuestro público objetivo, para ser su primera opción en el proceso de compra de una vivienda propia.

- Generar conocimiento por medio de nuestra estrategia de comunicación las modalidades de financiamiento a través del programa Mivivienda y Bono Verde.

\subsection{Estrategia}

\subsubsection{Concepto}

\section{"Persigue la huella de un sueño"}

La estrategia de comunicación para la venta de departamentos del Condominio Villa de Atletas estará alineada a los valores de marca, en los que se reflejan la familia, sostenibilidad, tranquilidad, comunidad y esfuerzo. Llegaremos al target con un concepto que genere identificación con los deportistas, quienes están en la constante búsqueda de sus sueños, cómo conseguir una medalla de oro, haciendo el símil con nuestro público objetivo, quienes se esfuerzan por perseguir el sueño de la casa propia y obtener una. Ambos dejan una gran huella al lograr su objetivo o sueño. 


\subsubsection{Idea Ejecucional}

\section{"Logra tu primera huella"}

Para poder aterrizar este concepto realizaremos un símil entre el esfuerzo que realizan los deportistas y nuestro público objetivo para lograr sus sueños, a pesar de las adversidades que se presentan en el proceso.

Asimismo, el objetivo logrado irá de la mano con el estilo de vida de cada uno de nuestros personajes en su día a día, usando una comunicación motivadora, cercana, emotiva y enérgica, pues nos alinearemos a nuestro tono de comunicación, que representa el espíritu de perseverancia.

\subsubsection{Eslogan}

\section{Persigue lo que sueñas, ¡Villa de Atletas te espera!}

Nuestro eslogan de campaña se basa en el concepto de perseguir y esforzarse hasta lograr el gran sueño, en este caso el departamento (casa propia) en Villa de Atletas Condominio. Creemos que nuestros valores: tranquilidad, familia, sostenibilidad, esfuerzo y comunidad; brindarán la confianza a nuestro público objetivo para poder plantearse nuevos sueños y lograrlos.

\subsection{Plan de comunicación o estrategia de medios}

\subsubsection{Etapas de la campaña}

Nuestra estrategia de medios está compuesta por 3 etapas:

- Pre Lanzamiento

- Lanzamiento

- $\quad$ Mantenimiento.

Comenzaremos la campaña el 15 de noviembre del 2019 hasta el 31 de marzo de 2020, haciendo un total de 20 semanas de campaña. 


\begin{tabular}{|l|l|l|l|}
\hline Etapa & Pre Lanzamiento & Lanzamiento & Mantenimiento \\
\hline Rango de Fechas & $\begin{array}{l}\text { 15 de Noviembre - } \\
\text { 30 de Diciembre } \\
\text { del } 2019\end{array}$ & $\begin{array}{l}\text { 01 de Enero - 28 de } \\
\text { Febrero del 2020 }\end{array}$ & $\begin{array}{l}\text { 01 de Marzo - } \\
31 \text { de Marzo del } \\
2020\end{array}$ \\
\hline Objetivo & $\begin{array}{l}\text { Generar awareness } \\
\text { o reconocimiento } \\
\text { de marca para ir } \\
\text { posicionándola } \\
\text { dentro del mercado } \\
\text { inmobiliario. }\end{array}$ & $\begin{array}{l}\text { Impulsar la } \\
\text { consideración y } \\
\text { conversión por } \\
\text { medio de la venta } \\
\text { masiva de } \\
\text { departamentos. }\end{array}$ & $\begin{array}{l}\text { Mantener el } \\
\text { reconocimiento de } \\
\text { marca en nuestro } \\
\text { público objetivo y } \\
\text { seguir generando } \\
\text { conversiones. }\end{array}$ \\
\hline Descripción & $\begin{array}{l}\text { Se realizará una } \\
\text { campaña 360 para } \\
\text { generar } \\
\text { reconocimiento de } \\
\text { marca y obtener } \\
\text { leads. }\end{array}$ & $\begin{array}{l}\text { Se impulsará la } \\
\text { venta de los } \\
\text { departamentos por } \\
\text { medio de una } \\
\text { campaña } 360^{\circ} .\end{array}$ & $\begin{array}{l}\text { Mantener el } \\
\text { conocimiento de la } \\
\text { marca por medio de } \\
\text { una estrategia } \\
\text { digital. }\end{array}$ \\
\hline Medios & $\begin{array}{l}\text { OoOH } \\
-\quad \begin{array}{l}\text { Prensa } \\
\text { digitales }\end{array}\end{array}$ & $\begin{array}{l}\text { OOH } \\
\text { Prensa } \\
\text { Publicidad } \\
\text { en Cines } \\
\text { Medios } \\
\text { digitales }\end{array}$ & $\begin{array}{l}\text { Medios } \\
\text { digitales }\end{array}$ \\
\hline
\end{tabular}

Tabla 4: Plan de comunicación. Fuente: Elaboración propia

\section{- Etapa de pre-lanzamiento}

El objetivo de esta etapa es generar reconocimiento de marca y awareness, para obtener el posicionamiento de marca. Nuestra campaña tendrá en un inicio (1 mes y 2 semanas) una etapa $360^{\circ}$, que incluirá 1 anuncio en Prensa, 4 paneles publicitarios en principales avenidas por las cuales hay mayor tránsito de nuestro público objetivo, 8 unidades de vallas ubicadas en las estaciones del Tren Línea 1 de Lima, a lo largo de los distritos de Surco, San Juan de Miraflores, Villa María del Triunfo y Villa el Salvador.

Esta etapa se realizará en las siguientes fechas desde el 15 de noviembre hasta el 31 de diciembre del 2019. 
Decidimos implementar una etapa de pre lanzamiento para ir posicionando a nuestra marca en la mente de nuestro público objetivo y reconocimiento del mismo, ello, con la finalidad de promover la venta de los departamentos en la etapa de lanzamiento.

\section{- Etapa de Lanzamiento}

Esta etapa tiene como objetivo impulsar la venta masiva de departamentos, por lo que decidimos mantener los medios antes implementados, además de incrementar la pauta para Facebook e Instagram con el objetivo de obtener leads y tráfico hacia la web. Así mismo, se trabajará en la producción de un spot comercial que será publicado en Facebook y YouTube. Para lograr el alcance masivo lo transmitiremos en las pantallas de Cineplanet, ubicados estratégicamente de acuerdo a la concurrencia de nuestro público objetivo.

En esta línea, trabajaremos con campañas por email-marketing y en una campaña de Google AdWords que generen tráfico a la web y con ello, obtener más conversiones.

Decidimos trabajar esta etapa desde el primero de enero hasta el 28 de febrero del 2020.

\section{- Etapa de Mantenimiento}

El objetivo de esta etapa es mantener el reconocimiento de marca e impulsar la venta de los departamentos restantes, por medio de una estrategia netamente digital. Por ello usaremos Facebook e Instagram como principales canales para llegar a nuestro público objetivo. Asimismo, usaremos email-marketing para poder incentivar la compra de los departamentos a nuestra base de datos obtenida en las etapas anteriores. El mensaje de esta etapa será con sentido de urgencia, comunicando que son pocos los departamentos en venta.

Decidimos trabajar esta etapa del 01 al 31 de marzo del 2020. 


\subsubsection{Ecosistema de Medios}

Nuestro ecosistema de Medios está compuesto por medios ATL y Digital. A continuación, los detallamos:

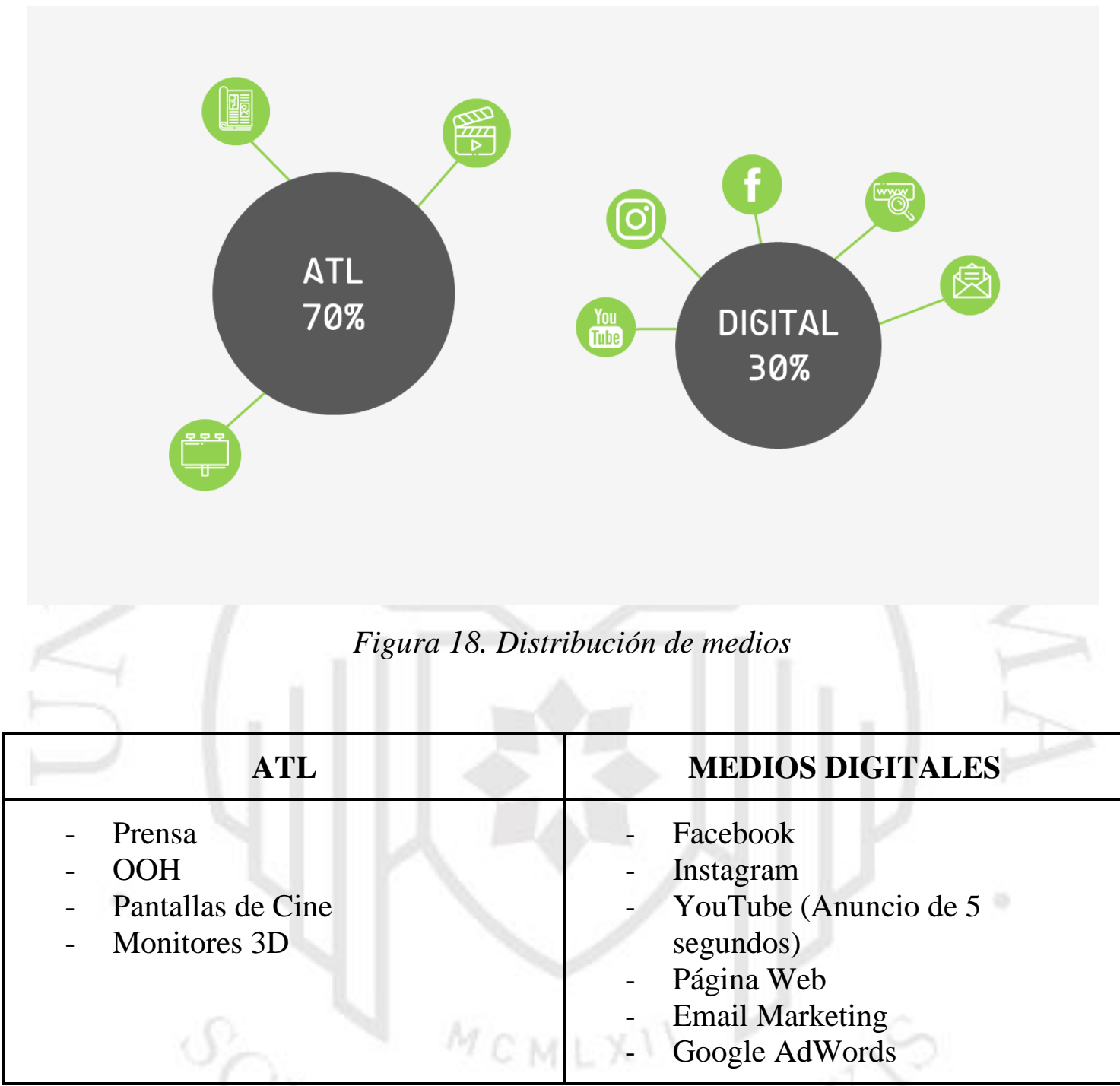

- ATL

○ Prensa

- Tendremos dos anuncios de página entera en el diario Trome, que serán publicados el martes 26 de noviembre de 2019 (etapa de pre-lanzamiento) y el martes 14 de enero de 2020 (etapa de lanzamiento). El objetivo de usar este medio es llegar de manera masiva a nuestro público objetivo, pues según el informe "CONSUMO DE MEDIOS 2018-Consumo de 
medios de comunicación digitales y tradicionales" realizado por IPSOS, este es el diario más leído. (IPSOS, 2018)

Asimismo, en el informe de Ecomedia, indican que el $48 \%$ de lectores del Trome pertenecen al NSE C. (Ecomedia, 2016).

Elegiremos Trome zonales, pues solo abordaremos publicidad en la zona sur de Lima: Barranco, SJM, VES, VMT, Pachacamac y Chorrillos. Elegimos esta modalidad de publicidad que ofrece el Trome, porque es en la zona sur dónde se encuentra la mayor cantidad de nuestro público objetivo.

\section{$\circ \mathrm{OOH}$}

En general, tenemos como objetivo impactar visualmente a nuestro público de manera rápida, sencilla y creativa; transmitiendo nuestro concepto y con ello ir formando una imagen de nuestra marca en nuestro público objetivo y promover las ventas de los departamentos, de acuerdo a la etapa en la que nos encontremos.

\section{Vallas Metro de Lima}

Tendremos una serie de vallas en el Metro de Lima a lo largo de 8 estaciones, desde Jorge Chávez hasta la última, en Villa el Salvador.

Escogimos este tipo de publicidad ya que tiene una afluencia mensual promedio de $14 \mathrm{MM}$ de personas, en donde predomina el NSE C con un $65 \%$ de pasajeros que usan este medio de transporte como el principal y lo hacen para movilizarse a su centro de trabajo.

\section{Leds}

Tendremos 4 Leds ubicados estratégicamente de acuerdo a la movilización hacia los centros de trabajo de nuestro público objetivo, como San Isidro (Centro financiero) y La Victoria (Zona Centro). Según el informe "Como vamos en movilidad" de Lima cómo vamos, el 14,5\% menciona que se dirige al centro de la ciudad por temas de trabajo o estudios, y el 4,7\% de 
los limeños se dirige a San Isidro (Lima Cómo Vamos - Observatorio ciudadano, 2015). La ventaja de ellos es que se encuentran en vías de alto tránsito y/o cruces de avenidas con semáforos, lo que proporciona buena exposición.

De acuerdo a una nota de prensa publicada por el diario Gestión, menciona que el número de personal ocupado que laboran en el emporio de comercial de Gamarra pasó de 7171,484 trabajadores en 2016 a 80,183 en 2017, mostrando un incremento de 12.2\%. (Gestión, 2019)

En este sentido, colocaremos los leds en 3 distritos:

- La Victoria: 1 Led

- San Juan de Miraflores: 1 Led

- San Borja: 2 Leds

Visualizar la distribución en el Anexo Nro. 4

\section{Pantallas de Cine}

Decidimos colocar nuestro spot en pantallas de Cineplanet, ya que es un tipo de publicidad en la que tenemos una oportunidad grande de retener la atención de nuestro público objetivo de manera efectiva. Por ello, abordaremos el $70 \%$ de las salas, dentro de 4 sedes de Cineplanet en base a la movilización que tienen gracias al Metro de Lima y uno adicional:

- Cineplanet Mall del Sur

- Cineplanet La Rambla - San Borja

- Cineplanet Primavera

- Cineplanet Centro Cívico

A pesar de que gran parte de nuestro público objetivo dedica semanalmente varias horas a la TV abierta nacional, consideramos como otra opción oportuna y rentable a las pantallas de cine por 3 razones:

a. Segmentación: 
Tenemos poder de decisión para poder colocar nuestro spot publicitario en las salas de cine a las que nuestro PO acude. Se eligieron las salas de cine que se encuentran dentro del rango de movilidad por medio de la Línea 1 del tren y por la cercanía a su lugar de residencia.

b. Atención

De acuerdo a los estudios previamente mencionados, el nivel de atención y captación de mensajes publicitarios en el cine es superior al de la TV, en donde se presenta un $34 \%$ vs. un $30 \%$ respectivamente. Cabe mencionar que las pantallas de cine son una gran oportunidad para una comunicación efectiva pues los distractores son mucho menores, además de la imposibilidad de hacer "zapping" o saltarse el anuncio.

Asimismo, existe una oportunidad muy grande para llegar a nuestro público objetivo debido al incremento y frecuencia en la que asisten por ser una forma de entretenimiento más.

c. Presupuesto

Realizamos una comparación entre el presupuesto mensual que significa tener una inversión en TV, en el canal 4 (América TV), debido a que es el canal líder en señal abierta, versus, la inversión en las pantallas de cine.

\begin{tabular}{|c|c|c|c|c|}
\hline \multicolumn{4}{|c|}{ COMPARATIVO PUBLICIDAD TV VS PANTALLAS DE CINE } \\
\hline & Costo semanal & Costo mensual & Mensual con IGV & $\begin{array}{c}\text { Atención } \\
\text { captada }\end{array}$ \\
\hline 4 Salas de cine & S/4,820 & S/115,680 & S/136,501 & $34 \%$ \\
\hline $\begin{array}{c}\text { TV: } 4 \\
\text { programas* }\end{array}$ & S/61,154.25 & S/819,466.95 & S/966,971 & $30 \%$ \\
\hline
\end{tabular}

*Conversión realizada al tipo de cambio: S/ 3.35

Tabla 5: Comparativo costos de publicidad en Tv y Pantallas de cine.

Fuente: Elaboración propia. 
En este sentido, podemos afirmar que la publicidad en pantallas de cine es un medio más rentable, además del nivel de captación que se consigue con ella es mayor y en un público más segmentado.

\section{Monitores 3D en Cines:}

Consideramos que es una buena oportunidad tener publicidad de gran impacto con monitores 3D de 52 pulgadas ubicados en el lobby principal de los cines, para mostrar parte de la infraestructura de los departamentos. Se encontrarán en los siguientes cines para dar una mayor exposición a nuestra campaña:

- Cineplanet Alcázar

- Cineplanet San Miguel

- Cineplanet Primavera

- Cineplanet La Molina

- Cineplanet San Borja

- Cineplanet Salaverry

- Cineplanet Mall del Sur

- Cineplanet Centro Cívico

- MEDIOS DIGITALES

\section{Facebook}

Según el informe de "CONSUMO DE MEDIOS 2018-Consumo de medios de comunicación digitales y tradicionales" realizado por IPSOS, del NSE C, uno de los medios digitales más consumidos es Facebook, por ello usaremos diferentes tipos de formatos de publicidad para esta plataforma, que irán variando a lo largo de la campaña publicitaria. Las imágenes a usar tendrán temáticas inspiracionales, promocionales e informativas. (IPSOS, 2018)

\section{- Anuncio con imagen en Facebook}

- CPM: Este tipo de formato será usado durante la etapa de Pre Lanzamiento, desde el 15 de noviembre hasta el 15 de diciembre 
del 2019, pues queremos posicionar nuestra marca por medio del awareness, para ello necesitaremos llegar a la mayor cantidad de personas. El CPM se traduce como el costo por cada 1,000 impresiones. Se entiende las impresiones como la cantidad de veces que se aparece la publicidad

- CPC: Este tipo de formato será usado durante la etapa de Pre Lanzamiento, desde el 16 al 31 de diciembre del 2019. Asimismo, en la etapa de Mantenimiento, desde el 01 al 31 de marzo. El objetivo es generar tráfico a nuestra página web para que nuestro público pueda obtener toda la información acerca de los Condominios.

- PPL: Este tipo de formato será usado en la etapa de Lanzamiento, desde el 01 de enero hasta el 28 de febrero de 2020, pues nuestro objetivo principal será conseguir leads, por medio de la landing page de formulario que tendremos en nuestra página web. Estos leads serán usados para una estrategia de email-marketing.

\section{- Anuncio con Video en Facebook}

Se usará el PPV en Facebook para nuestro spot publicitario, pues solo será considerado el costo por cada vista del video. El objetivo de este video será generar awareness de la marca.

Nuestro Spot durará 25 segundos y tendrá una temática de "piece of life", mostraremos a dos pantallas un comparativo entre la rutina de un deportista y una persona trabajadora, ambos esforzándose para lograr su más grande sueño personal. Al final del spot, será una sola pantalla que muestre a los personajes al frente de la Villa de Atletas, luego de lograr su objetivo.

Este spot comercial se usará durante la etapa de lanzamiento, para tener la cobertura $360^{\circ}$ de lanzamiento de campaña, en las fechas del 01 al 31 de enero del 2020. 


\section{- Carrusel en Facebook}

Se usará este tipo de formato para mostrar los espacios de los departamentos por medio de imágenes referenciales. Esto permitirá que nuestro público objetivo desee conocer más de los mismos. Asimismo, tendrá un call to action para derivarlo a nuestra página web.

\section{Instagram}

De acuerdo con el más reciente reporte "Estado de Social Media" de la consultora ComScore, Instagram es la aplicación social favorita de las marcas en Latinoamérica. En particular, Instagram es otra forma que pueden utilizar las marcas para hacer branding y atraer clientes a sus páginas o tiendas y de acuerdo a un informe de IPSOS, el NSE C es uno de los segmentos que más utiliza la red con un 34\%. (Entrepreneur en español, 2018)

Asimismo, elegimos esta plataforma debido a que es visualmente más atractiva que las demás, y le atribuimos los roles de "inspiración" y “atracción” e "información", en paralelo con el objetivo de generar leads.

En este sentido, usaremos diferentes tipos de formatos de publicidad para esta plataforma, que irán variando a lo largo de la campaña publicitaria:

\section{- Anuncios en Stories}

Emplearemos este formato debido a que ofrece muchas posibilidades de interacción: re-dirección a otras plataformas (tráfico), visita al feed, etc. Asimismo, cabe resaltar que este tipo de formato tiene un impacto bastante visual y sencillo.

En una primera etapa buscamos generar awareness por lo que planteamos usar anuncios en stories del concepto de nuestra marca, de las instalaciones, y con ello, reforzar el branding. 
En las dos etapas siguientes lo que buscamos es generar conversión, por lo que los stories derivarán en tráfico a la web y formularios para generar leads.

\section{- Anuncios con video}

Emplearemos el formato con video para generar el dinamismo en el feed y ello derivará en la web con la finalidad de atraer tráfico o la obtención de leads. En este caso, este tipo de formato será utilizado desde la etapa de lanzamiento, aprovechando nuestro spot y recorridos de las instalaciones de los departamentos.

\section{Anuncios por secuencia}

Emplearemos este formato para complementar los anuncios con varias fotos y las personas interactúen deslizando una tras otra. Es una oportunidad para mostrar más los diferentes ambientes de los departamentos y/o espacios compartidos. La finalidad es obtener leads a través del formulario integrado que nos ofrece la plataforma.

\section{YouTube}

Según la data presentada en el perfil de nuestro público objetivo, YouTube es el segundo canal digital más usado. Se usará el formato de "Anuncios de video que se pueden omitir" para nuestro spot publicitario en YouTube. El objetivo de usar este formato será mostrar nuestro spot comercial completo, pero nuestro público objetivo tendrá la opción de saltarse el video, pues tampoco queremos imponer nuestra publicidad. Este spot comercial será el mismo que usamos para Facebook y las Pantallas en el cine. Se usará durante la etapa de lanzamiento, para tener la cobertura $360^{\circ}$ de lanzamiento de campaña, en las fechas del 01 al 31 de enero del 2020.

\section{Página Web}

Uno de nuestros objetivos es generar conversiones, es decir, la separación o compra de los departamentos. Tener un portal web nos permite ser un nexo entre las redes sociales empleadas y la brindarle más información a 
nuestro público objetivo de manera dinámica, apuntando a una experiencia del usuario novedosa y enganchadora.

Para ello implementaremos un recorrido virtual de los diferentes espacios de los departamentos con la finalidad de que nuestros posibles clientes interactúen y tengan una idea de cómo sería el hogar de sus sueños.

Asimismo, se planteará una estrategia de Google AdWords:

- Google Ads: Una manera efectiva de generar tráfico hacia nuestra web es utilizando esta herramienta para lograr un posicionamiento en primera posición y ganar más oportunidades de compra.

\section{Email marketing}

Este canal será usado en la etapa de lanzamiento, en las fechas 6 y 18 de febrero. Asimismo, en la etapa de mantenimiento en las fechas 02 y 17 de marzo; en ambas etapas el objetivo será brindar información promocional de los departamentos por medio de un botón que derivará a la página web. Tendrá un sentido de urgencia en la comunicación, para generar la necesidad de compra en nuestro público objetivo.

\subsubsection{Piezas publicitarias}

\subsubsection{Etapa de Pre - Lanzamiento}

\subsection{ATL}

- $\underline{\mathrm{OOH}}$

\section{- Vallas en el Metro de Lima}

Se colocarán un total de 8 vallas en diferentes estaciones, desde Jorge Chávez hasta Villa el Salvador con un motivo durante esta etapa. 


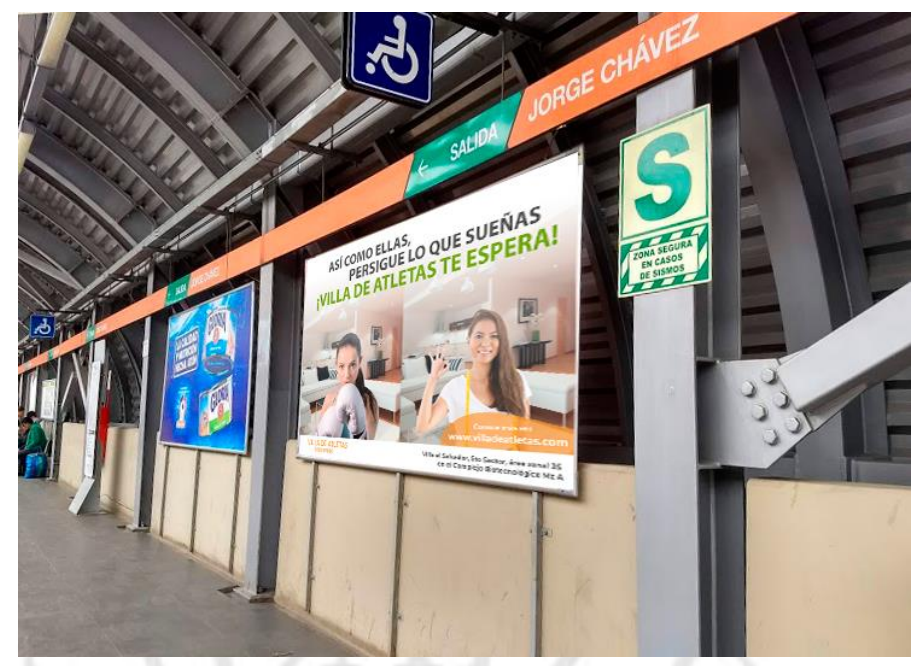

Ilustración 17. Vallas en Metro de Lima. Etapa pre lanzamiento Fuente: Elaboración Propia

\section{- Leds}

Se colocarán un total de 4 leds en los distritos de San Juan de Miraflores, San Borja y La Victoria (Gamarra) con un primer motivo durante esta etapa.

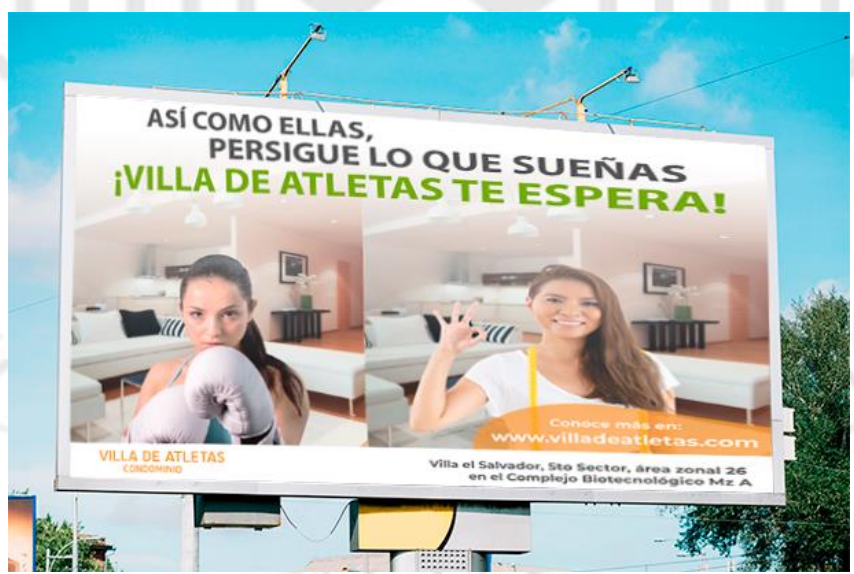

Ilustración 18. Leds. Etapa pre lanzamiento

Fuente: Elaboración Propia

\section{- $\quad \underline{\text { Prensa }}$}

Tendremos publicidad en el diario el Trome durante un día en el mes de noviembre, segmentado a la zona Sur de Lima, con la 
finalidad generar únicamente tráfico a la web a manera de información.
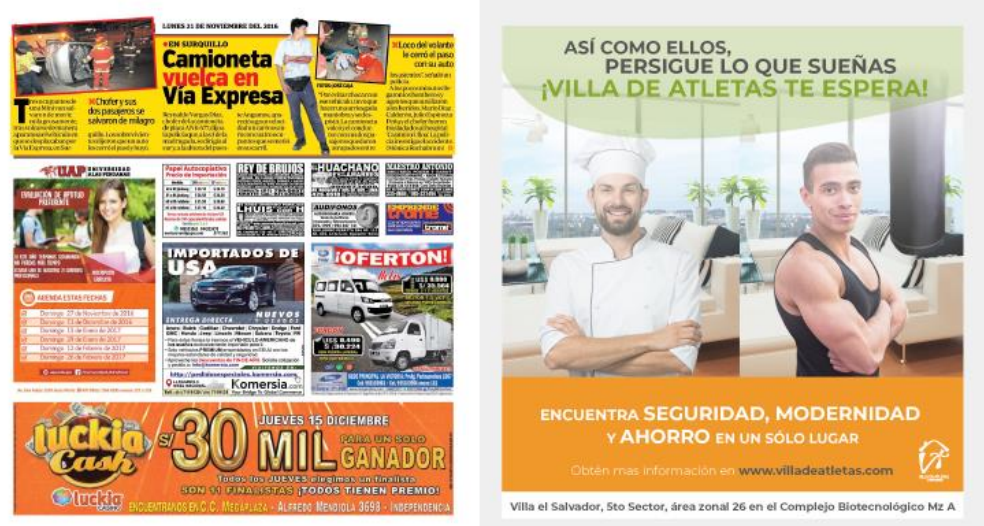

lustración 19. Anuncio en el Trome. Etapa pre lanzamiento

Fuente: Elaboración Propia

\subsection{Medios Digitales}

\section{- Facebook}

Emplearemos formatos CPC, con mensajes inspiradores que

llamen la atención y a su vez, genere tráfico hacia nuestra web.

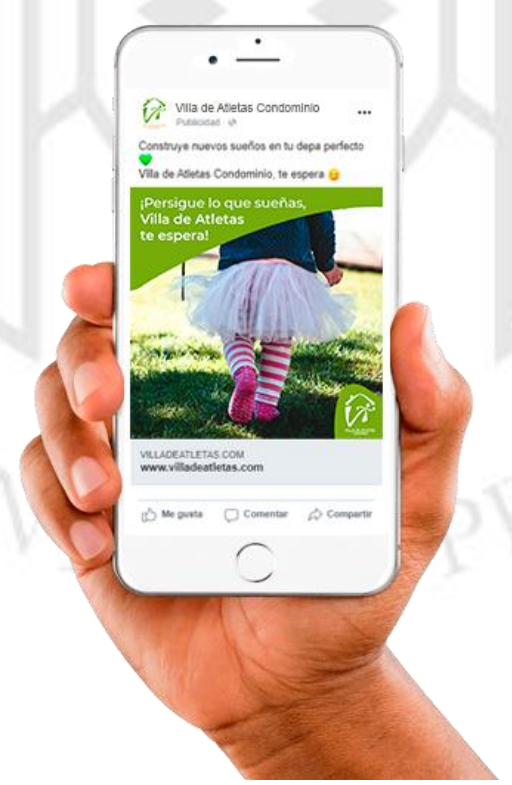

Ilustración 20. Post en Facebook. Etapa pre lanzamiento

Fuente: Elaboración Propia 


\section{- Instagram}

Usaremos Instastories en una primera etapa para generar awareness con mensajes relacionados a nuestro concepto de marca y reforzar el branding, además de conseguir visitas a nuestro portal web.

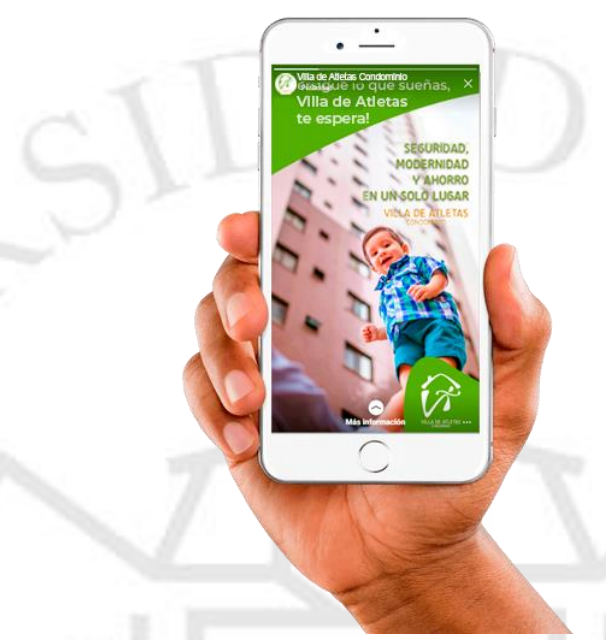

Ilustración 21. Instastorie. Etapa pre lanzamiento

Fuente: Elaboración Propia

- Página Web:

En el pre lanzamiento la publicidad en redes derivará a la web para dar mayor información sobre los departamentos e ir generando conocimiento. A continuación, el home principal de nuestro portal: 


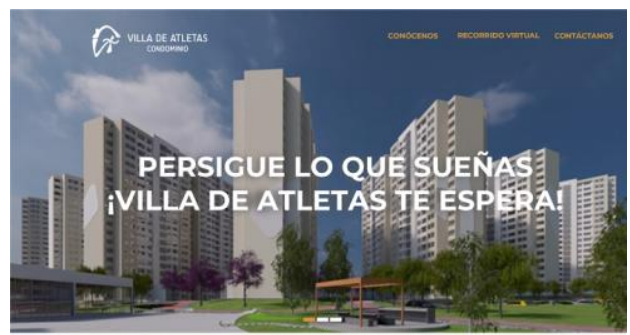

Seguridad, modemidad y ahorro

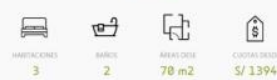
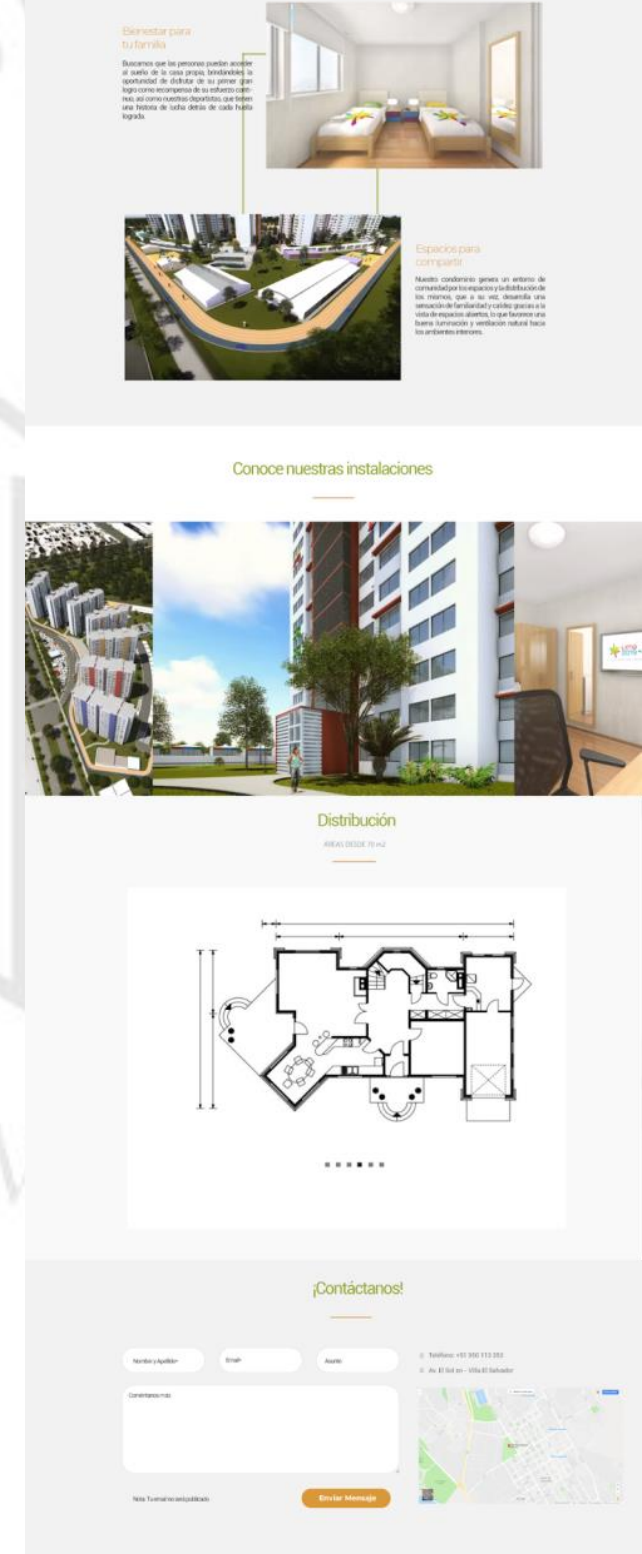

Ilustración 22. Portal web Villa de Atletas. Etapa pre lanzamiento Fuente: Elaboración Propia 


\subsubsection{Etapa de Lanzamiento}

\subsection{ATL}

\section{- $\quad \underline{\text { Prensa }}$}

El martes 14 de enero se publicará un anuncio en el diario El Trome zonal con un nuevo motivo, esta vez, promoviendo la venta de los departamentos a través de las cuotas referenciales, manteniendo el concepto de la marca.
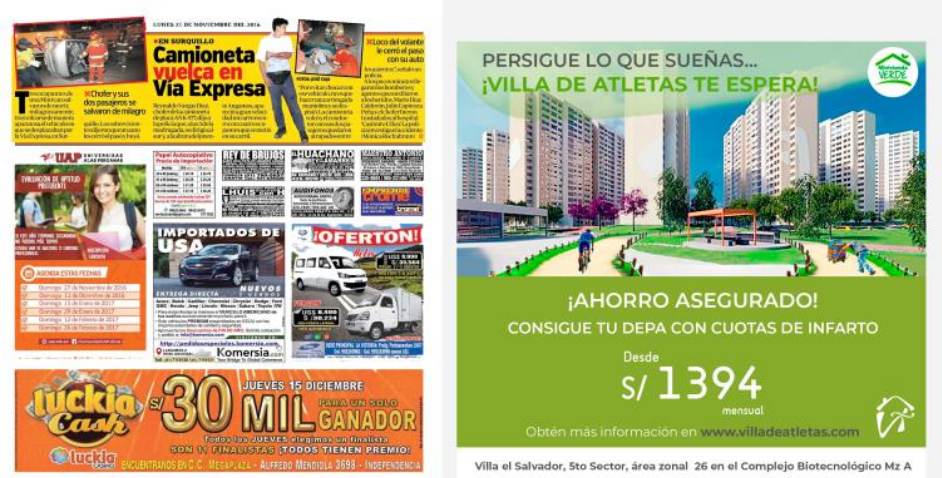

Ilustración 23. Anuncio en el Trome. Etapa lanzamiento Fuente: Elaboración

\section{Propia}

- $\underline{\mathrm{OOH}}$

- Vallas en el Metro de Lima

Se colocarán un total de 8 vallas en diferentes estaciones, desde Jorge Chávez hasta Villa el Salvador con una variación en el motivo, variando de personajes y carreras.

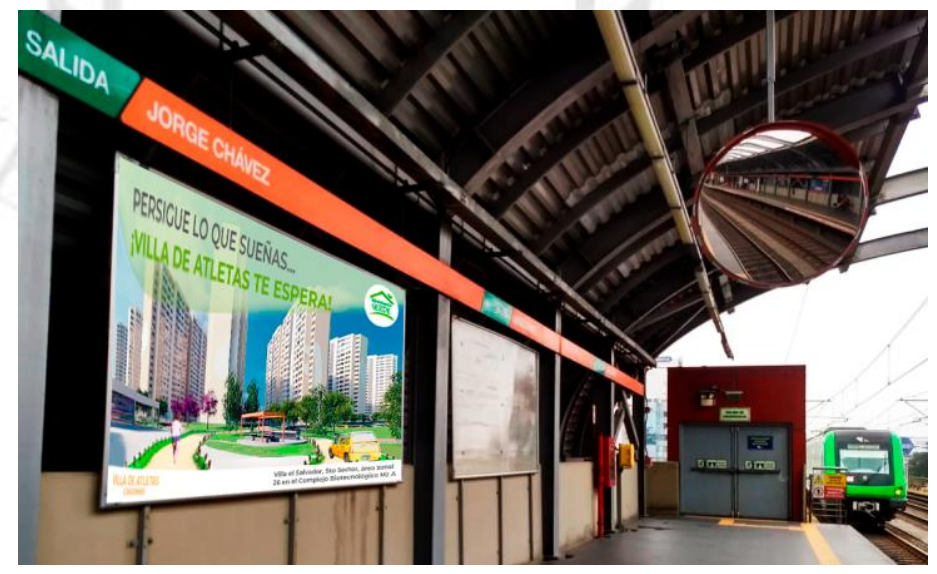

Ilustración 24. Vallas en Metro de Lima. Etapa lanzamiento. Fuente: Elaboración Propia 


\section{- Leds}

Se colocarán un total de 4 leds en los distritos de San Juan de Miraflores, San Borja y La Victoria (Gamarra) con una variación en el motivo, variando de personajes y carreras.

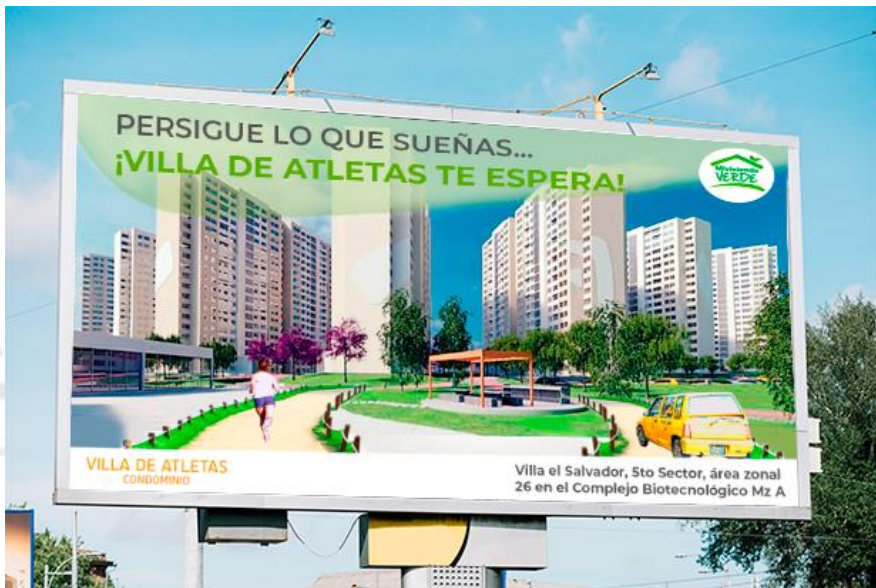

Ilustración 25. Leds. Etapa lanzamiento. Fuente: Elaboración Propia

\section{$\underline{\text { Pantallas de Cine }}$}

Como parte del lanzamiento y branding de nuestra marca, lanzaremos un spot de 25 segundos en la cadena de cines antes mencionados. Como recurso emplearemos un tono emotivo, que genere identificación de nuestro público objetivo y los deportistas. Este servirá también para redes sociales.

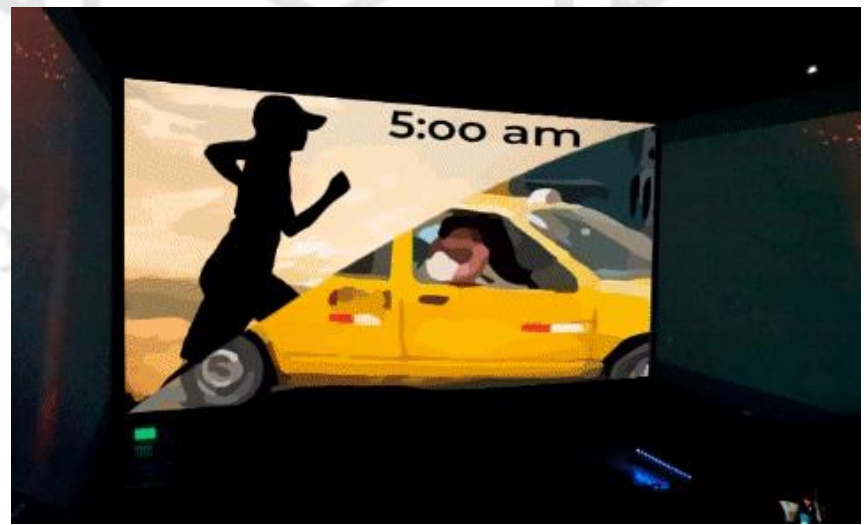

Ilustración 26. Pantallas de cine. Etapa lanzamiento. Fuente: Elaboración Propia 


\section{- Storyboard}

Planteamos un spot de 25 segundos con pantalla dividida, en dónde se muestre el día a día de un deportista y un personaje trabajador de nuestro público objetivo. La finalidad es hacer un símil entre ambos, quienes luchan por conseguir más logros.

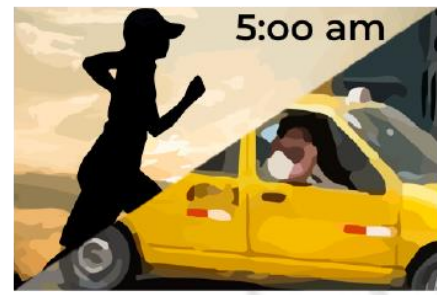

Escena 1: María comenzando a correr a las 5:00 am, en paralelo Juan Carlos se sube a su taxi para comenzar a trabajar.

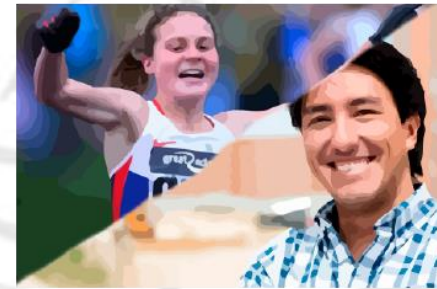

Escena 4: María gana la carrera, medalla de oro.

Juan Carlos acude al banco, lo llamaron para entregarle el crédito hipotecario por el que ha trabajado tanto.

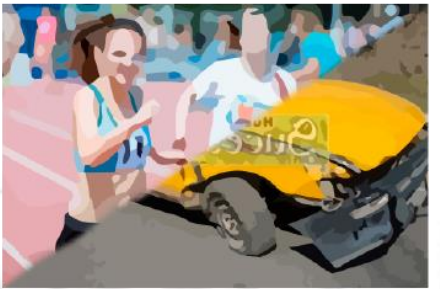

Escena 2: María está en una competencia de atletismo, otra corredora le pasa. La llanta de Juan Carlos se revienta, lo que le hace perder carreras.

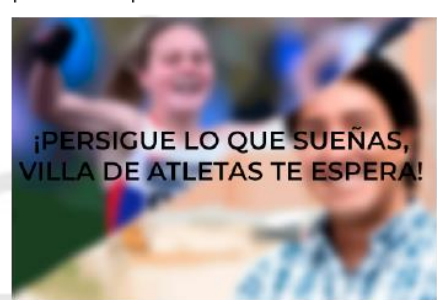

Escena 5: Sobreimpresión de la frase: ¡Persigue lo que sueñas, Villa de Atletas te espera!

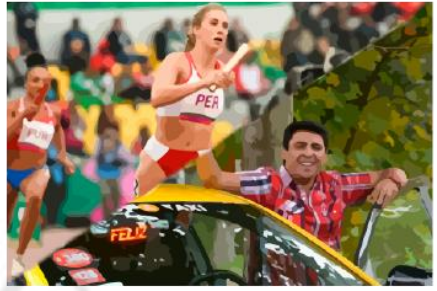

Escena 3: María se esfuerza y logra repuntar la carrera, va primera. Juan Carlos, arregla la llanta y consigue más carreras continúa trabajando.

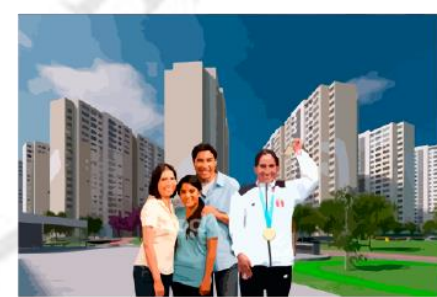

Escena 6: María, Juan Carlos y su familia, felices frente a los Condominios Villa de Atletas. Pantalla negra, logo de Villa de Atletas Condominio. Voz en off: Villa de Atletas Condominio.

Ilustración 27. Storyboard. Etapa lanzamiento. Fuente: Elaboración Propia

\section{- Monitores 3D}

Tener publicidad en el lobby de algunos cines es una gran oportunidad, además de las pantallas, pues capta la atención, genera exposición y ello refuerza la recordación de nuestra marca. El call to action final dirige a web y redes sociales. 


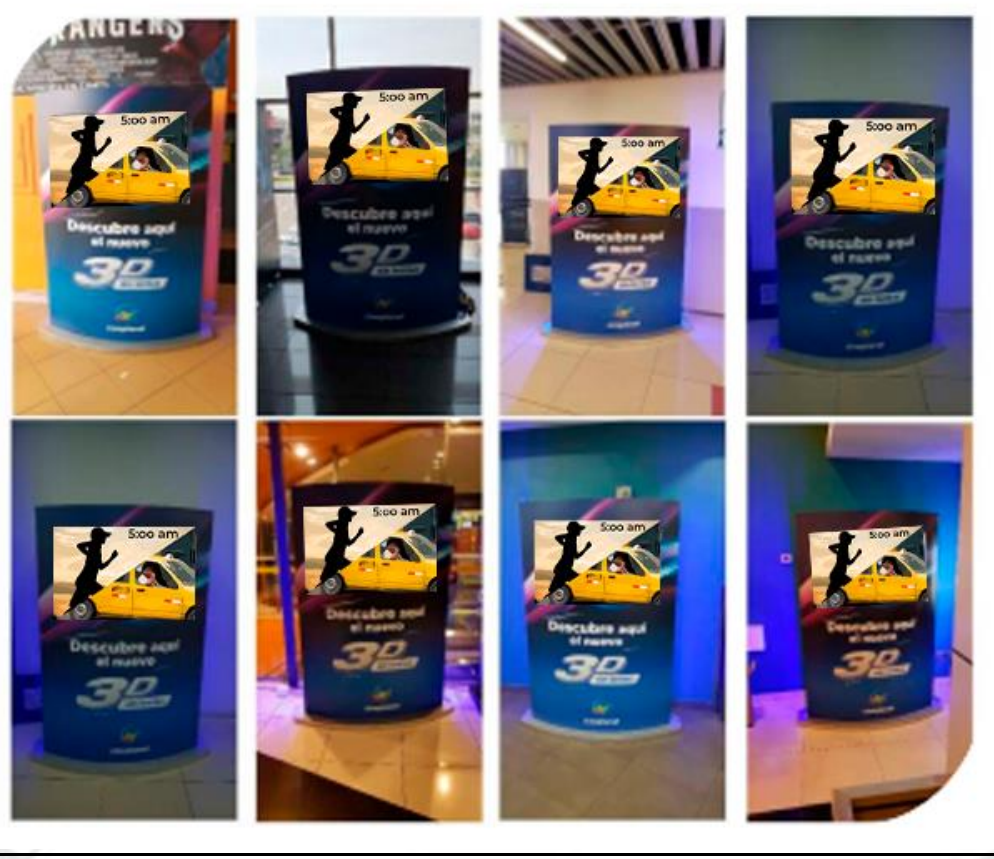

Ilustración 28. Monitor 3D. Etapa lanzamiento. Fuente: Elaboración Propia

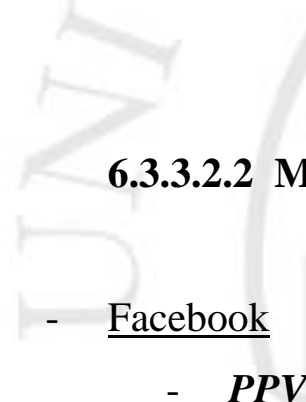

Consideramos este formato por cada vista de nuestro spot, con la finalidad de generar awareness de la marca.

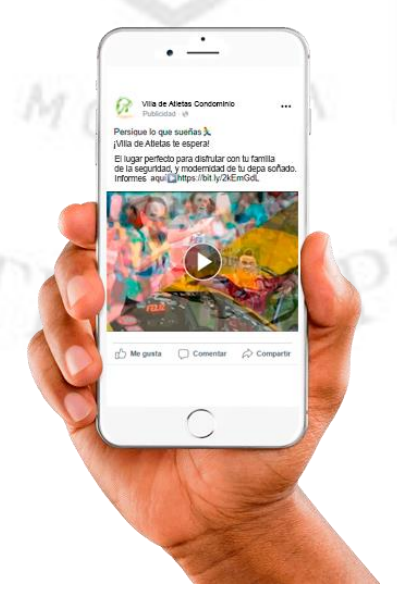

Ilustración 29. Post en Facebook. Formato PPV. Etapa lanzamiento. Fuente:

Elaboración Propia 


\section{- Carrusel}

Usamos este tipo de formato para mostrar diferentes imágenes de los espacios de los departamentos y las cuotas referenciales. El call to action deriva a la página web para incrementar el tráfico.

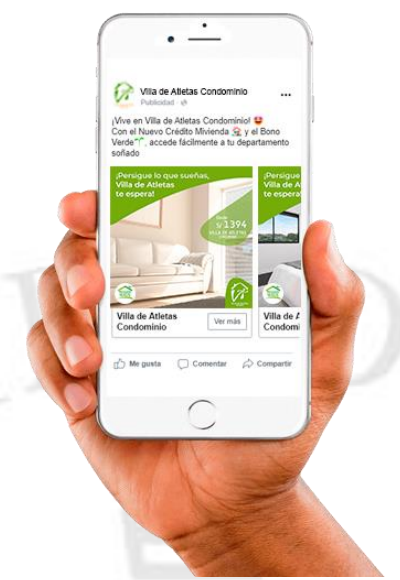

Ilustración 30. Post en Facebook. Formato Carrusel. Etapa lanzamiento. Fuente:

Elaboración Propia

- $\underline{\text { Instagram }}$

\section{- Anuncios en secuencia con Formulario}

Nuestro objetivo es conseguir leads, por lo que haremos anuncios en secuencia con formularios para ir armando una base de datos de clientes potenciales.
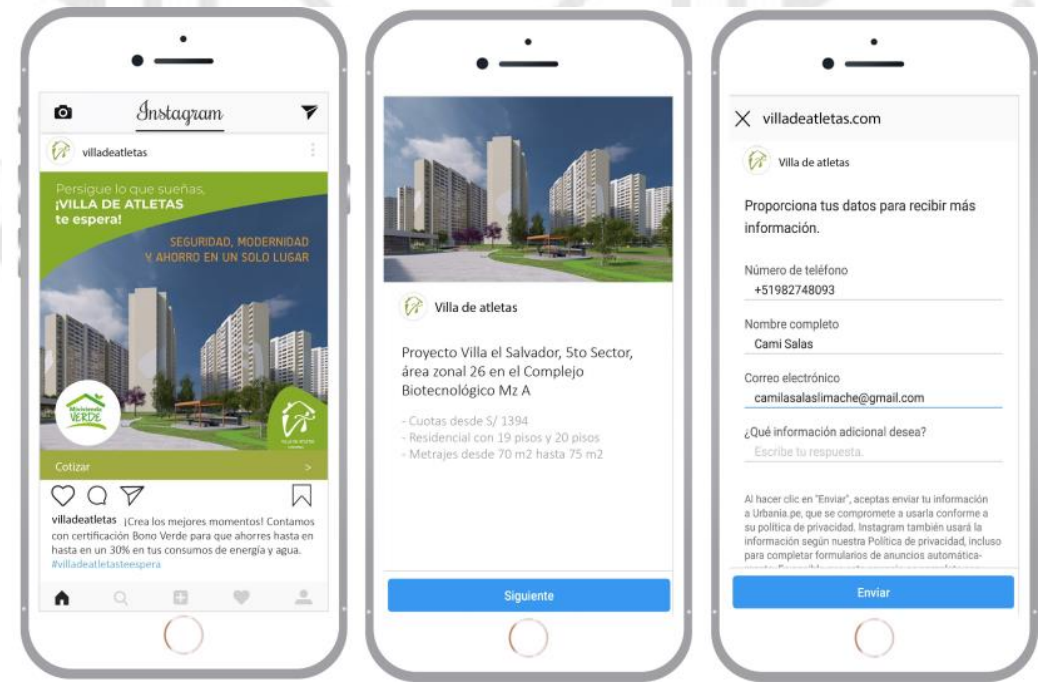

Ilustración 31. Post en Instagram. Formato secuencia con Form. Etapa lanzamiento. Fuente: Elaboración Propia 


\section{- Instastories}

Nuestro objetivo es conseguir leads, por lo que haremos anuncios en instastories que deriven a la web en el landing de Contacto para generar una cotización.

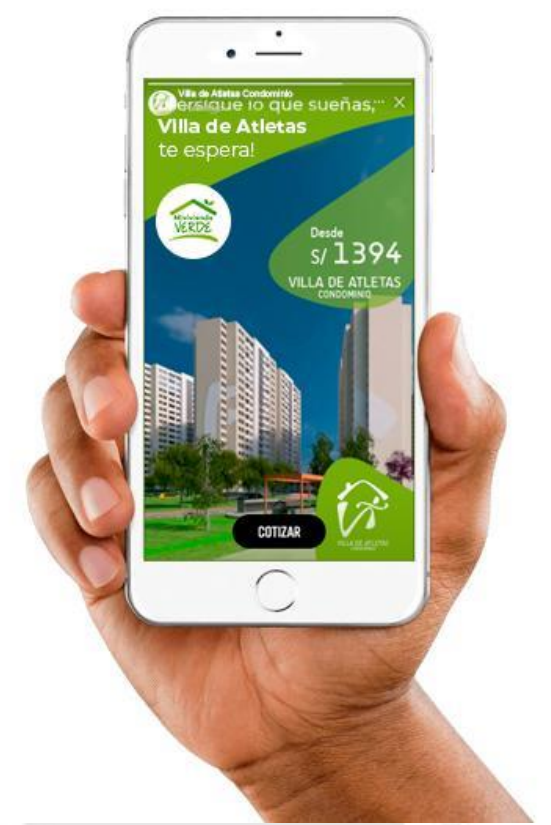

Ilustración 32. Instastories. Etapa lanzamiento.

\section{Fuente: Elaboración Propia}

\section{- $\quad$ Página Web}

Uno de los factores que influyen mucho en la decisión de compra de clientes potenciales es la posición web. Es por ello que trabajaremos en una campaña de Google Ads para que nuestra web aparezca en primera posición con la finalidad de obtener mayor número de conversiones.

\section{- Email marketing}

Se enviarán dos emails el 6 y 18 de febrero con mensajes motivadores e interesantes para llamar la atención de usuario. El botón derivará a la página web para incrementar el tráfico. Tendrá un sentido de urgencia en la comunicación, para generar la necesidad de compra en nuestro público objetivo. 

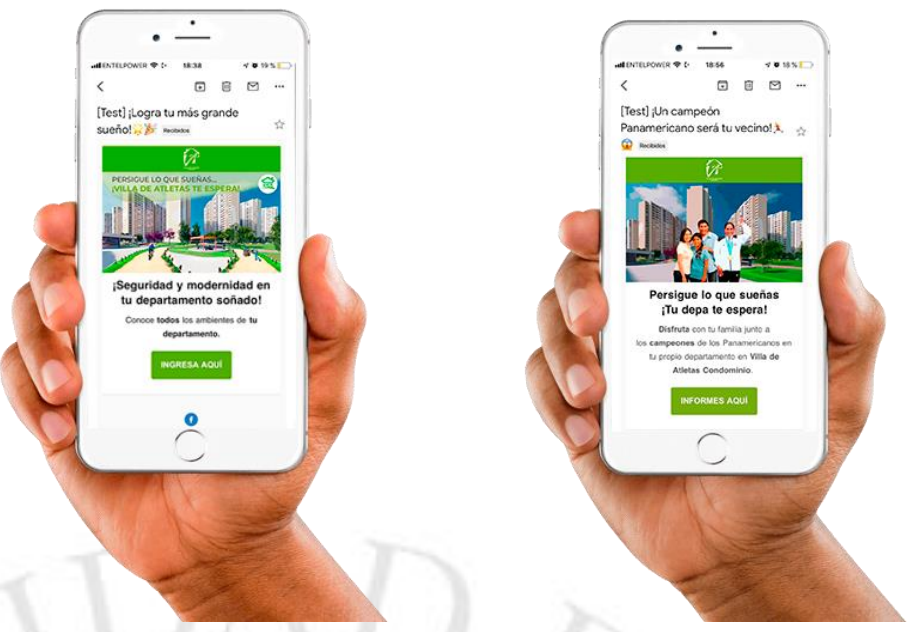

Ilustración 33. Email marketing. Etapa lanzamiento.

Fuente: Elaboración Propia

Youtube

Emplearemos "Anuncios de video que se pueden omitir" con nuestro spot completo. Consideramos que este tipo de publicidad puede llegar a ser intrusiva, por lo que no optamos por Bumpers sino este formato, con la finalidad de mejorar la experiencia del usuario y poder saltarse el anuncio en caso lo decida.

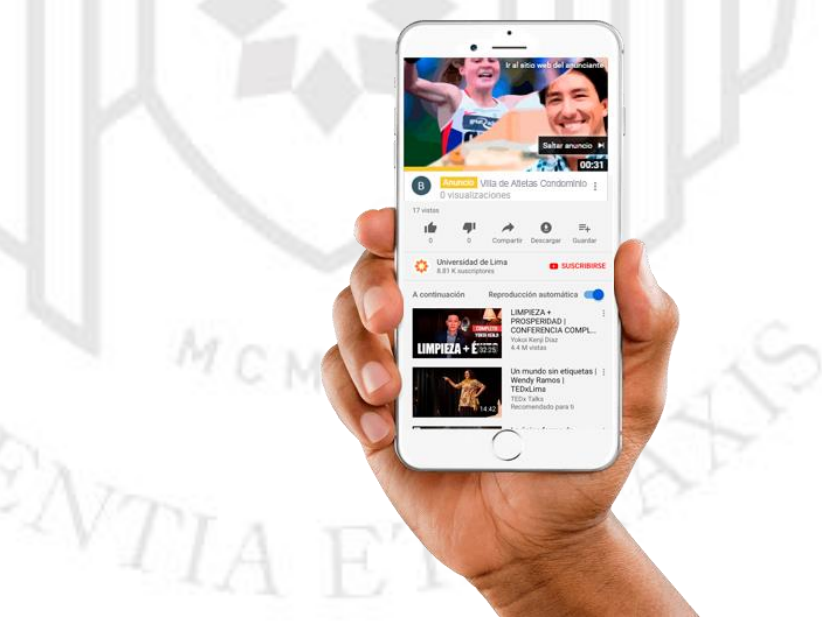

Ilustración 34. Anuncio en YouTube. Etapa lanzamiento.

Fuente: Elaboración Propia

\subsubsection{Etapa de Mantenimiento}




\subsection{Medios Digitales}

- Facebook

Optamos por el formato CPC para esta etapa con el objetivo de generar tráfico a la web y seguir impulsando la venta de los departamentos, con copys atractivos y relacionados a la sostenibilidad.

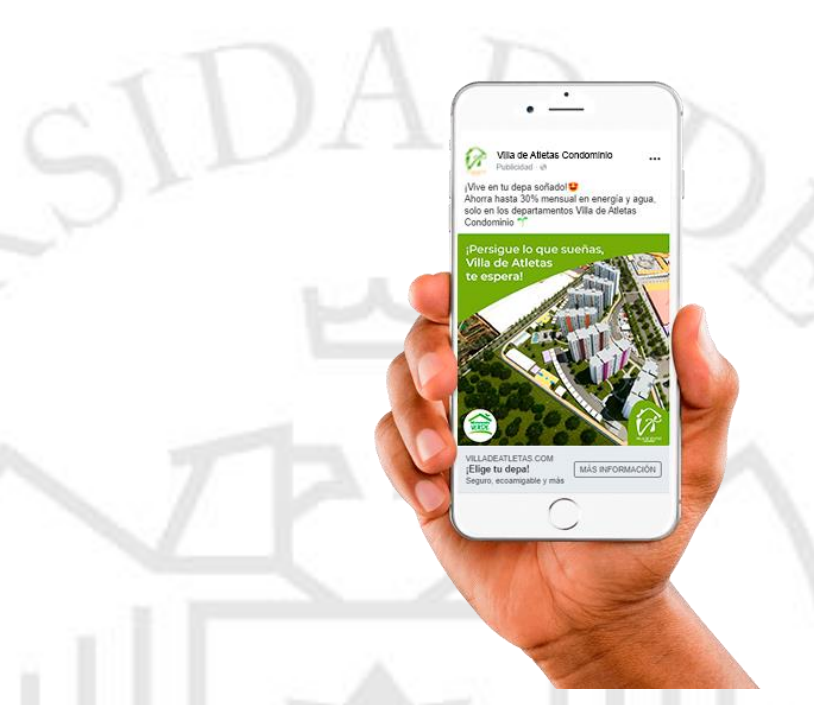

Ilustración 35. Post Facebook. Etapa mantenimiento.

\section{Fuente: Elaboración Propia}

\section{- Instagram}

Empleamos este formato para seguir generando conversión a través de leads o tráfico a la web. Por ello mantenemos el concepto a través de Insta stories mostrando más de los espacios de los departamentos. 


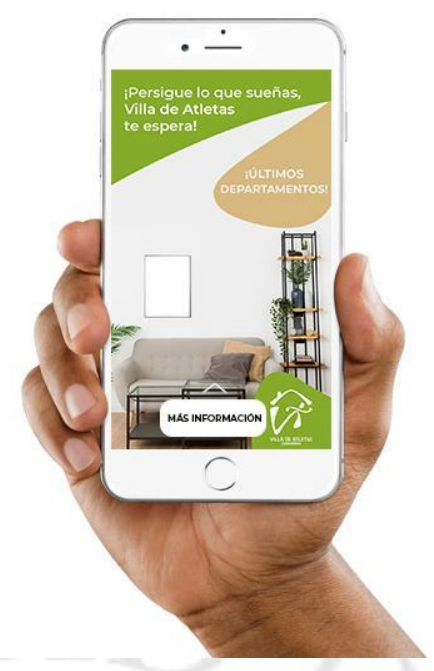

Ilustración 36. Instastorie. Etapa mantenimiento.

Fuente: Elaboración Propia

- Email marketing

En esta etapa trabajaremos dos emails, el 02 y 17 de marzo para seguir llamando la atención de posibles clientes. Esta vez tendrá un sentido de urgencia en la comunicación, para generar la necesidad de compra.
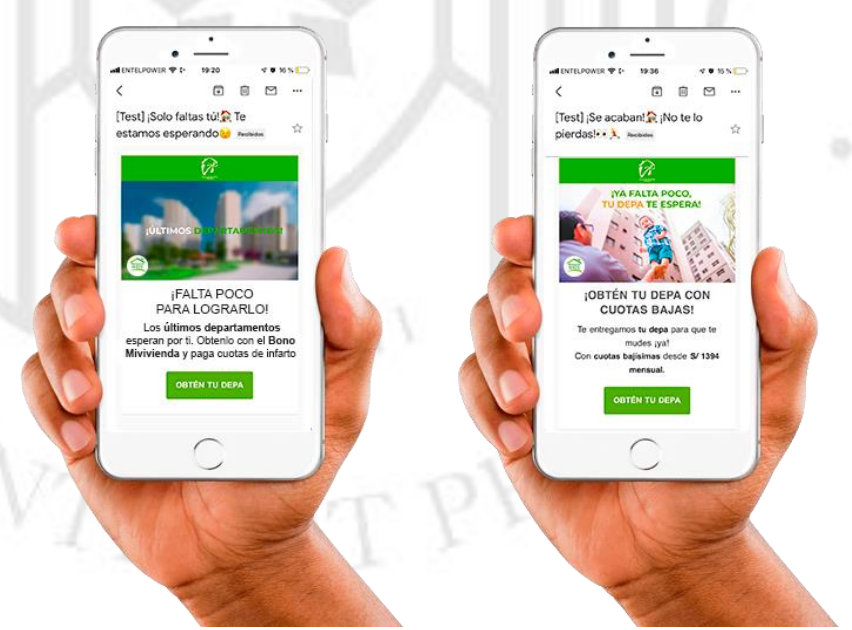

Ilustración 37. Email marketing. Etapa mantenimiento.

Fuente: Elaboración Propia 


\section{CAPÍTULO 7: DISTRIBUCIÓN DE LA INVERSIÓN}

\subsection{Sustentación de presupuesto}

Nuestra estrategia de medios se basa en un mix entre los medios ATL y medios digitales, para poder llegar a la mayor cantidad de puntos de contactos que tiene nuestro público objetivo con la publicidad. El $60.3 \%$ de nuestro presupuesto está invertido en medios masivos, como OOH, Prensa y Pantallas de Cine. Es importante hacer uso de estos medios en las etapas de Pre Lanzamiento y Lanzamiento, para poder generar el reconocimiento de la marca en nuestro público objetivo y lograr un posicionamiento en la decisión de compra de departamentos.

Para completar el ecosistema de medios, estamos invirtiendo un $31.7 \%$ de nuestro presupuesto en medios digitales tales como, Facebook, Instagram, Google AdWords y YouTube, siendo estos los medios que tienen mayor presencia en el día a día de nuestro público objetivo. Asimismo, la estrategia planteada será una campaña $360^{\circ}$ que nos permitirá tener contacto con nuestro P.O. por al menos uno de los canales de comunicación.

Finalmente, consideramos un $8 \%$ del total de presupuesto para la producción de las piezas de los diferentes canales de comunicación, que incluye la licencia de uso del Logo de Bono Verde.

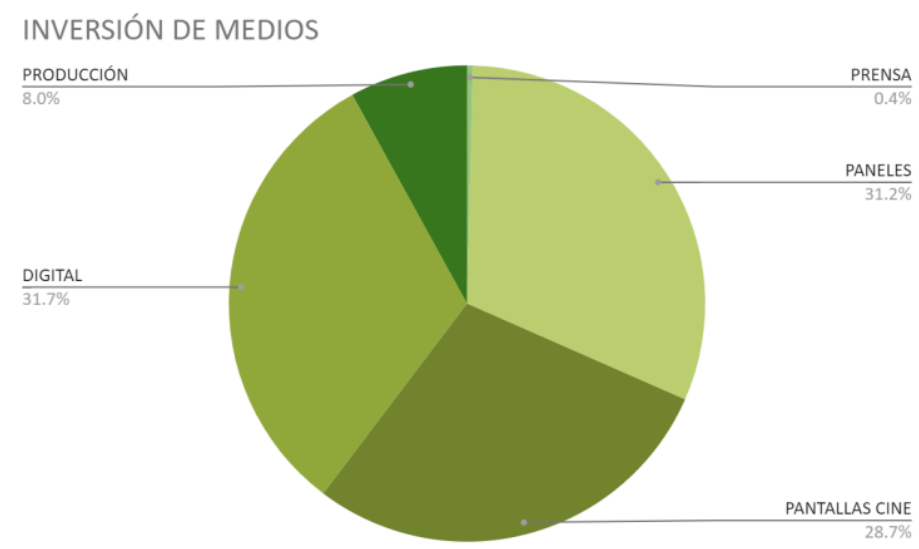

Figura 19. Gráfica distribución de presupuesto. Fuente: Elaboración propia 


\section{CAPÍTULO 8: CONCLUSIONES}

- Los medios de comunicación tradicionales, como televisión y radio, si bien son utilizados por nuestro público objetivo, la publicidad colocada en estos no genera el impacto esperado en proporción a la inversión realizada, debido a que sólo captan 30\% y 29\%, respectivamente, de la atención de los espectadores; por ello preferimos enfocarnos en el medio tradicional, pantallas de cine, con un spot publicitario, pues generará mayor recordación y reconocimiento en nuestro target ya que tiene mayor captación con un $34 \%$.

- Consideramos que colocar una pantalla Led en Gamarra es una estrategia clave debido a la afluencia de gente que asiste, de acuerdo a una nota por TV Perú, menciona que aproximadamente 300 mil personas llegan a Gamarra. (TV Perú Noticias, 2018)

- Todos los esfuerzos publicitarios apuntan a establecer a Villa de Atletas Condominio como un lugar con espacios compartidos que promueven formar una comunidad en donde las familias pueden crecer de manera segura, y para lograr esto se usan recursos inspiracionales como la figura del deportista, quienes luchan por tener más logros, al igual que nuestro público objetivo.

- La decisión de colocar el nombre Villa de Atletas Condominio, permitió generar mayor recordación de la marca y generar mayor acercamiento con nuestra propuesta de marca. Pues lo más importante es recordar el nombre "Villa de Atletas", más que el descriptivo del producto "Condominio".

- Comunicar los beneficios de seguridad y modernidad en las piezas de comunicación, son importantes para nuestro público objetivo pues son un target aspiracional que le gustaría vivir en la Zona moderna de Lima, pero por cuestiones de precio deberán elegir una vivienda acorde a su presupuesto. En ese contexto será importante posicionarnos, como un condominio seguro, moderno, sostenible y familiar, los valores de marca que hemos planteado para nuestra marca y que se asemejan a las viviendas que se ofrecen en las zonas modernas de Lima.

- Un atributo que puede influir mucho en la decisión de compra final es el de la entrega inmediata, ya que, por lo general, la mayoría de ventas de departamentos se hace en el periodo previo a la construcción, con muestras en videos y planos en 3D. En este caso, podemos hacer uso de departamentos pilotos ya listos y 
recorrido por los diferentes complejos deportivos y zonas compartidas que tiene nuestro condominio, lo cual es un plus.

- Con respecto a la publicidad en prensa lo más estratégico fue elegir la opción Trome Zonales, pues permite llegar de manera puntual a la zona de mayor concentración de nuestro público objetivo. 


\section{CAPÍTULO 9: RECOMENDACIONES}

- Para poder llegar de manera más efectiva a un público que se encuentre en la etapa de consideración, lo ideal es poder participar en Ferias Inmobiliarias con un stand, que pueda brindar información y mostrar por medio de la tecnología 3D los ambientes de los departamentos.

- Es importante considerar un Punto de Venta para poder brindar la información adecuada sobre los departamentos, tipos de financiamiento y beneficios adicionales. Desde nuestro punto de vista, lo ideal sería colocar uno dentro del Centro Comercial "Mall del Sur", por ser el lugar más cercano a la ubicación del Condominio Villa de Atletas y porque es el más cercano de dónde vive nuestro público objetivo (Zona 9).

- Una manera de conseguir posicionamiento web de manera orgánica es generar contenido relevante, por lo que recomendamos hacer un blog relacionado a noticias del mundo inmobiliario o información que facilite a nuestro público como, por ejemplo, el tema de los créditos Mi vivienda y Bono Verde.

- El uso de las redes puede ser propicio para promover eventos inmobiliarios en los que estemos participando, así como generar interacciones motivando a la gente en la decisión de compra de un departamento dentro de nuestro condominio.

- Una manera creativa de llamar la atención del público son las activaciones y muchos de ellos se dan en Centros comerciales. Recomendamos hacer una dinámica en el Mall del Sur un domingo, pues es un C.C. ubicado en una zona estratégica en relación a clientes potenciales, además de la afluencia de gente que recibe por ser un día en el que las familias buscan algún tipo de recreación.

- Se recomienda crear un video explicativo acerca de los beneficios de adquirir un departamento en nuestro condominio por las facilidades que el Estado brinda, además del proceso de compra y evaluación previos. Ello sirve para educar a la gente acerca de las cosas que deben hacer en dicho proceso.

- Crear una alianza con un Banco, pues sería de gran ayuda utilizar sus canales de comunicación para generar awareness en nuestro público objetivo, sobre todo en 
los Videos Reel en sus Agencias, Email marketing segmentada a su base de datos y publicidad por medio de sus canales digitales.

\section{REFERENCIAS}

1. Abarca, D. (19 de agosto de 2019). Precio del metro cuadrado en Lima crecería hasta en 8\% al cierre de 2019. (Gestión, Entrevistador)

2. APEIM. (2018). Nivel Socioeconómico. (Asociación Peruana de Empresas de Investigación de Mercados) Obtenido de http://apeim.com.pe/

3. Apoyo \& Asociados. (2019). Cineplex S.A. (CINEPLANET). Informe anual. Obtenido de http://www.aai.com.pe/wpcontent/uploads/2019/05/Cineplanet_Dic-18.pdf

4. BBVA Research. (marzo 2018). Mercado de viviendas nuevas y oficinas prime en Lima Metropolitana. Lima. Obtenido de https://www.bbvaresearch.com/wpcontent/uploads/2019/03/MercadoViviendasNuevas_OficinasPrime_Lim a.pdf

5. Construye, P. (2018). Unión de Ingeniería, Planeamiento y Productividad. Perú Construye. Obtenido de https://peruconstruye.net/wp-content/uploads/2018/11/VILLA-DEATLETAS-LIMA-2019.pdf

6. Costos, R. (2018). Villa de Atletas. Innovación en gestión. Obtenido de https://es.calameo.com/read/00522867927a37b37971f

7. CPI. (2016). Market Report - Transporte utilizado diariamente. Lima Metropolitana. Lima.

8. CPI. (abril de 2019). Compañía peruana de estudio de mercados y opinión pública S.A. Obtenido de http://cpi.pe/images/upload/paginaweb/archivo/26/mr_poblacional_peru _201905.pdf

9. DIPROMIN. (16 de agosto de 2019). ¿En qué distritos de Lima se recupera más rápido la inversión en viviendas? Diario Digital de Minería, Energía y Construcción. Obtenido de 
https://www.dipromin.com/noticias/en-que-distritos-de-lima-serecupera-mas-rapido-la-inversion-en-viviendas/

10. Ecomedia, M. . (2016). Tarifario Actualización El Comercio. Lima, Perú. Obtenido de http://e.gec.pe/67/doc/0/0/7/4/7/747749.pdf

11. El Comercio. (21 de agosto de 2018). Google: $94 \%$ de peruanos decide una compra basado en lo que investiga en Internet. Obtenido de https://elcomercio.pe/economia/peru/google-94-peruanos-decidecompra-basado-investiga-internet-noticia-549163

12. El Comercio. (04 de agosto de 2019). El 49\% de peruanos afirma ir al cine al menos una vez a la semana. Obtenido de https://elcomercio.pe/economia/peru/49-peruanos-afirma-cine-vezsemana-fotos-america-latina-noticia-nndc-661043-noticia/?foto $=2$

13. El Economista América. (11 de enero de 2019). Proyecciones del mercado inmobiliario para el 2018. Obtenido de https://www.eleconomistaamerica.pe/economia-eAmperu/noticias/9629180/01/19/Proyecciones-del-mercado-inmobiliariopara-el-2019.html

14. El País. (15 de abril de 2017). El sector inmobiliario abraza la tecnología. Obtenido de https://elpais.com/economia/2017/04/12/actualidad/1492007284_883392 .html

15. Entrepreneur en español. (11 de abril de 2018). ¿Por qué debes usar Instagram en tu negocio? Obtenido de https://www.entrepreneur.com/article/265085

16. Fondo Mi vivienda. (s.f.). Nuevo Crédito Mivivienda. Obtenido de https://www.mivivienda.com.pe/PortalWEB/usuario-buscaviviendas/pagina.aspx?idpage $=20$

17. Fondo Mivivienda. (2018). ESTUDIO DE DEMANDA DE VIVIENDA A NIVEL DE LAS PRINCIPALES CIUDADES - LIMA SUR. LIMA: Instituto CUÁNTO.

18. Fondo Mivivienda. (2019). Boletín Estadístico.

19. Fondo Mivivienda. (s.f.). Fondo Mivivienda. Obtenido de Bono del buen pagador: https://www.mivivienda.com.pe/PORTALWEB/usuario-buscaviviendas/pagina.aspx?idpage $=22$ 
20. G., N. S. (abril de 2016). Marketing del Color: ¿Cómo Influyen El Color Del Logotipo En La Personalidad De Una Marca? Postgrado Economía y Negocios Universidad de Chile. Santiago de Chile, Chile. Obtenido de http://repositorio.uchile.cl/bitstream/handle/2250/140132/Marketing\%20 del $\% 20$ color $\% 20 \% 20 \% \mathrm{C} 2 \% \mathrm{BFc} \% \mathrm{C} 3 \% \mathrm{~B} 3 \mathrm{mo} \% 20$ influye $\% 20 \mathrm{el} \% 20$ colo r\%20del\%20logotipo\%20en\%20la\%20personalidad\%20de\%20una\%20 marca.pdf?sequence $=1$

21. Gestión. (28 de octubre de 2014). El 56\% de peruanos prefiere adquirir un inmueble nuevo. Obtenido de https://gestion.pe/tudinero/inmobiliarias/56-peruanos-prefiere-adquirir-inmueble-nuevo78997-noticia

22. Gestión. (27 de febrero de 2018). El 40.7\% de los ingresos de cadena Cineplanet proviene de la venta de snacks y confitería. Obtenido de https://gestion.pe/economia/40-7-ingresos-cadena-cineplanet-provieneventa-snacks-confiteria-228162-noticia/?ref=gesr

23. Gestión. (18 de Julio de 2018). Las cinco tecnologías que están cambiando el sector construcción. Obtenido de https://gestion.pe/fotogalerias/cinco-tecnologias-cambiando-sectorconstruccion-238741-noticia/?foto $=6$

24. Gestión. (13 de marzo de 2019). Gamarra y las cifras económicas más relevantes del emporio comercial.Obtenido de https://gestion.pe/economia/gamarra-cifras-economicas-relevantesemporio-comercial-fotos-nndc-261222-noticia/

25. Gestión. (30 de marzo de 2019). Arellano: "Viene un boom de demanda inmobiliaria, pero hace falta innovar en los créditos". Obtenido de https://gestion.pe/tu-dinero/inmobiliarias/arellano-viene-boom-demandainmobiliaria-falta-innovar-creditos-262869-noticia/

26. Gestión. (24 de agosto de 2019). El 60\% de millennials que adquiere vivienda lo hace con fines de inversión. Obtenido de https://gestion.pe/tu-dinero/inmobiliarias/el-60-de-millennials-queadquiere-vivienda-lo-hace-con-fines-de-inversion-noticia/

27. Gestión. (19 de agosto de 2019). Precio del metro cuadrado en Lima crecería hasta en $8 \%$ al cierre de 2019 . Obtenido de 
https://gestion.pe/economia/precio-del-metro-cuadrado-en-lima-creceriahasta-en-8-al-cierre-de-2019-noticia/

28. Gestión. (11 de Setiembre de 2019). Publicidad en medios tradicionales todavía capta mayor atención que los digitales. Obtenido de https://www.ipsos.com/sites/default/files/ct/publication/documents/201909/publicidad_en_medios_tradicionales_todavia_capta_mayor_atencion. pdf

29. Idealista News. (30 de enero de 2018). Obtenido de https://www.idealista.com/news/finanzas/tecnologia/2018/01/30/76263510-tecnologias-que-cambiaran-el-sector-inmobiliario-en-2018

30. Instituto Nacional de Estadística e Informática. (2017). Provincia de Lima Compendio Estadístico. Lima. Obtenido de https://www.inei.gob.pe/media/MenuRecursivo/publicaciones_digitales/ Est/Lib1477/libro.pdf

31. Ipsos. (2017). Perfiles Socioeconómicos Lima Metropolitana. Lima Metropolitana.

32. IPSOS. (2018). Bancarización del peruano. Bancos, Cajas y Financieras. Ipsos Perú, Perú Urbano.

33. IPSOS. (2018). Consumo de medios de comunicación digitales y tradicionales.

34. Ipsos. (2018). Estadística Poblacional Lima Metropolitana (Edición Especial) - Proyecciones poblacionales.

35. Ipsos. (2018). Perfil del adulto joven peruano. Perú Urbano.

36. Kaizen Arquitectura \& Ingeniería. (s.f.). Obtenido de https://www.kaizenai.com/bim/que-es-el-bim/

37. La República. (13 de 08 de 2019). Fondo Mivivienda: ¿A cuánto ascienden los bonos que ofrece el Estado? Obtenido de https://larepublica.pe/economia/2019/08/12/fondo-mivivienda-cualesson-y-a-cuanto-ascienden-los-bonos-que-ofrece-el-estado/

38. La República. (13 de abril de 2019). Tecnologías para el mercado inmobiliario. (A. Delafuente, Ed.) Obtenido de https://larepublica.pe/sociedad/1448880-tecnologias-mercadoinmobiliario/\%2020.\%20https://www.merca20.com/tag/psicologia-delcolor/ 
39. Lima Cómo Vamos - Observatorio ciudadano. (2015). Cómo vamos en movilidad - Sexto Informe de resultados sobre calidad de vida. Lima.

Obtenido de http://www.limacomovamos.org/cm/wpcontent/uploads/2016/09/InformeMovilidad2015-1.pdf

40. LN Creatividad y Tecnología Blog. (s.f.). Tipografías que expresan sensaciones. Obtenido de Luisannet Creatividad y Tecnología: https://www.luisan.net/blog/diseno-grafico/las-tipografias-definen

41. Merca 2.0. (06 de febrero de 2019). Los colores más utilizados por las marcas en la industria. Obtenido de https://www.merca20.com/tag/psicologia-del-color/

42. Perú 21. (16 de 03 de 2018). ¡Presta atención! Estos son los programas que te ofrece el Fondo MiVivienda. Obtenido de https://peru21.pe/economia/conoce-programas-ofrece-fondo-mivivienda399586-noticia/

43. Perú 21. (23 de mayo de 2019). Sector inmobiliario crecerá $10 \%$ con la venta de más de 14,500 viviendas este año, según expertos. Obtenido de https://peru21.pe/economia/sector-inmobiliario-crecera-10-venta-14500-viviendas-ano-expertos-nndc-479991-noticia/

44. PNUD. (s.f.). Objetivo 11: Ciudades y comunidades sostenibles. Obtenido de http://www.pe.undp.org/content/peru/es/home/sustainabledevelopment-goals/goal-11-sustainable-cities-and-communities.html

45. Revista Mivivienda. (Julio 2019). Perfil del cliente Crédito Mivivienda. Mirada en perspectiva, 24. Obtenido de file:///C:/Users/Galilea/Downloads/revista\%20fmv\%20139_pyg3872.pdf

46. Revista Perú Construye. (2019). Villa de Atletas - Lima 2019: Unión de Ingeniería, Planeamiento y Productividad. 16,21. Obtenido de https://peruconstruye.net/villa-de-atletas-lima-2019-union-de-ingenieriaplaneamiento-yproductividad/?fbclid=IwAR2XLbrnGZqGBKMCVZbMb6fXEc7XdWI m3nmM009ww8KhCiS4fcmCbUFr9_I

47. TV Perú Noticias. (20 de diciembre de 2018). Gamarra recibe a 700 mil personas por día para hacer compras navideñas. Obtenido de 
https://tvperu.gob.pe/noticias/locales/gamarra-recibe-a-700-milpersonas-por-dia-para-hacer-compras-navidenas

48. Vigil, A. (24 de agosto de 2019). El 60\% de millennials que adquiere vivienda lo hace con fines de inversión. (Gestión, Entrevistador) Lima. Obtenido de https://gestion.pe/tu-dinero/inmobiliarias/el-60-demillennials-que-adquiere-vivienda-lo-hace-con-fines-de-inversionnoticia/ 


\section{ANEXOS}

\section{Plan de medios}

https://drive.google.com/open?id=1SSK4ERmt1Ut8XDUfGUvDNHIKeNx

Ww1Yw

\section{Piezas publicitarias:}

https://drive.google.com/drive/u/1/folders/1N14cf_jcJfXiLF3qiwO6zdJ0ExdSODn

\section{Preguntas de Encuestas: Estudio sobre Villa de Atletas Condominio}

\section{Sección 1: Perfil del usuario}

1. ¿Tienes vivienda propia?

2. Sexo

3. Edad

4. Estado Civil

5. Distrito de residencia

6. ¿Con quién vives?

7. Si respondiste que vives con pareja e hijos, ¿cuántos hijos tienes?

\section{Sección 2: Nivel de adquisición de una vivienda propia}

1. ¿Estás considerando adquirir una vivienda propia?

2. ¿Por qué te gustaría tener una vivienda propia?

3. ¿En qué distrito te gustaría adquirir una vivienda propia? ¿Por qué?

4. ¿Qué tipo de vivienda te gustaría adquirir?

5. ¿Qué es lo que más valoras al momento de adquirir una vivienda propia?

6. ¿Cuánto estarías dispuesto a pagar por una vivienda?

7. ¿Qué sistemas de financiamiento para obtener una vivienda nueva conoces? 
8. ¿En cuántos años estarías dispuesto a financiar la compra de tu vivienda?

9. ¿Qué atributos asocias a un Condominio?

10. ¿Te gustaría adquirir una vivienda propia dentro de un condominio? ¿Por qué?

11. ¿Qué conoces acerca del Condominio de Villa de Atletas?

12. ¿Te animarías a adquirir un departamento dentro del Condominio Villa de Atletas? ¿Por qué?

4. Mapa explicativo de la colocación de Pantallas LED

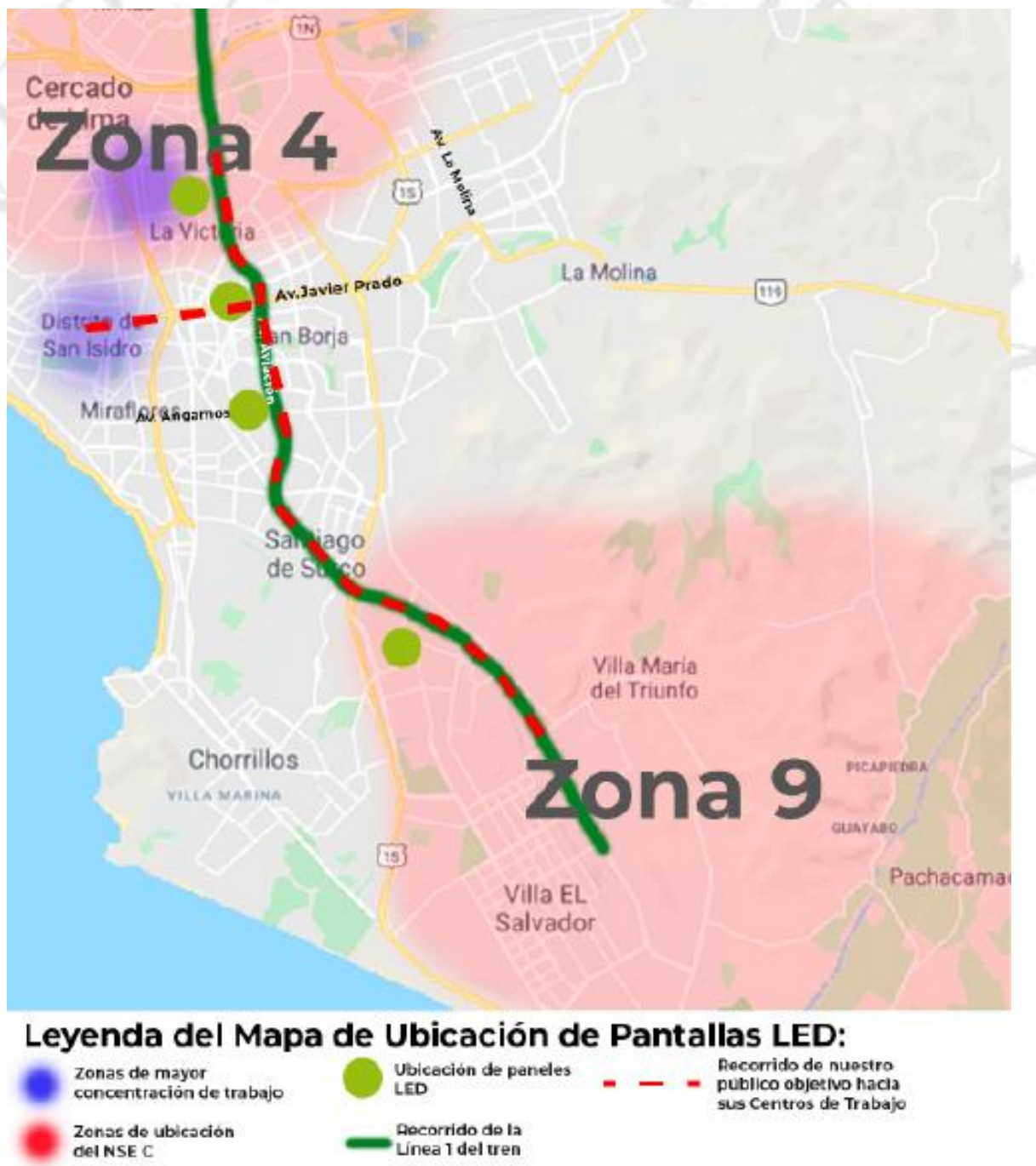

